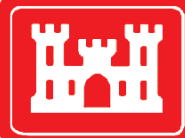

US Army Corps of Engineers ${ }_{\circledast}$

Engineer Research and

Development Center

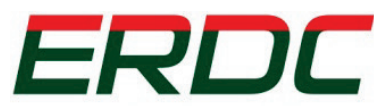

INNOVATIVE SOLUTIONS for a safer, better world

Dredging Operations and Environmental Research

\title{
Identification of Sediment Sources to Calumet River through Geochemical Fingerprinting
}

David W. Perkey, Mark A. Chappell, Jennifer M. Seiter, April 2017 and Heidi M. Wadman

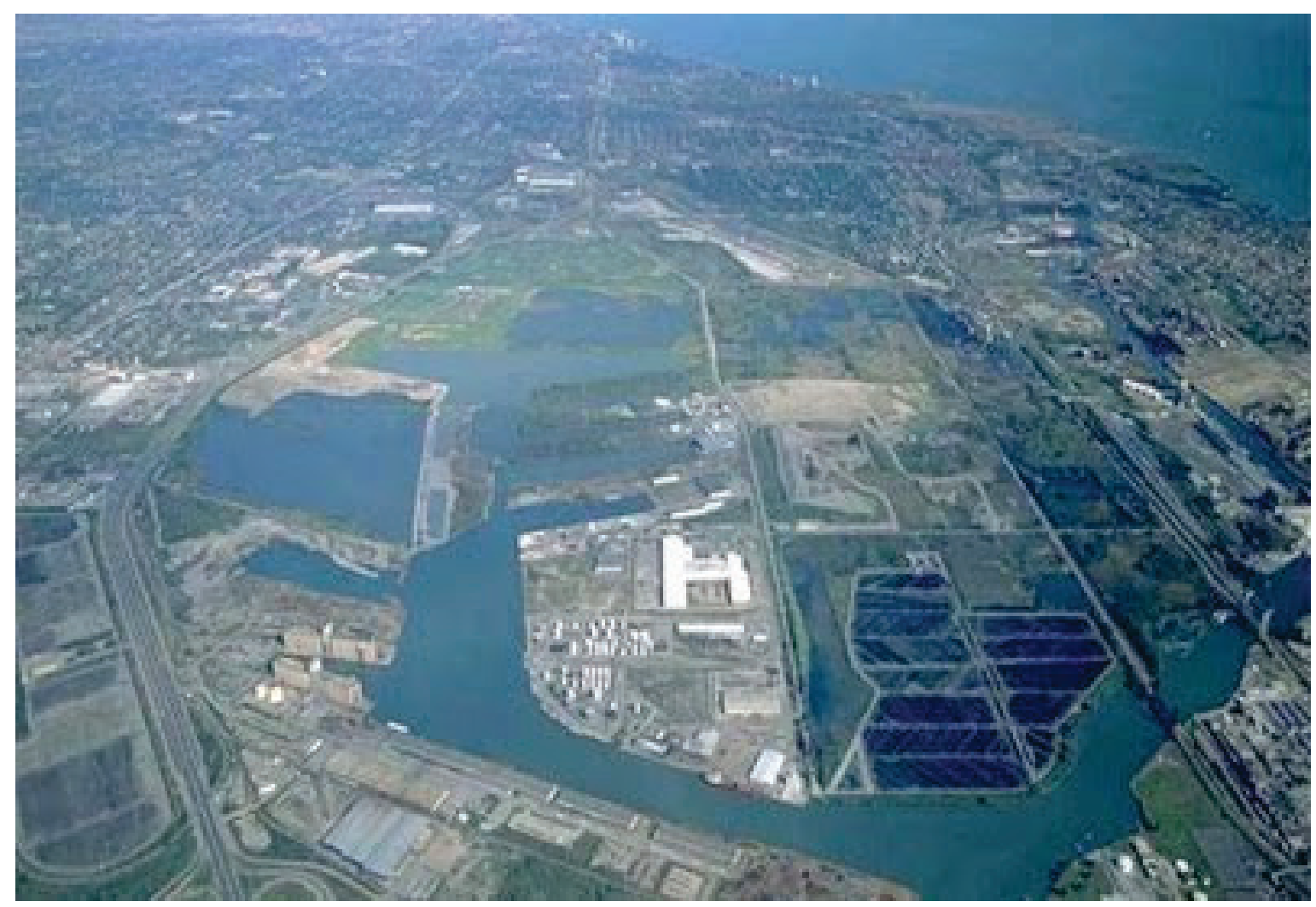


The U.S. Army Engineer Research and Development Center (ERDC) solves the nation's toughest engineering and environmental challenges. ERDC develops innovative solutions in civil and military engineering, geospatial sciences, water resources, and environmental sciences for the Army, the Department of Defense, civilian agencies, and our nation's public good. Find out more at www.erdc.usace.army.mil.

To search for other technical reports published by ERDC, visit the ERDC online library at http://acwc.sdp.sirsi.net/client/default. 


\section{Identification of Sediment Sources to Calumet River through Geochemical Fingerprinting}

David W. Perkey and Heidi M. Wadman

Coastal and Hydraulics Laboratory

U.S. Army Engineer Research and Development Center

3909 Halls Ferry Road

Vicksburg, MS 39180-6199

Mark A. Chappell and Jennifer M. Seiter

Environmental Laboratory

U.S. Army Engineer Research and Development Center

3909 Halls Ferry Road

Vicksburg, MS 39180-6199

Final report

Approved for public release; distribution is unlimited.

Prepared for Dredging Operations and Environmental Research Program

Coastal and Hydraulics Laboratory

Environmental Laboratory

U.S. Army Engineer Research and Development Center

3909 Halls Ferry Road

Vicksburg, MS 39180-6199

Under Project A1060-449021-56B673, "Geochemical and Other Tracers for Dredged Material Fate" 


\section{Abstract}

Geochemical sedimentary markers provide a well-established methodology for fingerprinting various sources of sediments accumulating within a region of concern. To help identify possible sources of contaminated sediment infilling a reach of the Calumet River between the Thomas J. O'Brien lock and Lake Michigan, multiple bottom sediment samples were collected in 2014 from six potential sediment sources. Additionally, geochemical data from historic dredging records spanning a 40-year period were examined to develop a historic geochemical fingerprint for sediments within this reach of the river.

Geochemical measurements and advanced multivariate statistics were used to successfully distinguish between all six potential sediment sources. Calumet River samples showed elevated levels of heavy metals and a geochemical signature that was distinct from the potential source sediments, suggesting that heavy metal contamination was occurring locally within the river. Additionally, multivariate analysis was able to show historic reductions in heavy metal and organic contaminants in the dredge records that likely correlates with implementation of the Clean Water Act. Geochemical fingerprints were successfully used to track changes in sediments both spatially and temporally within the project area. These fingerprints could be used further to identify any future changes in sediments within this reach of the Calumet River.

DISCLAIMER: The contents of this report are not to be used for advertising, publication, or promotional purposes. Citation of trade names does not constitute an official endorsement or approval of the use of such commercial products. All product names and trademarks cited are the property of their respective owners. The findings of this report are not to be construed as an official Department of the Army position unless so designated by other authorized documents. 


\section{Contents}

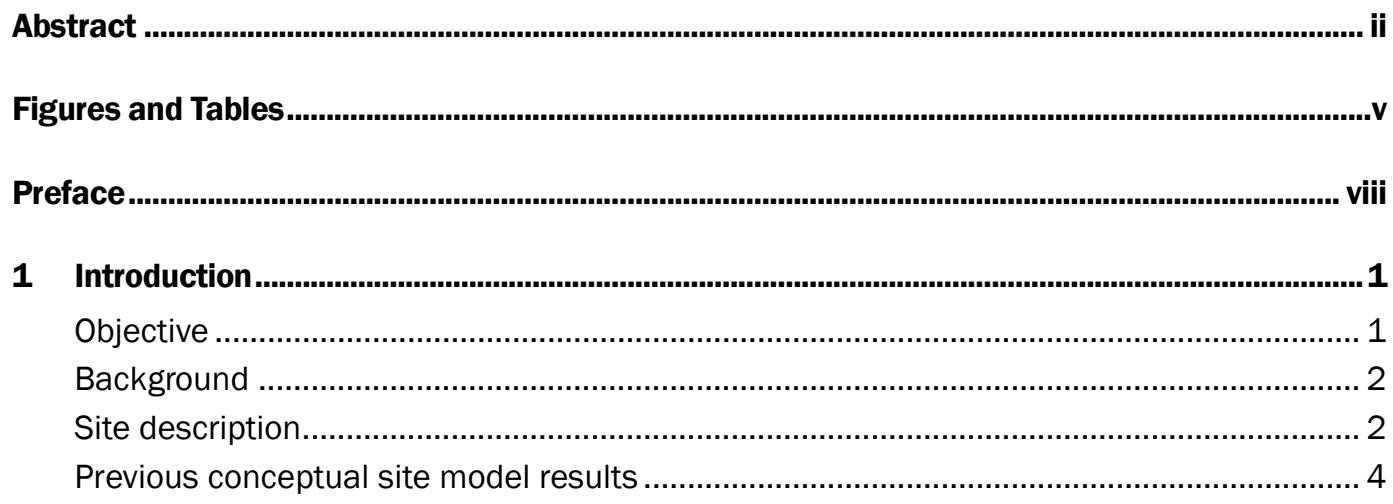

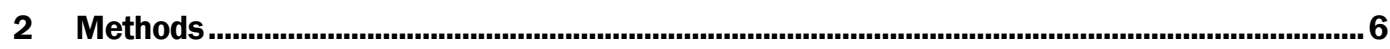

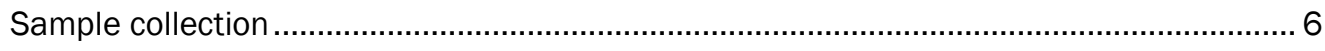

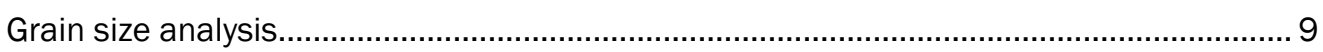

Light element analysis ......................................................................................... 10

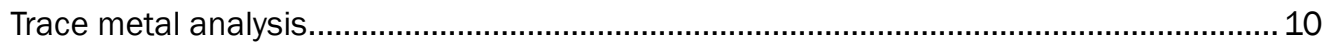

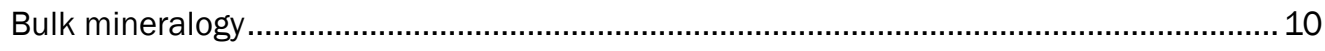

Electrical conductivity and $\mathrm{pH}$ measurements ........................................................... 10

Radioisotope analysis ......................................................................................... 11

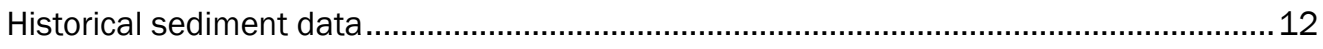

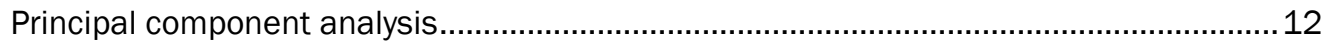

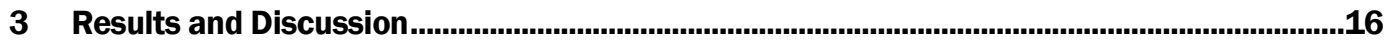

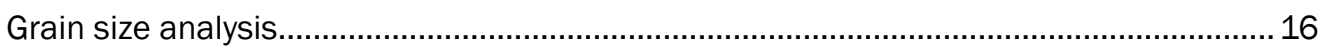

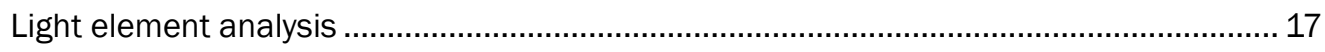

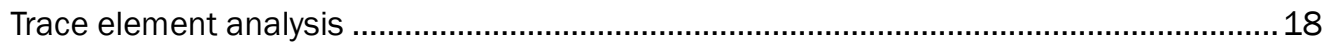

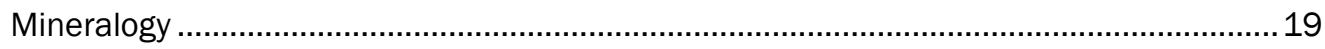

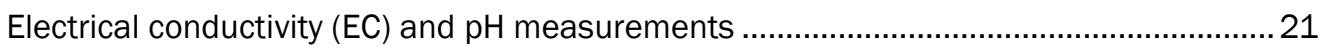

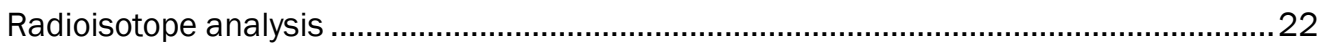

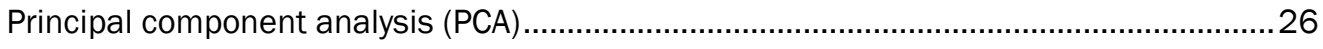

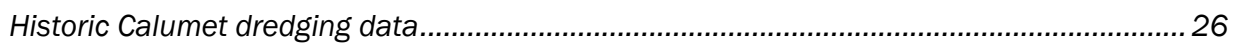

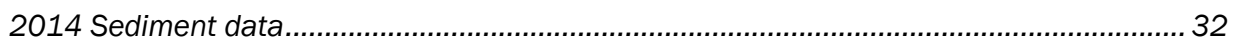

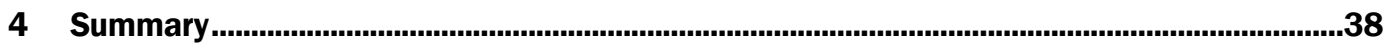

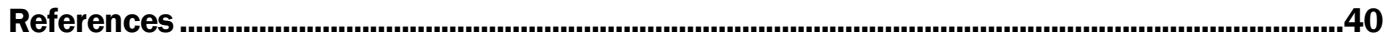

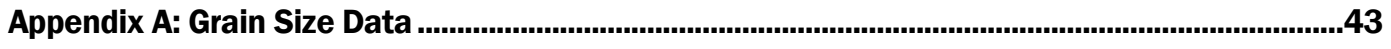

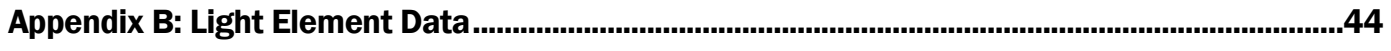

Appendix C: Trace Element Data ......................................................................................................45

Appendix D: Electrical Conductivity (EC) and pH Data.........................................................51 


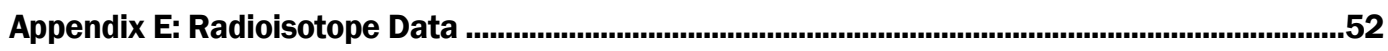

Appendix F: Multivariate Statistic Data SIMCA Classification Results..

Report Documentation Page 


\section{Figures and Tables}

\section{Figures}

Figure 1. Calumet Harbor and River, Illinois and Indiana. Approximate locations of the CSM monitoring stations are indicated with numbers 1, 2, 3, 4, and 6.

Figure 2. Locations of samples collected in the northern sample area from Lake Michigan (orange pins), Calumet Harbor (blue pins), and northern Calumet River (green pins) are shown in panel A. Lower Calumet River (green pins), Lake Calumet (red pins), and Pullman and Indian Creek (pink pins) samples in the southern sampling area are found in panel B...

Figure 3. Images of the sampling devices used for sediment collection. A petite Ponar sampler is shown in the left panel, and an image of the $5 \mathrm{~cm}$ (2 in.) diameter push corer is shown in the right panel.

Figure 4. XRD patterns of representative samples from Calumet Harbor, Lake Michigan, Pullman Creek, Lake Calumet, and the Calumet River.

Figure 5. XRD patterns of selected Calumet River samples showing the presence of chromite.

Figure 6. Location of radioisotope samples classified by (1) measurable gamma activity of ${ }^{7} \mathrm{Be},{ }^{137} \mathrm{Cs},{ }^{234} \mathrm{Th}$, and/or ${ }^{210} \mathrm{~Pb}$ (white pins); (2) measurable alpha activity only of ${ }^{210} \mathrm{~Pb}$ (yellow pins); or (3) no measurable radioisotope activity at all (red pins).

Figure 7. (A) Gamma activity of ${ }^{210} \mathrm{~Pb}$ in all radioisotope samples via gamma (red bars) and alpha (green bars) counting. Error bars are generated via laboratory-reported counting error and detector efficiency for each individual sample. Red boxes outlining the Sample IDs ( $X$-axis) indicate significant gamma and alpha activity, green boxes indicate significant alpha activity, only, and the dashed red box indicates significant gamma activity, only. Negative values, either in activity or in error, are not shown for clarity. (B) Spatial distribution of samples with (1) significant measurable gamma and alpha 210Pb activity (yellow ovals), only alpha activity (green ovals), or gamma-only activity (red oval).

Figure 8. Bivariate plot showing the variable loadings and sample scores ( $P$ and $T$, respectively in Equation 1) for the first two PCs of the historical Calumet sediment characterization data.

Figure 9. Plots showing the relative concentration ranges for (A) $\mathrm{NH}_{4}-\mathrm{N}$, (B) $\mathrm{Cu}$, and (C) $\mathrm{Zn}$ as reported in the historic sediment Calumet data.

Figure 10. Scores for the historic Calumet samples for PC 1-2 plotted with respect to their sampling time. The dashed lines demonstrate the collapse of the data set to a single cluster with time.

Figure 11. Loading plots calculated from PCA of the refined historical data set. Panel A shows PC-3 plotted against PC-1 while panel B plots PC-3 against PC-2.

Figure 12. Score plots calculated from PCA of the refined historical data set. The above plots represent the loadings in three dimensions, with (B) representing a $90^{\circ}$ rotation of plot (A).

Figure 13. Overall PCA model for all the entire dataset of sediment samples. (A) The loading plot showing interrelationships among the variables. (B) Score plot showing covariate relationships among the samples based on the covariance among its constituent variables. 
Figure 14. Results of the overall PCA model after removing the leverage outliers, Pullman and Indian Creeks, and the variable Sn. Note that there was virtually no change in the correlations displayed in the loading plot from the model optimization.

Figure 15. (A) Score and (B) loading plots from PLS-DA of the Calumet River samples. Here, important variables for Factors 1-2 are found within the outer ellipse of the loading plot.

Figure 16. Samples grouped by selected variables influential in discriminating the sediment types by their geochemistry for the first PCs explaining $40 \%$ of the variance in the data: (A) \%sand, (B) TC, and (C) sediment Ni concentration, as determined in the optimized PCA calculations.

Figure 17. Plot showing the discriminating variables most important for distinguishing members of the Lake Calumet class from members of the Calumet River class, as defined by their calculated PCA models.

\section{Tables}

Table 1. Coordinates of sampling locations in Lake Michigan (LM), Calumet Harbor (CH), Calumet River (CR), Lake Calumet (LC), Indian Creek (IC), and Pullman Creek (PC).

Asterisk indicates sample was analyzed for radio isotope activity.

Table 2. Average weight percentage sand, silt, and clay of sediments collected from the six sampling regions.

Table 3. Average weight percentage TOC, TN, and OC/N for sediments collected from the six sampling regions.

Table 4. Average $\mathrm{As}, \mathrm{Cr}, \mathrm{Cu}, \mathrm{Pb}$, and $\mathrm{Zn}$ concentrations (mg/kg) for the six sampling regions.

Table 5. Average $\mathrm{pH}$ and electrical conductivity values $(\mu \mathrm{S} / \mathrm{cm})$ for the bottom sediments collected from the six sampling regions.

Table A1. Weight percentage sand, silt, and clay are presented for the bottom samples collected in May 2014. PC=Pullman Creek, IC=Indian Creek, LC=Lake Calumet, $\mathrm{CR}=$ Calumet River, $\mathrm{CH}=$ Calumet Harbor, $\mathrm{LM}=$ Lake Michigan.

Table B1. Weight percent TOC, TC, TN along with atomic OC/N ratios for the bottom samples collected in May 2014 are presented. PC=Pullman Creek, IC=Indian Creek, $\mathrm{LC}=$ Lake Calumet, $\mathrm{CR}=$ Calumet River, $\mathrm{CH}=$ Calumet Harbor, $\mathrm{LM}=$ Lake Michigan, $\mathrm{BD}=$ Below Detection, $\mathrm{N} / \mathrm{A}=$ Not Applicable.

Table $\mathrm{C} 1$. Total metal concentrations ( $\mathrm{mg} / \mathrm{kg}$ ) of aluminum, arsenic, barium, cadmium, calcium, chromium, cobalt, and copper for the bottom sediment samples collected in May 2014. $P C=$ Pullman Creek, IC=Indian Creek, LC=Lake Calumet, $C R=$ Calumet River.

Table $\mathrm{C} 2$. Total metal concentrations ( $\mathrm{mg} / \mathrm{kg}$ ) of aluminum, arsenic, barium, cadmium, calcium, chromium, cobalt, and copper for the bottom sediment samples collected in May 2014. $\mathrm{CH}=$ Calumet Harbor, $\mathrm{LM}=$ Lake Michigan, $\mathrm{BD}=$ Below Detection.

Table C3. Total metal concentrations ( $\mathrm{mg} / \mathrm{kg}$ ) of iron, lead, magnesium, manganese, molybdenum, phosphorous, nickel, and potassium for the bottom sediment samples collected in May 2014. PC=Pullman Creek, IC=Indian Creek, LC=Lake Calumet, $\mathrm{CR}=$ Calumet River.

Table C4. Total metal concentrations ( $\mathrm{mg} / \mathrm{kg}$ ) of iron, lead, magnesium, manganese, molybdenum, phosphorous, nickel, and potassium for the bottom sediment samples collected in May 2014. $\mathrm{CH}=$ Calumet Harbor, LM=Lake Michigan

Table C5. Total metal concentrations ( $\mathrm{mg} / \mathrm{kg}$ ) of selenium, sodium, silver, thallium, tin, Vanadium, zinc, and strontium for the bottom sediment samples collected in May 2014. 
$\mathrm{PC}=$ Pullman Creek, $\mathrm{IC}=$ Indian Creek, $\mathrm{LC}=$ Lake Calumet, $\mathrm{CR}=$ Calumet River, $\mathrm{BD}=$ Below

Detection.

Table C6. Total metal concentrations ( $\mathrm{mg} / \mathrm{kg}$ ) of selenium, sodium, silver, thallium, tin, Vanadium, zinc, and strontium for the bottom sediment samples collected in May 2014.

$\mathrm{CH}=$ Calumet Harbor, $\mathrm{LM}=$ Lake Michigan, $\mathrm{BD}=$ Below Detection.

Table D1. pH and EC $(\mu \mathrm{S} / \mathrm{cm})$ data for the bottom sediments collected in May 2014.

$\mathrm{PC}=$ Pullman Creek, $\mathrm{IC}=$ Indian Creek, $\mathrm{LC}=$ Lake Calumet, $\mathrm{CR}=$ Calumet River, $\mathrm{CH}=$ Calumet Harbor, LM=Lake Michigan.

Table E1. Radioisotope activity (dpm/g) and error ( \pm ) for all samples. Significant, measurable activities and associated error are indicated by black font. Red font indicates that no significant radioisotope activities were measured.

Table F1. SIMCA classification results. No grouping was assigned to PC samples because they were previously identified as outliers and removed from the model.

Table F2. SIMCA classification results. No grouping was assigned IC samples because they were previously identified as outliers and removed from the model.. 


\section{Preface}

This study was conducted for the Dredging Operations and Environmental Research (DOER) Program under Project Number A1060-449021-56B673, "Geochemical and Other Tracers for Dredged Material Fate." The DOER Program Manager was Dr. Todd Bridges.

The work was performed by the Field Data Collection and Analysis Branch (HN-F) of the Navigation Division (CF), U.S. Army Engineer Research and Development Center, Coastal and Hydraulics Laboratory (ERDC-CHL). At the time of publication, Thad C. Pratt was Chief, CEERD-HN-F; Dr. Jackie Pettway was Chief, CEERD-HN; and W. Jeff Lillycrop, CEERD-HV-T, was the Technical Director for Navigation. Jeffrey R. Eckstein was the Deputy Director of ERDC-CHL, and José E. Sánchez was the Director.

COL Bryan S. Green was the Commander of ERDC, and the Acting Director was Dr. David W. Pittman. 


\section{Unit Conversion Factors}

\begin{tabular}{|c|c|c|}
\hline Multiply & By & To Obtain \\
\hline cubic inches & 1.6387064 E-05 & cubic meters \\
\hline cubic yards & 0.7645549 & cubic meters \\
\hline degrees Fahrenheit & $(\mathrm{F}-32) / 1.8$ & degrees Celsius \\
\hline feet & 0.3048 & meters \\
\hline inches & 0.0254 & meters \\
\hline microinches & 0.0254 & micrometers \\
\hline miles (US statute) & $1,609.347$ & meters \\
\hline pounds (mass) & 0.45359237 & kilograms \\
\hline
\end{tabular}




\section{Introduction}

The U.S. Army Corps of Engineers (USACE) dredges more than 200 million $\mathrm{yd} 3$ of material annually in order to operate and maintain thousands of miles of navigation channels and hundreds of harbors. Managing and monitoring these dredging operations is a key mission of the USACE. The high costs of dredging are only expected to increase over the near future, highlighting the imperative need to quantify the sources of infilling sediment. Identification of these sediment sources could potentially allow USACE to reduce dredging volumes through engineering and/or regulatory action that minimizes or prevents sedimentation when possible. Geochemical fingerprinting is a well-established method for distinguishing among sediment sources (Collins and Walling 2002; Collins et al. 2010; Papanicolaou et al. 2003; Gireeshkumar et al. 2013). This technique relies on the link between the geochemical properties of the sediments transported into an area of interest (AOI) and those of their sources.

Identifying and establishing distinct geochemical markers for the sources of sediments is the first and most critical step when trying to quantify sediment inputs to a given AOI. These distinct markers may be a unique trace metal, an elemental composition or ratio of elements, the presence of radio or stable isotopes, a sediment/soil mineral, or a combination of many of these parameters. Once the likely sources of infilling sediment have been characterized, then samples are collected from areas where sediment mixing has occurred. The origin of these samples can then be analyzed and essentially fingerprinted to determine the source of the sediment in question.

\section{Objective}

The objective of this report is to showcase how geochemical fingerprinting can be coupled with multivariate statistics as a tool to determine sediment sources impacting an area of the Calumet River between the Thomas J. O'Brien lock and Lake Michigan. This methodology was applied to sediment samples collected from the Calumet River and Harbor, Lake Calumet, and lower Lake Michigan areas as supplementary work to help further identify and constrain sources of sediment and contamination for a conceptual site model being conducted in the region. 


\section{Background}

The U.S. Army Corps of Engineers, Chicago District (LRC) annually dredges approximately 19,000 $\mathrm{m}^{3}$ (25,000 $\mathrm{yd}^{3}$ ) of contaminated sediment from the Calumet River. An additional 19,000 m³ (25,000 yd3) of less-contaminated sediments are also dredged from Calumet Harbor annually. Currently, both sources of material are placed in a lined confined disposal facility (CDF) located at the mouth of the Calumet River with Lake Michigan. The present CDF is projected to have approximately 5 years of remaining capacity. LRC is developing a dredged material management plan (DMMP) to determine options for the next 20 years of maintenance dredging. The DMMP is exploring opportunities for reducing dredging requirements, beneficial use of the material, and confined placement of contaminated material. LRC is seeking to identify the least-cost DMMP, which could include reduction of sediment loads to the river and harbor. In 2013, at the request of LRC, the U.S. Army Engineer Research and Development Center, Coastal and Hydraulics Laboratory (ERDC-CHL), was asked to develop a conceptual site model (CSM) to identify sediment sources to the Calumet Harbor and River. As part of that CSM, a monitoring plan to identify sediment sources to the Calumet Harbor and River was implemented. The original scope of the plan proposed by ERDC-CHL called for geochemical analysis of potential sediment sources; however, due to funding restrictions, sediment sampling for geochemical analysis was not included in the 2013 study. In 2014, the Dredging Operations and Environmental Research (DOER) Program funded a Research Task (RT) to demonstrate the use of geochemical techniques to identify sediment sources into and out of areas impacted by dredging operations. This DOER Program RT partnered with the LRC on the CSM project to provide geochemical information on sediments infilling the harbor and river channel in an attempt to identify those sediment sources.

\section{Site description}

Calumet Harbor is located on the southwest shore of Lake Michigan, west of the Illinois-Indiana state border and approximately $18 \mathrm{~km}$ (11 miles) southeast of Chicago. The harbor is protected to the north and northeast by a breakwater with a single gap on the northeast facing wall (Figure 1). Suspended sediment concentrations along the southern Lake Michigan shoreline are typically low; however, during large winter and spring wave events, suspended sediment levels become elevated as a result of the erosion of fine sediments on the southern Lake Michigan coastal shelf 
(Eadie et al. 1996, 2002; Lou et al. 2000; Beletsky et al. 2003). These storms may produce sediment plumes lasting several days to weeks, which are available for transport into Calumet Harbor.

Figure 1. Calumet Harbor and River, Illinois and Indiana. Approximate locations of the CSM monitoring stations are indicated with numbers $1,2,3,4$, and 6.

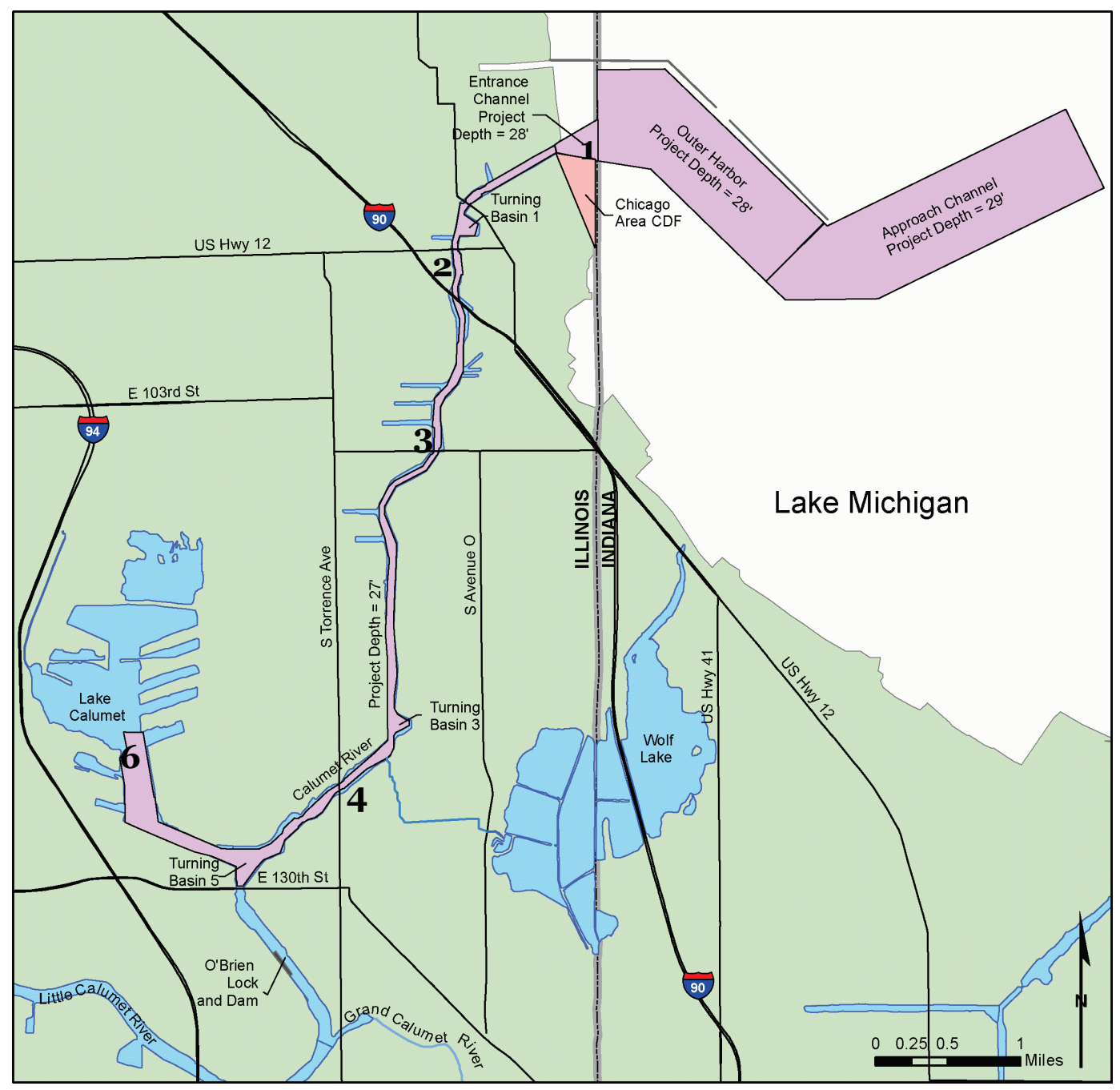

The Calumet River flows south approximately $11 \mathrm{~km}$ (7 miles) from Lake Michigan and Calumet Harbor towards the Thomas J. O'Brien Lock and Dam (Figure 1). Severe rainfall events occasionally result in flow reversal, with river discharge from the lock and dam flowing towards Lake Michigan. This stretch of river is industrially developed with multiple stockpiles of road salt, coal, and other bulk materials located adjacent to the river banks, which are predominantly lined with sheet pile or riprap. A total of nine stormwater and combined sewer outfalls along with two channel outlets were identified as potential sources of sediment to the 
Calumet River. The two channels were identified as Indian Creek, which enters the river near Turning Basin 3, and Pullman Creek, which enters the system on the western side of Lake Calumet near I-94 ${ }^{1}$.

Lake Calumet is generally less than $1.2 \mathrm{~m}$ ( $4 \mathrm{ft}$ ) deep; however, a deeper legacy channel still exists connecting the southern end of Lake Calumet to the Federal channel. Lake Calumet receives watershed runoff from Pullman Creek, which receives flow from a highly urbanized watershed, composed primarily of freeway. No information exists quantifying the exchange of sediment between Lake Calumet and the Calumet River.

\section{Previous conceptual site model results}

From December 2012 through May 2014, ERDC-CHL collected data to construct a CSM to describe the primary sediment sources and the physical processes that deliver sediment to the Calumet system. The CSM was developed from comparisons of environmental forcing conditions and measured turbidity within the system. Primarily through turbidity monitoring and bottom sediment erosion testing, several potential sediment sources and delivery mechanisms were identified. Large wave events on Lake Michigan that frequently occur from late autumn through early spring were identified as transport mechanisms for delivering fine sediments into Calumet Harbor and River. Turbidity responses to these events were limited to the northern section of the river, closest to the harbor and Lake Michigan, and were not transported throughout the entire river. On the inland side of the system, Pullman Creek, which empties into western Lake Calumet, was identified as a primary source of water and sediment into the system during precipitation events. Sediments from Pullman Creek were found to either transport directly into the river or deposit in the shallow waters of Lake Calumet, where they were available for resuspension and transport during strong ( $>8 \mathrm{~m} / \mathrm{s}$ ) wind events. Again, however, these observed increases in turbidity levels were limited to the stretches of river closest to Lake Calumet and were not transported through the entire system. In contrast, a heavy rain event in April of 2013 resulted in flow reversal of the Calumet River. A large turbidity plume was observed throughout the system for three days. This extreme event was shown to transport a large amount of sediment to the Calumet River and Harbor, though at lower (decadal scale) frequency than Pullman Creek sediment plumes. In addition to transport of sediments in from outside sources, the bottom sediments within the Calumet River

\footnotetext{
${ }^{1}$ ERDC CSM-TR in progress.
} 
were found to be mobilized as a result of deep-draft vessel passage. Once resuspended, these bottom sediments are redistributed by currents and waves within the system.

In addition to identifying likely sources and transport mechanisms of sediments in the Calumet system, the CSM also identified two potential sources that did not appear to contribute significant sediment loads to the system. Neither monitoring station 3, located at 106th Street near a stretch of unprotected river bank, nor station 4, positioned just downstream of Indian Creek, showed turbidity responses associated with precipitation events. The lack of response of turbidity in these locations throughout the study indicated that neither potential source was likely to be a significant contributor of sediment to the Calumet River. 


\section{Methods}

This section describes the field sampling and laboratory methods, along with data analysis methods, used in characterizing the sediments from various sources to the Calumet Harbor and River in the vicinity of Calumet City, IL. Sample collection techniques are presented first, followed by detailed methodology of all the geochemical techniques and multivariate statistics used. Results are presented in the context of the study objective: to identify the sources of sediment to the Calumet system.

\section{Sample collection}

To help identify sediment sources to the Calumet system, the project area was divided into six regions composed of Lake Calumet, Calumet River, Calumet Harbor, Lake Michigan, Pullman Creek, and Indian Creek. A total of 55 bottom sediment samples were collected and analyzed to characterize the sediment from these regions. Sample collection occurred 18 through 20 May 2014. Maps of sample locations are found in Figure 2. Table 1 lists their longitude and latitude. No sample was able to be recovered from site LM2O.

Samples collected from the Calumet Harbor and River, along with those from Lake Michigan, were obtained with a petite Ponar bottom sampler (Figure 3). Prior to sampling at each location, all equipment contacting sediment samples was decontaminated with Simple Green cleaning solution, distilled water, and site water. Sediment recovered from each Ponar cast was placed in a stainless steel basin and visually examined. Multiple casts were made as needed to collect approximately 1-2 L of sediment. The sediment was then homogenized in the basin and transferred to a sterile whirl-pak bag.

In the shallow water sampling areas of Lake Calumet, Indian Creek, and Pullman Creek, sediments were obtained with a $5 \mathrm{~cm}$ (2 in.) diameter push core (Figure 3). Core lengths at these sampling locations typically ranged from 5 to $13 \mathrm{~cm}$ ( 2 to $5 \mathrm{in}$.). Multiple cores were collected at each location until sufficient material was obtained. As with Ponar sampling, material at each push core site was placed in a stainless steel basin and homogenized prior to being transferred to sterile whirl-pak bags. A new, 2 in. diameter, clear, polyvinyl chloride coring sleeve was utilized at each location and all other equipment contacting the sediment was decontaminated with Simple Green cleaning solution, distilled water, and site water prior to sampling at another location. 
Figure 2. Locations of samples collected in the northern sample area from Lake Michigan (orange pins), Calumet Harbor (blue pins), and northern Calumet River (green pins) are shown in panel A. Lower Calumet River (green pins), Lake Calumet (red pins), and Pullman and Indian Creek (pink pins) samples in the southern sampling area are found in panel B.

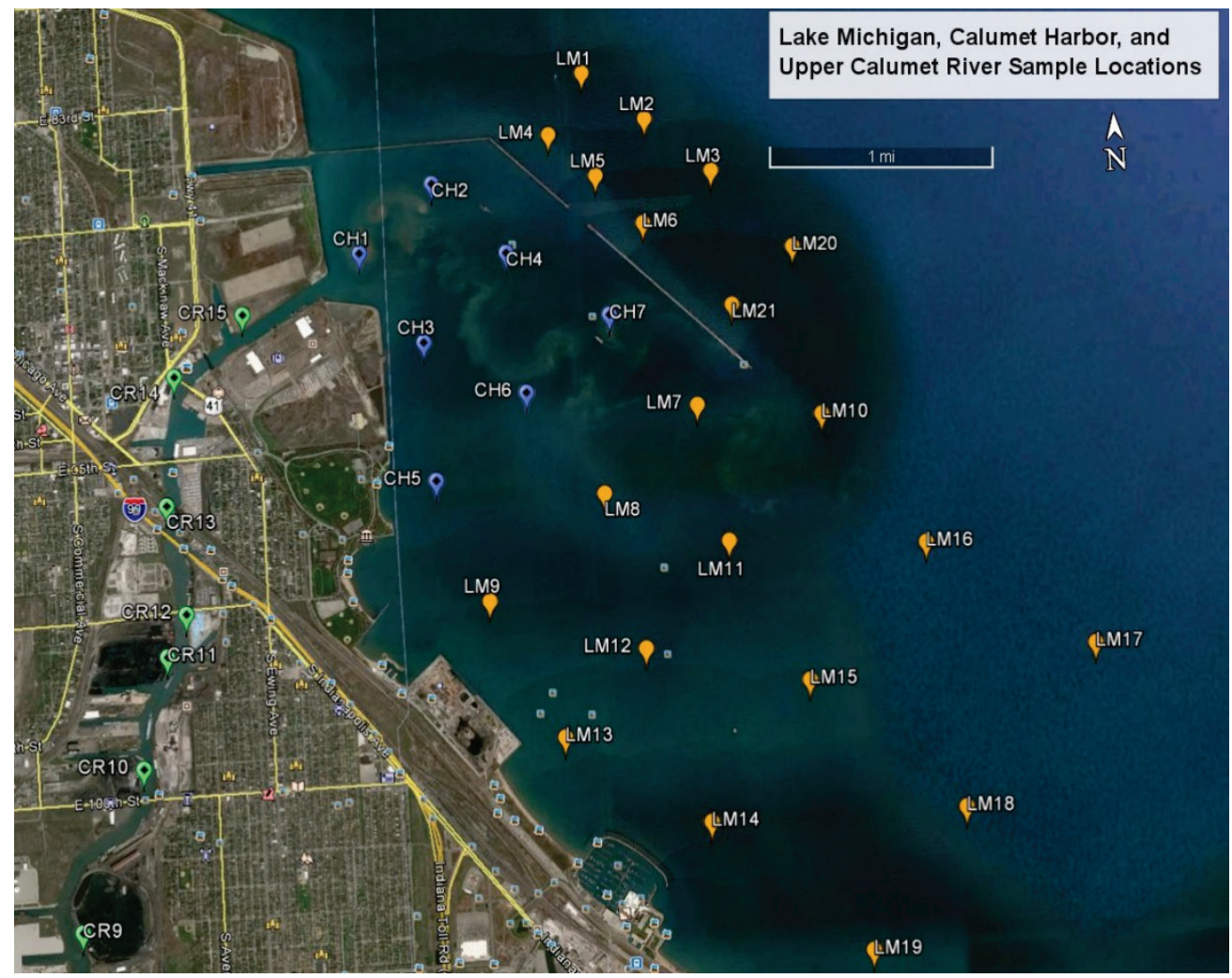

A

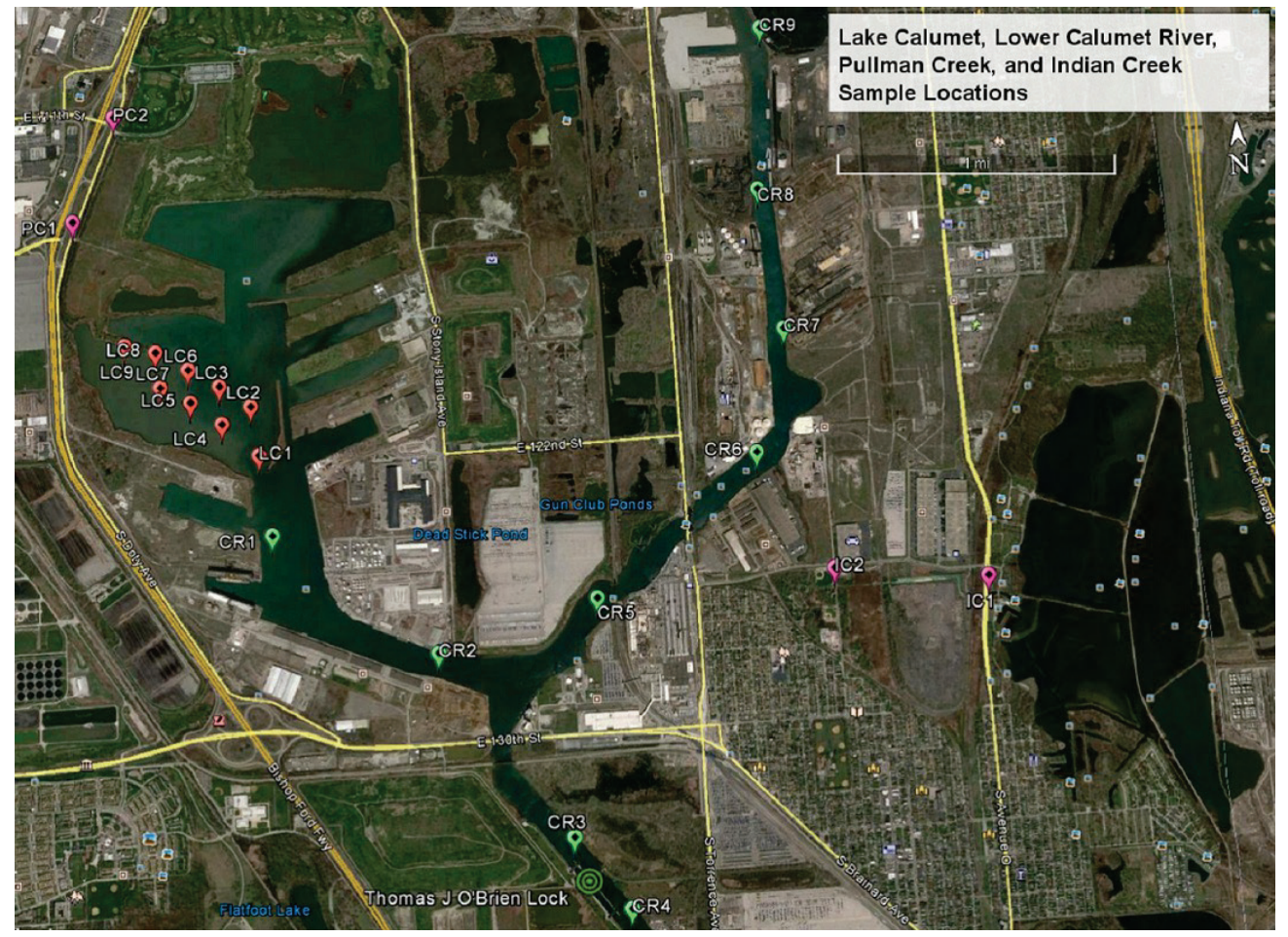


Table 1. Coordinates of sampling locations in Lake Michigan (LM), Calumet Harbor (CH), Calumet River (CR), Lake Calumet (LC), Indian Creek (IC), and Pullman Creek (PC). Asterisk indicates sample was analyzed for radio isotope activity.

\begin{tabular}{|c|c|c|c|c|c|}
\hline & & & & & \\
\hline LM & & & & & \\
\hline & & & & & \\
\hline & & & & & \\
\hline LM4 & & & CR4 & & \\
\hline LM5 & & & & & \\
\hline LM6 & & & & & \\
\hline LM7* & & & & & \\
\hline LM8* & & & CR8* & & \\
\hline LM9 & & & & & \\
\hline LM10 & & $6 " W$ & & & \\
\hline LM11 & & & R11 & & \\
\hline & & & & & \\
\hline LM13 & $20 " \mathrm{~N}$ & $7^{\circ} 30^{\prime} 40.48 " W$ & $\mathrm{R} 13$ & & \\
\hline LM14 & $5 " \mathrm{~N}$ & $7^{\circ} 29^{\prime} 58.59 " W$ & CR14* & $41^{\circ} 43^{\prime} 36.05^{\prime \prime N}$ & \\
\hline LM15 & & & & & \\
\hline LM16 & & & & & \\
\hline LM17 & & 39"W & LC2* & & \\
\hline LM18* & & $46 " \mathrm{~W}$ & & $64 " \mathrm{~N}$ & \\
\hline LM19 & & & & & \\
\hline LM20 & $5.44 " \mathrm{~N}$ & $87^{\circ} 29^{\prime} 21.03^{\prime \prime W}$ & LC5* & $.99 " \mathrm{~N}$ & $87^{\circ} 3$ \\
\hline LM21 & $1^{\circ} 43^{\prime} 43.37^{\prime \prime N}$ & $87^{\circ} 29^{\prime} 40.99 " \mathrm{~W}$ & & $41^{\circ} 40^{\prime} 40.10^{\prime \prime} \mathrm{N}$ & \\
\hline $\mathrm{CH} 1$ & & & LC7 & & \\
\hline $\mathrm{CH} 2 *$ & $1^{\circ} 44^{\prime} 15.26 " \mathrm{~N}$ & $87^{\circ} 31^{\prime} 10.96 " \mathrm{~W}$ & LC8 & $41^{\circ} 40^{\prime} 43.75^{\prime \prime} \mathrm{N}$ & $87^{\circ} 3$ \\
\hline CH3* & & $87^{\circ} 31^{\prime} 16.13 " W$ & LC9* & & \\
\hline $\mathrm{CH} 4 *$ & $41^{\circ} 43^{\prime} 58.53^{\prime \prime N}$ & $87^{\circ} 30^{\prime} 49.27^{\prime \prime W}$ & IC1 & $52.67 " \mathrm{~N}$ & $87^{\circ} 3$ \\
\hline $\mathrm{CH} 5$ & & & IC2 & $41^{\circ} 39^{\prime} 55.91^{\prime \prime N}$ & $87^{\circ} 32^{\prime} 58.76^{\prime \prime W}$ \\
\hline & $41^{\circ} 43^{\prime} 27.08^{\prime \prime N}$ & $87^{\circ} 30^{\prime} 45.65^{\prime \prime} \mathrm{W}$ & PC1 & $41^{\circ} 41^{\prime} 9.40^{\prime \prime} \mathrm{N}$ & $87^{\circ} 36^{\prime} 0.78^{\prime \prime W}$ \\
\hline $\mathrm{CH} 7 *$ & $41^{\circ} 43^{\prime} 43.06 " \mathrm{~N}$ & $87^{\circ} 30^{\prime} 18.74 " \mathrm{~W}$ & PC2 & $41^{\circ} 41^{\prime 2} 29.09^{\prime \prime N}$ & $87^{\circ} 35^{\prime} 50.07^{\prime \prime W}$ \\
\hline
\end{tabular}


Figure 3. Images of the sampling devices used for sediment collection. A petite Ponar sampler is shown in the left panel, and an image of the $5 \mathrm{~cm}$ (2 in.) diameter push corer is shown in the right panel.
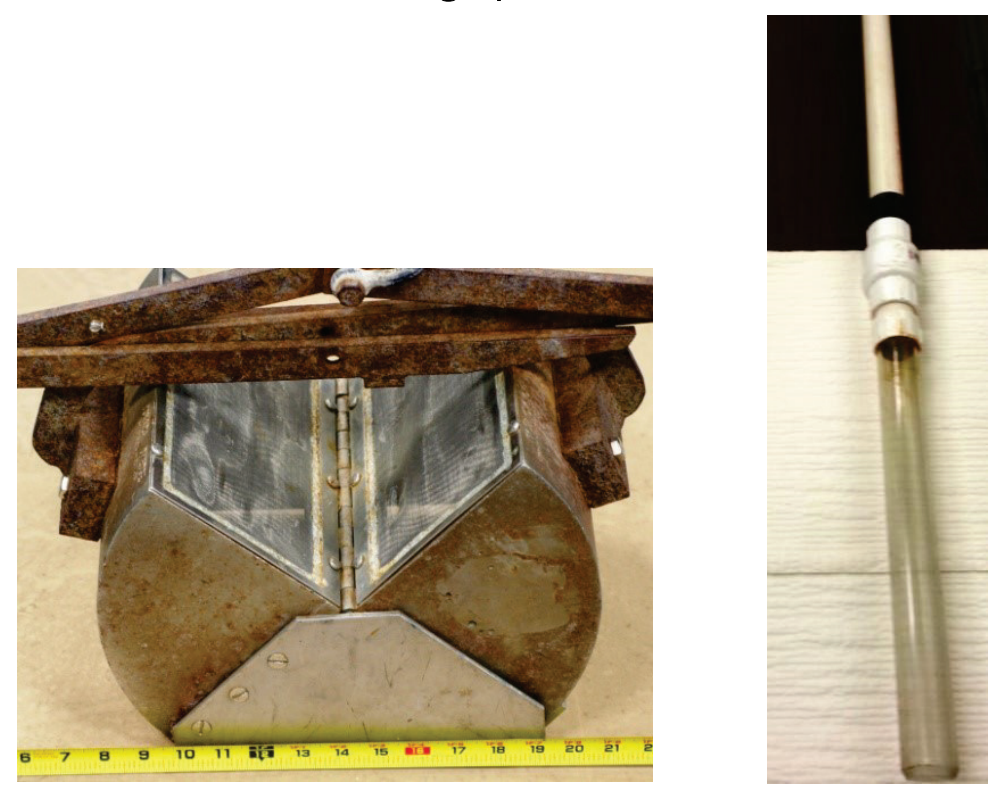

After collection, all sample bags were packed into coolers and transported back to ERDC-CHL in Vicksburg, MS. Upon arrival at ERDC-CHL, samples were kept in a walk-in cooler and maintained at a temperature of approximately $4{ }^{\circ} \mathrm{C}\left(39^{\circ} \mathrm{F}\right)$.

\section{Grain size analysis}

Each sediment sample was homogenized, subsampled (1-2 g), and deflocculated overnight in a solution of sodium metaphosphate $(40 \mathrm{~g} / \mathrm{L})$ prior to grain size analysis. A Malvern Mastersizer 2000 laser diffraction particle-sizer was used to measure the particle-size distributions of the subsamples. The particle-sizer measures particle size over the range 0.02 to $2000 \mu \mathrm{m}$. Particle size distributions were determined by first removing and sieving (\#18 mesh) debris and organic material larger than $1000 \mu \mathrm{m}$. The passing portion of the sample was added to the instrument's reservoir and sonicated for $60 \mathrm{~s}$ prior to analysis. The sample was then pumped and recirculated through the optical module, which includes a spatial filter assembly containing a laser diode and laser beam collimator. The diffraction detector assembly contains a custom photodetector array that is used for the measurement of light scattering by the suspended particles. The distribution of grain sizes and median grain sizes was derived from this light scattering measurement. Organic material was not oxidized before grain 
size analysis was performed; therefore, grain size distributions include organic material less than $1000 \mu \mathrm{m}$.

Four samples collected from Lake Michigan were composed of coarse material beyond the range of laser diffraction detection limits. Grain size distribution of these samples was obtained through dry sieving according to ASTM D6913-04 (2009) protocols.

\section{Light element analysis}

Total inorganic and organic carbon, total nitrogen, and total sulfur, were determined by catalytic combustion using CN628 Carbon/Nitrogen Determinator by LECO Corporation, Inc. Analysis was performed on whole sediment samples and completed in triplicate to evaluate any heterogeneity within samples. Carbon/nitrogen ratios were calculated from the averaged results and determined for both percent and atomic ratios.

\section{Trace metal analysis}

Total metal content of all sediment samples were determined through total metal digestion using the USEPA $3050 B$ (USEPA 1986) method.

\section{Bulk mineralogy}

Sediment mineralogy was determined through X-ray diffraction (XRD) of the bulk sediment material. Whole sediment samples were dried, sieved, and ground. A subset of 20 of the 55 total surface samples was selected for bulk XRD analysis. Initially, 10 samples were selected from each of the designated areas (Lake Michigan, Calumet Harbor, Calumet River, Lake Calumet, Pullman Creek, and Indian River). Data processing indicated that minimal changes were apparent among all samples. Therefore, an additional 10 samples were prepared, and data were collected. All samples were run on a Panalutical X'Pert Pro Materials Research Diffractometer unit at Co-Ka wavelength, and the data were processed using MDI Jade 2010 software.

\section{Electrical conductivity and pH measurements}

Soil $\mathrm{pH}$ was conducted using standard methods using $10 \mathrm{~g}$ of sediment to 10 $\mathrm{mL}$ of deionized (DI) water, being careful to maintain a 1:1, sediment:water ratio. The system was allowed to stand and settle for $10 \mathrm{~min}$ before reading the $\mathrm{pH}$ with a calibrated Cole-Palmer combination, solid-state $\mathrm{pH}$ electrode. 
Electrical conductivity (EC) was conducted using standard methods using $10 \mathrm{~g}$ of sediment to $10 \mathrm{~mL}$ of DI water, being careful to maintain a 1:1, sediment:water ratio. The EC was then measured using a calibrated solidstate conductivity probe.

\section{Radioisotope analysis}

A subset of 23 of the 55 total surface samples was identified for radio isotope analysis. Samples (indicated with an asterisk in Table 1) were selected from four of the six project areas. Subsamples were initially selected based on grain size, with preference given to fine-grained (muddy) samples as the higher surface area of fine-grained particles yields substantially better radioisotope results. Accordingly, no samples from Indian or Pullman Creek could be used for isotope analysis due to the coarse grain size of those samples. Gamma activities of $7 \mathrm{Be}$, supported ${ }^{234 \mathrm{Th}}$, and ${ }^{137 C s}$ were measured by GEL Laboratories LLC. Samples were dried, pulverized, and packed into a $100 \mathrm{cc}$ gamma can $(\sim 150-200 \mathrm{~g}$ of dried sediment). Samples were then placed into lead-shielded, standard highpurity germanium detectors and counted to achieve a minimum detection count (MDC) above the required detection limit for ${ }^{137 \mathrm{Cs}}(0.1 \mathrm{pCi} / \mathrm{g}$; generally approximately 24 hours). If an MDC for activity for ${ }^{137} \mathrm{Cs}$ was not achieved, the gamma spectrum was examined for evidence of activity for the other radioisotopes. If activity was noted, the samples were counted to the MDC, if necessary, for those isotopes. If no activity was noted, counting ceased. All measured activity was calibrated to individual detector efficiency. Radioisotope activity errors were calculated for each sample by GEL Laboratories LLC and are a function of software sensitivity as well as the efficiency of each individual radioisotope detector. Activities were converted from picocuries per gram of sediment (pCi/g) to disintegrations per minute per gram of sediment (dmp/g), as per GEL Laboratories LLC recommended standard, by multiplying the value of pCi by 2.22 .

Surface activities of $210 \mathrm{~Pb}$ were determined via alpha spectrometry by measuring the activity of its granddaughter, secular equilibrium isotope ${ }^{210} \mathrm{Po}$. Dried samples were spiked with a known amount of $209 \mathrm{~Pb}$ and partially digested in $16 \mathrm{~N} \mathrm{HNO}_{3}$ and $6 \mathrm{~N} \mathrm{HCl}$, resulting in the release of ${ }^{210} \mathrm{~Pb}$ from the fine fraction. Following the methods of Flynn (1968) and Nittrouer et al. (1979), the polonium was leached onto a silver planchette placed in the resulting solution. Alpha activity on the planchette was measured using gas scintillation counting on a standard alpha detector for a minimum of 24 hours. 


\section{Historical sediment data}

Historic sampling records of dredged material from the Calumet River and Harbor had been maintained in a database by the LRC spanning a 40-year period from 1967 to 2007. The database includes results from various geochemical analyses that had been performed on dredged material from this region. Parameters that have been measured in the past include levels of metals, nitrogen, phosphorous, carbon, and organic contaminants. Prior to the collection of the samples previously described, the LRC database was reviewed to identify possible geochemical parameters that could be helpful in distinguishing Calumet River and Harbor sediments from other regional sediments. To help elucidate this information, principal component analysis was performed on the historical sediment data.

\section{Principal component analysis}

When considering methods to geochemically distinguish sediments, it is important to realize that physicochemical characteristics rarely exist independently of each other in soils/sediments but are instead spatially and temporally interrelated. The presence of these covariate relationships among sediment geophysical and geochemical properties complicates distinguishing sources with a single defining property, as is commonly attempted. Therefore, the formulated nature of sediment's geochemical characteristics makes them better suited to be distinguished by multivariate approaches. This allows consideration of the entire geochemical characterization matrix instead of arbitrarily selecting from one or a handful of seemingly important properties, which could potentially bias the study. A well-established multivariate technique is principal component analysis or PCA. This method quantifies inherent (and often unseen) relationships existing in samples based on the existing covariance among variables (Esbensen 2010). The combination of PCA with a Partial Least Squares Discriminant Analysis (PLS-DA) and a Soft Independent Models for Classification Analogy (SIMCA) was used to determine if sediments from different geographic areas (e.g., Lakes Calumet and Michigan, Calumet River and Harbor) were geochemically distinguishable.

In essence, PCA clusters samples (e.g., sediments) are based on their statistical similarity. These statistical similarities are the calculated scores for each reduced dimension, defined as a principle component (PC). To formally assess the statistical validity of the assigned class memberships for the sediment samples, or groupings, as defined by PCA, the 
unsupervised classification method called SIMCA and PLS-DA was utilized. SIMCA allows for the classification of samples based on the relative distance among the different PCA models built for each group of sediments. This classification thus allows the sediment samples or groups to be sorted with geochemically similar sediments (Wold 1977). PLS-DA is subsequently performed in order to sharpen the separation between groups of observations by analyzing and rotating PCA components such that a maximum separation among classes (in this case, sediment groupings) is obtained. From this analysis, the variables (e.g., geochemical parameters) that carry the class-separating information are defined. Altogether, the results are then used to infer information about geochemically indistinguishable sediments (e.g., likely sediment sources). The following paragraphs provide a detailed description of the PCA, PLSDA, and SIMCA analyses applied to the Calumet River system data.

Loadings in PCA are defined as the correlation $(r)$ between two variables (vectors), $x$ and $y$ as

$$
r(x, y)=\frac{\operatorname{Cov}(x, y)}{S_{x} S_{y}}
$$

where $\operatorname{Cov}=$ covariance between $x$ and $y$ and $S_{i}=$ standard deviation of the variables. Here, the variables represent the geochemical characterization data used to describe each sample type. If projected in reduced space, based on the direction of the principal axis, then the relationship between the variable covariance and angle of the vectors separating $\mathrm{x}$ and $\mathrm{y}$ is

$$
r(x, y)=\cos \theta=\frac{x^{T} y}{\|x\|\|y\|}
$$

where $x^{T}$ represents the transpose of the variable $x$ and $\|i\|$ represents the mean-centered variables. Thus, the correlation of variables $x$ and $y$ to the PCs as well as to each other is indicated graphically by their respective angles to the principal axes. For example, if the angle between the vectors (plotted in reduced space) describing variable $x$ and the principal axis (PC-1) is close to zero, then variable $x$ is well described by PC-1 (because $\cos 0=1)$. Similarly, if the angle between variable $x$ and PC- 1 is close to $180^{\circ}$, then variable $x$ is considered negatively correlated to PC- 1 (because $\left.\cos \left(180^{\circ}\right)=-1\right)$. Finally, if the angle between two variables is close to $180^{\circ}$, 
the two variables $x$ and $y$ are considered anti-correlated. In summary, if the variables are close together geometrically, then they are correlated.

By quantifying the correlations among all the variables in a data matrix, PCA can essentially reduce the dimensionality of large, multivariable datasets to small subsets of orthogonal principal components. The advantage of this technique is that it elucidates latent structure in multivariate data matrices that may not be readily apparent from a univariate comparison of the absolute values within the characterization data. Furthermore, these relationships extend to the samples by which the variables are described through the decomposition of the raw data matrix $(X)$ as indicated by the general centered PCA model (Esbensen 2010):

$$
X=T P^{T}+E
$$

where $T$ = score matrix, $P^{T}=$ accompanying loading matrix (transposed), and $E=$ the error (nonstructural) or residual matrix in the data isolated from the analysis. Thus, the PC model represents the matrix product of $\mathrm{TP}^{\mathrm{T}}$.

These relationships are important when comparing the score and loading plots. The two plots are considered complementary and are most revealing when the positions of the objects and variables are studied together. By mentally superimposing the score and loading plots, the same rules described above apply for matching correlated variables with objects. Thus, PCA is a powerful approach that has proven particularly effective in finding relationships among complex soil and sediment data that may not have been apparent from simply qualitatively looking at populations of geochemical data (Mathangwane et al. 2008; Chappell et al. 2011; Steevens et al. 2011; Chappell et al. 2014).

For this project, prior to commencing PCA, the data were preprocessed by mean-centering (around zero) and normalizing by the standard deviation to remove any parametric bias. Characterization data reported as below the reported limit or nondetects were removed from the matrix and treated as missing data. Dimension reduction was carried out via the Nonlinear Iterative Partial Least Squares algorithm (which is appropriate for missing data) with the model allowed to select the optimal number of PCs. In the PCA, soil characterization data were treated as variables while the samples were treated as objects. Variables containing $>10 \%$ missing data and poorly 
contributing to the PCs were eliminated to minimize model uncertainty. PCA models were statistically cross validated using a bootstrapping approach and a Leave-One-Out Method for samples. Note that the radioisotope data were not included in the PCA analysis for this project. Cost restrictions as well as grain size limitations resulted in radioisotope analysis of only 23 of the 55 collected samples. This limited sample population risks potentially introducing spatial bias into the population that would likely impact the PCA results. The radioisotope data were thus analyzed on a stand-alone basis, in the context of the other data, post-PCA analysis. 


\section{Results and Discussion}

Bottom sediments collected from the Calumet River and surrounding area were analyzed to determine likely sources of sediment infilling the river. The results of the data analyses are presented in the following sections. This section will also include general observations as well as interesting contrasts in the data. The reader will be referred to technical appendices for full presentation of the analyzed dataset.

\section{Grain size analysis}

Weight percentages of sand, silt, and clay fractions based on the Wentworth scale for the 55 bottom samples collected throughout the study can be found in Appendix A. Table 2 presents a summary table that lists the average sand, silt, and clay content for each region. Overall, samples collected from Lake Michigan were generally found to have the highest percentage of sand with an average sand content of $79 \%(n=20)$. The bottom samples collected from Pullman Creek and Indian Creek were similarly sand dominated with average sand contents of $78 \%(\mathrm{n}=2)$ and $57 \%(n=2)$, respectively. Sediments within the protected breakwater of Calumet Harbor had a lower average sand content $(41 \%, n=7)$ than those sediments located just outside the harbor. The fine portion $(<63 \mu \mathrm{m})$ of these sediments was composed mostly of silt, which on average accounted for $50 \%$ of the total sample. By comparison, samples collected from within the Calumet River and Lake Calumet were found to be silt dominated, with average silt contents of $58 \%(n=15)$ and $61 \%(n=9)$, respectively. There was very little textural difference observed between samples collected from these two sampling regions. Average sand content for the river was $28 \%$ compared to $24 \%$ for Lake Calumet, and average clay contents were within $1 \%$ of each other.

Table 2. Average weight percentage sand, silt, and clay of sediments collected from the six sampling regions.

\begin{tabular}{|l|c|c|c|}
\hline Region & Sand & \multicolumn{1}{l|}{ Silt } & \multicolumn{1}{l|}{ Clay } \\
\hline Pullman Creek (PC) & 78 & 19 & 3 \\
\hline Indian Creek (IC) & 57 & 41 & 2 \\
\hline Lake Calumet (LC) & 24 & 61 & 15 \\
\hline Calumet River (CR) & 28 & 58 & 14 \\
\hline Calumet Harbor (CH) & 41 & 50 & 9 \\
\hline Lake Michigan (LM) & 79 & 19 & 2 \\
\hline
\end{tabular}




\section{Light element analysis}

Weight percentages of total organic carbon (TOC), total nitrogen (TN), and the atomic organic carbon to nitrogen ratios $(\mathrm{OC} / \mathrm{N})$ for the 55 samples collected are presented in Appendix B. Table 3 provides a summary of the results via averages of TOC, TN, and $\mathrm{OC} / \mathrm{N}$ for each region. Overall, the measured TOC of sediments ranged from $7.96 \%$ to below detection limits. Samples collected from the Calumet River (CR) tended to have the highest TOC values with a mean of $3.39 \%(n=15)$. These levels of TOC were similar to some of the higher TOC percentages previously reported in the historical dredge material records for this area. Calumet Harbor samples showed the lowest TOC values with a mean of $1.32 \%(n=7)$. Note that while Table 3 shows Lake Michigan samples (LM) as having the second highest mean TOC $(2.17 \%, n=17)$, there were three samples from this group (LM 2-4) that had TOC values below detection and were therefore not included in the reported average. Had values $<0.1 \%$ been utilized for these three samples, then the resulting mean TOC for the LM samples would have been $<2.0 \%$.

Table 3. Average weight percentage TOC, TN, and OC/N for sediments collected from the six sampling regions.

\begin{tabular}{|l|c|c|c|}
\hline Region & TOC & TN & OC/N \\
\hline Pullman Creek (PC) & 1.87 & $\mathrm{BD}^{*}$ & $\mathrm{~N} / \mathrm{A}$ \\
\hline Indian Creek (IC) & 1.90 & 0.18 & 12.31 \\
\hline Lake Calumet (LC) & 1.48 & 0.12 & 14.39 \\
\hline Calumet River (CR) & 3.39 & 0.20 & 19.78 \\
\hline Calumet Harbor (CH) & 1.32 & 0.12 & 12.83 \\
\hline Lake Michigan (LM) & 2.17 & $0.13 * *$ & $19.51 * *$ \\
\hline
\end{tabular}

*Indicates measurements below detection thresholds of $0.1 \%$.

** LM mean calculated from only 2 of 20 samples that had TN values above detection threshold.

As with TOC, CR samples tended to have the highest \%TN with a mean of $0.2 \%(n=15)$. In many instances, the other sediment groupings contained samples with $\mathrm{TN}$ values below the detection point of $0.1 \%$. For instance, only 2 LM samples (LM9 \& LM13) and none of the Pullman Creek (PC) samples had TN percentages above detection limits. In contrast, all 15 samples from the CR group had measurable levels of TN.

Overall, the atomic ratios calculated for this dataset ranged from 4.33 to 54.63. In instances where TN values were below the detection limit, no $\mathrm{OC} / \mathrm{N}$ could be calculated. $\mathrm{CR}$ samples once again showed the highest mean 
OC/N (19.78, n=15) for the study area. As previously described, only two of the twenty LM samples had TN values high enough to allow for the calculation of OC/N. Therefore, the reported mean of 19.51 in Table 3 is not representative of the majority of LM samples collected. The other sediment groupings had mean $\mathrm{OC} / \mathrm{N}$ ratios that ranged from 12.31 to 14.39.

\section{Trace element analysis}

Trace element analysis of the 55 samples showed that there is variability across the system. Given the large amounts of data yielded by this methodology, this report summarizes the data only for common metals of concern. Table 4 presents mean values reported in $\mathrm{mg} / \mathrm{kg}$ of sediment for each of the six sampling regions for the selected metals arsenic, chromium, copper, lead, and zinc. Complete data of all trace element analysis can be found in Appendix C.

Table 4. Average As, $\mathrm{Cr}, \mathrm{Cu}, \mathrm{Pb}$, and $\mathrm{Zn}$ concentrations ( $\mathrm{mg} / \mathrm{kg}$ ) for the six sampling regions.

\begin{tabular}{|l|c|c|c|c|c|}
\hline Region & As & $\mathrm{Cr}$ & $\mathrm{Cu}$ & $\mathrm{Pb}$ & $\mathrm{Zn}$ \\
\hline Pullman Creek (PC) & 13.85 & 31.05 & 32.50 & 136.50 & 204.00 \\
\hline Indian Creek (IC) & 20.96 & 97.65 & 37.75 & 268.40 & 287.00 \\
\hline Lake Calumet (LC) & 22.51 & 17.41 & 20.89 & 46.82 & 133.44 \\
\hline Calumet River (CR) & 13.85 & 37.26 & 60.62 & 150.05 & 457.87 \\
\hline Calumet Harbor (CH) & 9.91 & 13.28 & 18.41 & 38.90 & 78.70 \\
\hline Lake Michigan (LM) & 7.03 & 7.22 & 7.57 & 17.57 & 80.44 \\
\hline
\end{tabular}

Arsenic values ranged from 2.75 to $35.70 \mathrm{mg} / \mathrm{kg}$ with higher concentrations typically being found in LC samples, which had a mean value of $22.51 \mathrm{mg} / \mathrm{kg}(\mathrm{n}=9)$ and lower concentrations associated with LM samples with a mean of $7.03 \mathrm{mg} / \mathrm{kg}(\mathrm{n}=20)$. Chromium levels ranged from 2.42 to $172.0 \mathrm{mg} / \mathrm{kg}$. The highest $(172.0 \mathrm{mg} / \mathrm{kg}$ ) concentration was associated with a sample from Indian Creek (IC1) which was found to be anomalously high when compared to the rest of the data set. Excluding this sample, the highest concentrations of chromium were typically associated with sediments from the $\mathrm{CR}$ region. A similar trend was apparent in the lead $(\mathrm{Pb})$ data. Again, the highest single $\mathrm{Pb}$ concentration (441.0 mg/kg) was found to be anomalously high and associated with Indian Creek sediment (IC2). Outside of this sample, elevated $\mathrm{Pb}$ concentrations were commonly found to be associated with sediments from the $\mathrm{CR}$ region. Calumet River sediments also typically showed the highest concentrations of both copper $(\mathrm{Cu})$ and zinc $(\mathrm{Zn})$ and had the 
highest mean levels of both at $60.62 \mathrm{mg} / \mathrm{kg}$ and $457.87 \mathrm{mg} / \mathrm{kg}$, respectively $(\mathrm{n}=15)$. By comparison, Lake Michigan samples showed the lowest mean concentrations of $\mathrm{As}, \mathrm{Cr}, \mathrm{Cu}$, and $\mathrm{Pb}$ (Table 4). The lower trace metal concentrations associated with these samples are likely linked to their sand dominated texture. Overall, the samples with the highest trace metal values were associated with areas of active industry and higher anthropogenic activity (i.e., the Calumet River).

\section{Mineralogy}

XRD data did not show significant mineralogical differences between the Calumet River and the potential sediment sources. All samples contained common soil-forming minerals including quartz, iron oxides (hematite), clay minerals (chlorite, kaolinite, and muscovite), feldspars (albite, orthoclase), dolomite, and calcite. However, a mineralogical anomaly was discovered in the Calumet River at sampling site 9. This sampling location is located among industrial areas and slag piles. At this site, XRD results showed the formation of an iron/chromium oxide mineral: chromite $\left(\mathrm{FeCr}_{2} \mathrm{O}_{4}\right)$. Chromite is an oxide mineral belonging to the spinel group and is an industrially important mineral for the production of metallic chromium, used as an alloying ingredient in stainless steels.

Below are two examples of the Calumet River system mineralogy as determined by XRD. Figure 4 shows representative patterns from Calumet Harbor, Lake Michigan, Pullman Creek, Lake Calumet, and the Calumet River. Although peak intensity may change from sample to sample, the overall mineralogy does not differ significantly. Arrows indicate major peaks for some of the dominant mineral forms in the samples.

By comparison, Figure 5 shows three XRD spectra from the Calumet River (CR5, CR7, and CR9). Overall, the mineralogy is fairly consistent as demonstrated by the similar XRD spectra. However, there are some subtle changes in the 38-42 $2 \theta$ region of the spectra, due to the presence of hematite and chromite. Chromite in particular was only found in portions of the Calumet River and not in any of the potential sediment sources. These data further support the idea that anthropogenic activity greatly influences the geochemical nature of the sediments in the river. 
Figure 4. XRD patterns of representative samples from Calumet Harbor, Lake Michigan, Pullman Creek, Lake Calumet, and the Calumet River.

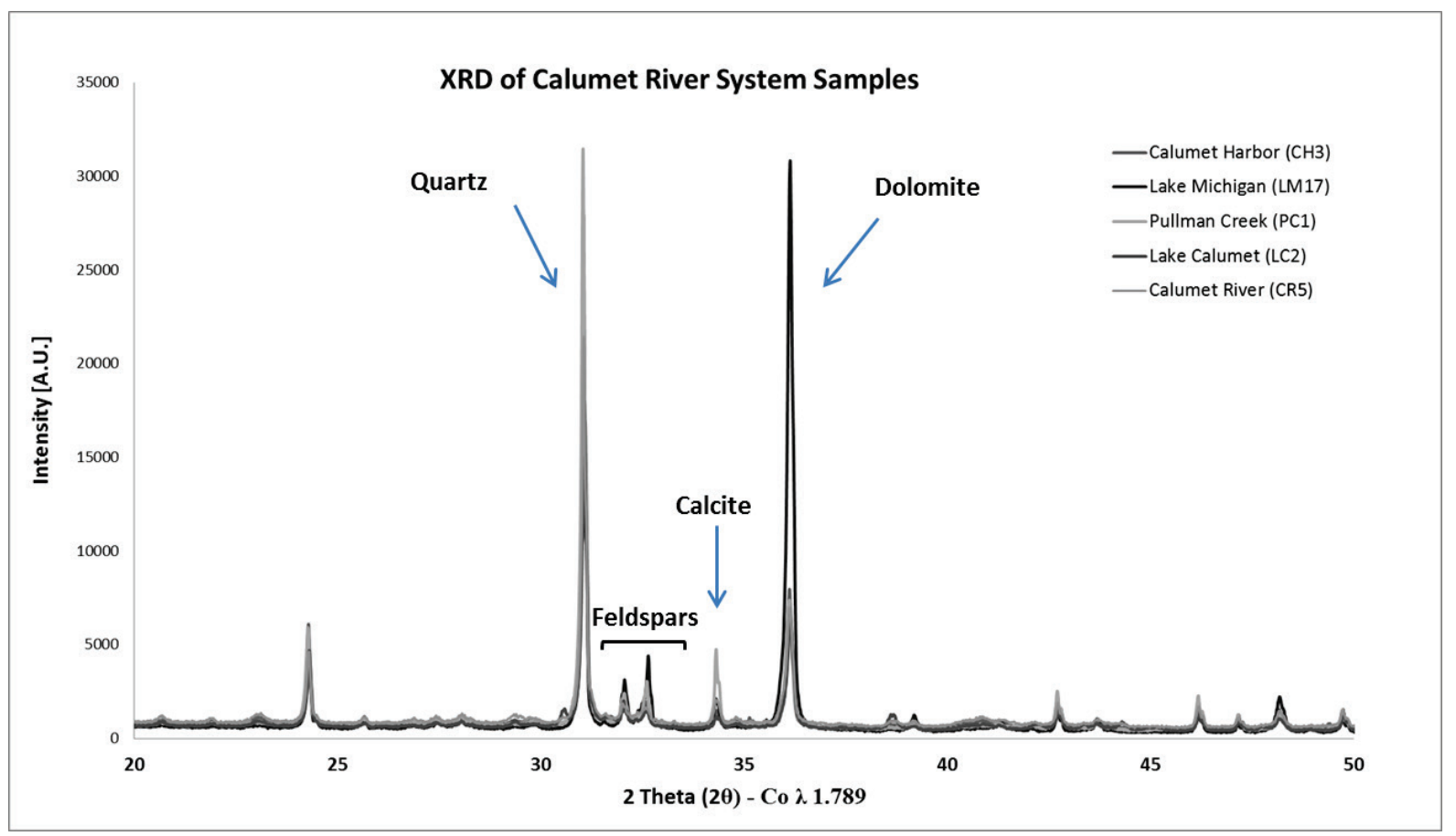

Figure 5. XRD patterns of selected Calumet River samples showing the presence of chromite.

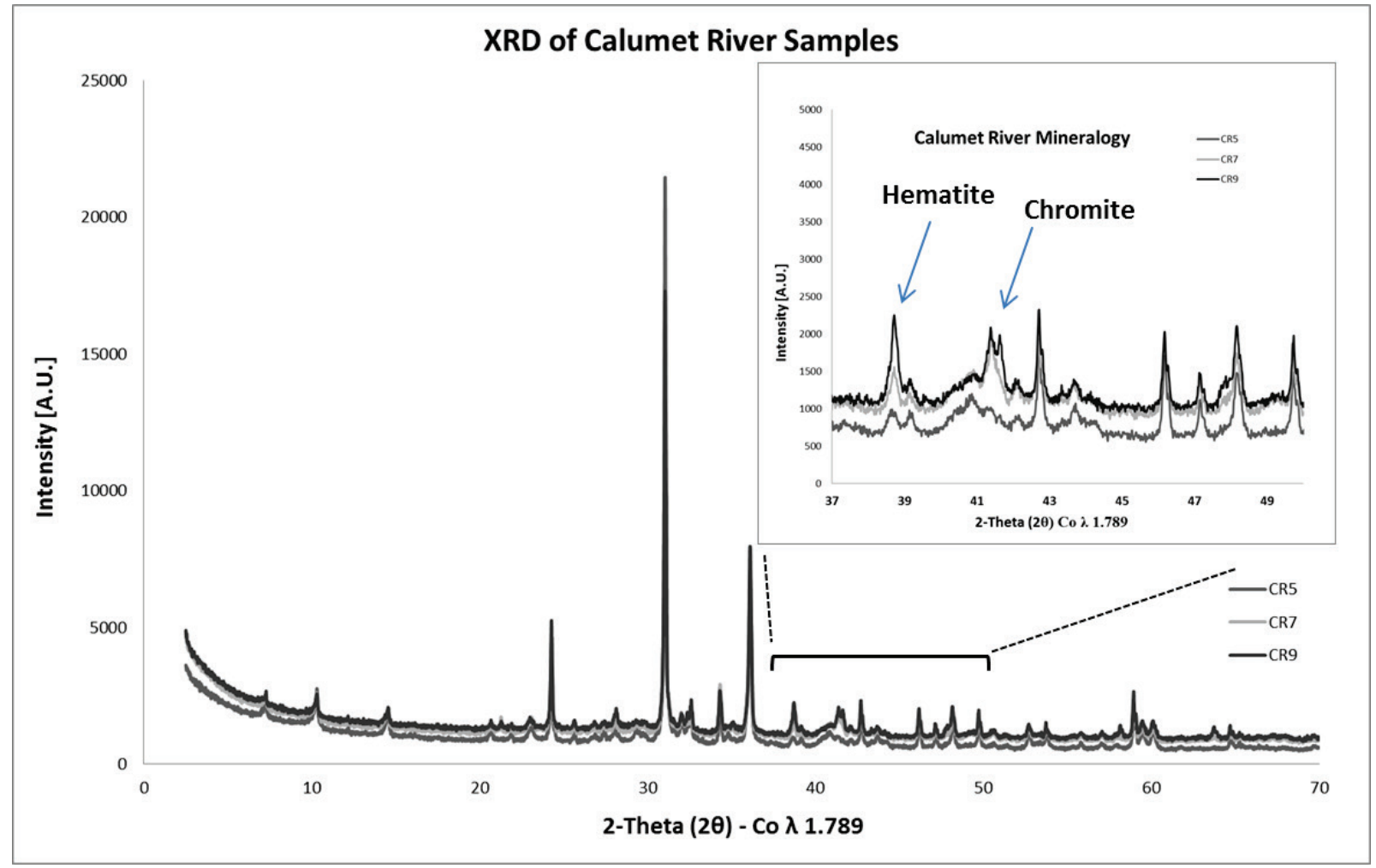




\section{Electrical conductivity (EC) and pH measurements}

Sediment $\mathrm{pH}$ and $\mathrm{EC}$ were measured for all 55 sediment bottom samples collected in May 2014. Individual sediment $\mathrm{pH}$ measurements ranged from 6.82 in the Calumet Harbor (CH4) to 8.84 in Lake Michigan (LM21). The average $\mathrm{pH}$ for each of the sampling regions was within 0.4 of each other and ranged from 7.46-7.86 (Table 5).

Table 5. Average $\mathrm{pH}$ and electrical conductivity values $(\mu \mathrm{S} / \mathrm{cm})$ for the bottom sediments collected from the six sampling regions.

\begin{tabular}{|l|c|c|}
\hline Region & pH & EC \\
\hline Pullman Creek (PC) & 7.65 & $1.68 \mathrm{E}+03$ \\
\hline Indian Creek (IC) & 7.49 & $2.78 \mathrm{E}+03$ \\
\hline Lake Calumet (LC) & 7.82 & 686.46 \\
\hline Calumet River (CR) & 7.46 & 579.11 \\
\hline Calumet Harbor (CH) & 7.63 & 449.43 \\
\hline Lake Michigan (LM) & 7.86 & 258.86 \\
\hline
\end{tabular}

EC ranged from $112.9 \mu \mathrm{S} / \mathrm{cm}$ in Lake Michigan (LM4) to $4198 \mu \mathrm{S} / \mathrm{cm}$ in the Indian Creek (IC1). This wide range indicates that there is a high degree of variability throughout the system. The Indian Creek and Pullman Creek samples exhibited higher mean EC values when compared to the rest of the system: 2784 and $1686 \mu \mathrm{S} / \mathrm{cm}$, respectively (Table 5). These values are $2.5-4$ times greater than the mean EC value of Lake Calumet sediments, which had the next highest mean EC. EC in sediment is commonly linked to texture (sands exhibit lower EC values, and clays exhibit higher EC values), nutrients and salinity (cations/anions), organic matter, and cation exchange capacity (Grisso el al. 2009). With the exception of the IC and PC samples, mean EC values increased from Lake Michigan inland towards Lake Calumet (Table 5). This trend followed the textural pattern commonly associated with conductivity; sandy LM samples displayed low EC while the fine-dominated CR and LC samples showed higher EC. While the reasons for why the sand-dominated PC and IC samples had such elevated EC values is not known for sure, one possible explanation could be due to higher salt content. Due to their urban environment, both of these shallow water creeks would receive a large amount of road runoff, which could transport a significant amount of road salt into their systems. While salinity was not directly measured for any of the sediments, it was observed that both PC and IC samples had the highest mean concentrations of sodium compared to the other regions 
(Appendix C). Sodium is a major component of road salt, and while there are many different forms of salt, the elevated level of sodium in the PC and IC samples offers some support to the idea that they may have had a higher salt content than the other sediments. Complete data of all the $\mathrm{pH}$ and EC analyses can be found in Appendix D.

\section{Radioisotope analysis}

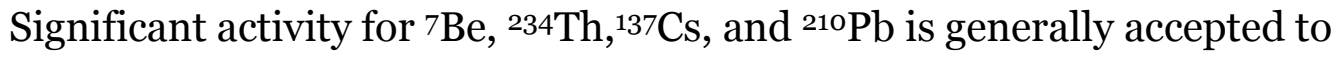
be measurable activities reported as disintegrations per minute per gram

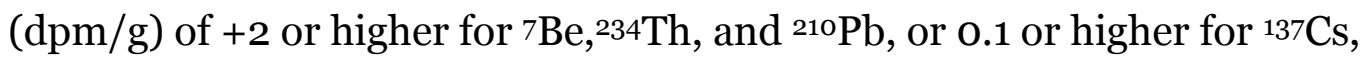
after counting and detector efficiency errors are accounted for. Of the 23 samples selected for radioisotope analysis, none showed any significant ${ }^{7 B e}$ activity. One sample ( $\mathrm{LC1}$ ) showed detectable levels of ${ }^{234} \mathrm{Th}$, and three sites (CR8, CR15, and $\mathrm{CH}_{7}$ ) had detectable ${ }^{137 \mathrm{Cs}}$ levels. In contrast, 10 samples showed significant measurable gamma $(\gamma)$ and alpha $(\alpha)^{210} \mathrm{~Pb}$ activity, and a further six samples had significant measurable $\alpha$, but no measurable $\gamma,{ }^{210} \mathrm{~Pb}$ activity. Only one sample had measurable $\gamma$, but not $\alpha$, ${ }^{210} \mathrm{~Pb}$ activity: LCO2. This is likely due to a laboratory error. The $\alpha^{210} \mathrm{~Pb}$ activity measured for this sample was less than $1 \mathrm{dpm} / \mathrm{g}$, which usually indicates that the ${ }^{209} \mathrm{Po}$ isotope used to extract ${ }^{210} \mathrm{~Pb}$ from the sediment sample did not properly leach onto the silver planchette during standard alpha preparation, resulting in a lack of measurable $\alpha$ radioisotope activity. Overall, of the 23 samples selected for radioisotope analysis, 11 did not have significant gamma activity of any of the selected radioisotopes. Further, of those 11 samples, 5 did not have measurable $\alpha$ ${ }^{210} \mathrm{~Pb}$ activity. All of the samples without detectable $\alpha$ or $\gamma$ activity were distributed fairly evenly throughout the study site (Figure 6), with no obvious spatial bias. Appendix E provides a table with the complete, processed results for all of the radioisotope analyses.

In terrestrial systems, significant measurable activities of $7 \mathrm{Be}$ and ${ }^{137 \mathrm{Cs}}$ usually indicate runoff from the land surface into a body of water, as well as discharge from a stream or river into a larger aqueous system (Feng et al. 1999; Mullenbach and Nittrouer 2000; Mullenbach et al. 2004; Wilson et al. 2005). Complicating the use of $7 \mathrm{Be}$ is that the isotope's activity is strongly dependent on latitude and season. Peak 7 Be deposition occurs at latitudes of $30^{\circ}$ or lower, and during the early spring and/or late summer (Olsen et al. 1985; Baskaran 1995; Kim et al. 2000). In essence, the higher the latitude, and the further in time from early spring in which the sampling occurs, the lower overall 7Be activities that will be expected in the samples. 
Figure 6. Location of radioisotope samples classified by (1) measurable gamma activity of ${ }^{7} \mathrm{Be},{ }^{137} \mathrm{Cs},{ }^{234} \mathrm{Th}$, and/or ${ }^{210} \mathrm{~Pb}$ (white pins); (2) measurable alpha activity only of ${ }^{210} \mathrm{~Pb}$ (yellow pins); or (3) no measurable radioisotope activity at all (red pins).

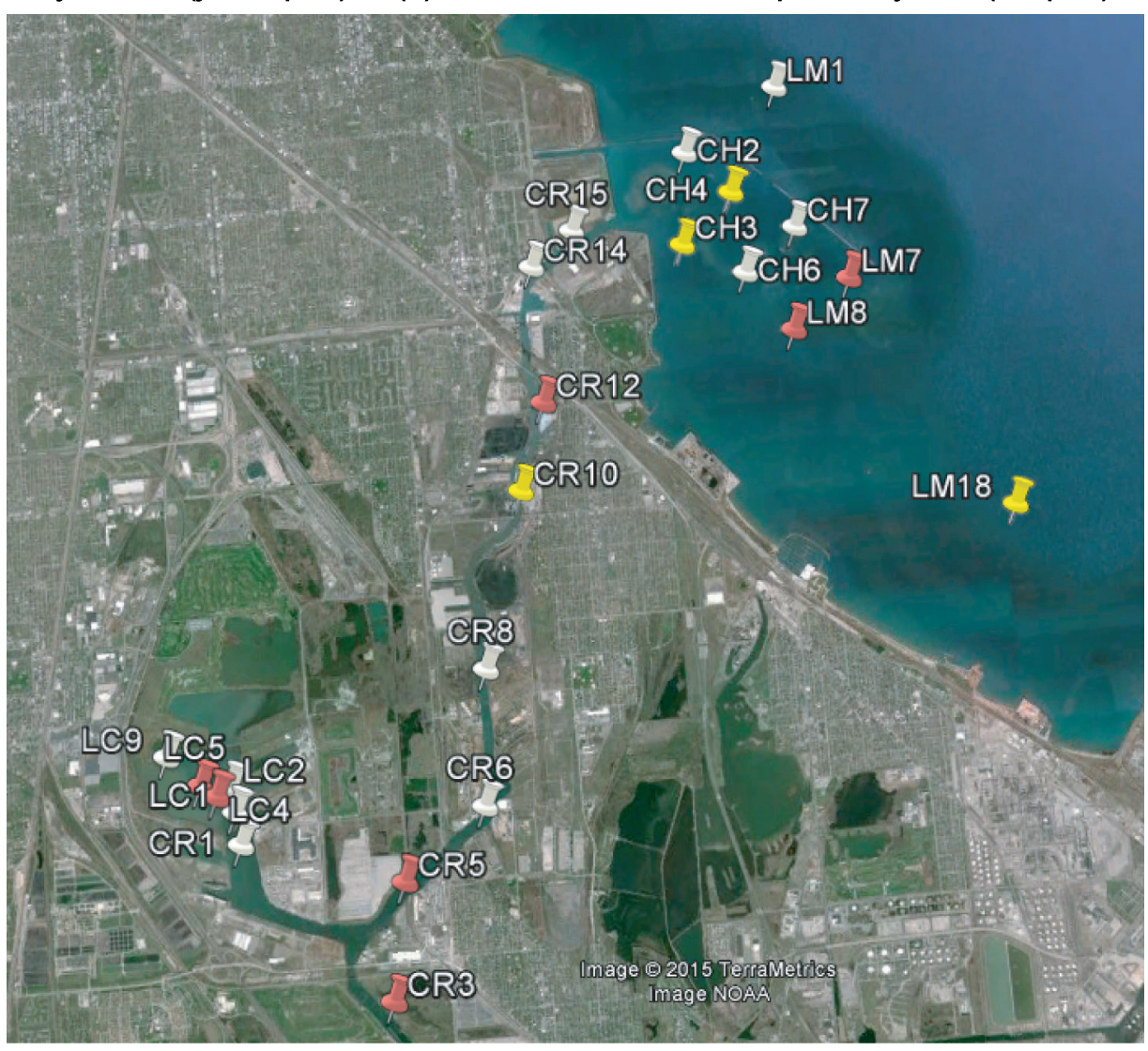

Given the timing of the bottom sampling event (late May 2014), as well as the latitude of the Calumet region $\left(41^{\circ}\right)$, it is not surprising that no measurable activities of $7 \mathrm{Be}$ were seen at the site. In contrast, sedimentary

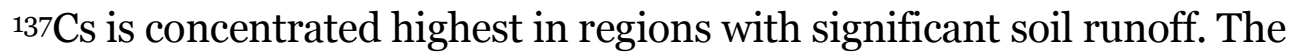
Calumet River, as well as the adjacent Lake Calumet and surrounding environment, is highly urbanized, with very little exposed riverbank or shoreline. In addition, the previous CSM developed by ERDC in 2014 indicated that an exposed stretch of erodible shoreline on Calumet River in the vicinity of CR1O was not a significant source of turbidity to the main Calumet system. Accordingly, the lack of input of both isotopes resulted in

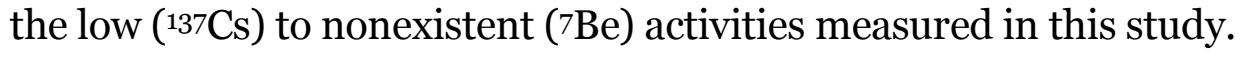

Calumet Harbor consistently showed significant levels of ${ }^{210} \mathrm{~Pb}$ activities, either in $\gamma, \alpha$, or both (Figure 7 [A]). Of the two methods, $\alpha$-counting of ${ }^{210} \mathrm{~Pb}$ allows for a higher resolution of small radioisotope activity levels, and generally yields improved detection of lower activities than traditional gamma counting. Two of the four Lake Michigan samples (LM1 \& LM18) 
and both of the upper Calumet River samples (CR15 and CR14) also showed significant ${ }^{210} \mathrm{~Pb}$ activities that might reflect some resuspension and transport of nearshore Lake Michigan and Calumet Harbor sediments into the upper river. This transport, however, is not extensive as no detectable ${ }^{210} \mathrm{~Pb}$ activity was seen at the next downstream station, CR12.

In Lake Calumet, the highest activities were measured at LC9, the site closest to Pullman Creek ( $\gamma=13.54 \pm 9.8 \mathrm{dpm} / \mathrm{g}$; Figure 7 [B]). The remaining activities were confined to the deeper legacy channel running south through the lake towards the Calumet River (Figure 7 [B]). The closest Calumet River sample to Lake Calumet, CR1, also had measurable ${ }^{210} \mathrm{~Pb}$ activity, but the next sample upriver, CR05, did not. These data indicate that Lake Calumet sediment is not likely transported much farther into the Calumet River than site CR1. Most of the remaining samples in the southern portion of the Calumet River showed lower or no significant ${ }^{210} \mathrm{~Pb}$ activities, often measurable by alpha spectroscopy only, and likely reflect the limited local runoff from the adjacent banks (Figure 7, [A]).

Given that both ${ }^{210} \mathrm{~Pb}$ and ${ }^{234} \mathrm{Th}$ are daughter isotopes of ${ }^{238} \mathrm{U}$, which is generally considered to be ubiquitous in terrestrial sediment, one might normally expect to see at least supported levels of ${ }^{210} \mathrm{~Pb}$ and/or ${ }^{234} \mathrm{Th}$ in every sediment sample in the Calumet system (Borole et al. 1982; Appleby and Oldfield 1983; Feng et al. 1998; Savoye et al. 2006; Sommerfield 2006; Waples et al. 2006; Jweda et al. 2008; Hancock and Caitcheon 2010). The lack of significant ${ }^{234} \mathrm{Th}$ and relatively patchy distribution of ${ }^{210} \mathrm{~Pb}$ activity seen in this region instead suggests two things: (1) sedimentary sources to the system (whether from fluvial, runoff, or wave resuspension) were minimal and isolated spatially; and (2) sediment, once in the system, is not transported in significant enough concentrations to result in an even distribution of ${ }^{210} \mathrm{~Pb}$ activity throughout the study site. This first point supports the CSM findings of most turbidity responses following either precipitation or wave events being spatially limited. Additionally, while a large precipitation event occurred in April 2014 that resulted in a large turbidity event that was observed throughout the entire system, as the second point above stated, the concentration of sediment in suspension during this event may not have been sufficient enough to result in an even distribution of sediment throughout the region. 
Figure 7. (A) Gamma activity of ${ }^{210} \mathrm{~Pb}$ in all radioisotope samples via gamma (red bars) and alpha (green bars) counting. Error bars are generated via laboratory-reported counting error and detector

efficiency for each individual sample. Red boxes outlining the Sample IDs ( $X$-axis) indicate significant gamma and alpha activity, green boxes indicate significant alpha activity, only, and the dashed red box indicates significant gamma activity, only. Negative values, either in activity or in error, are not shown for clarity. (B) Spatial distribution of samples with (1) significant measurable gamma and alpha $210 \mathrm{~Pb}$ activity (yellow ovals), only alpha activity (green ovals), or gamma-only activity (red oval).

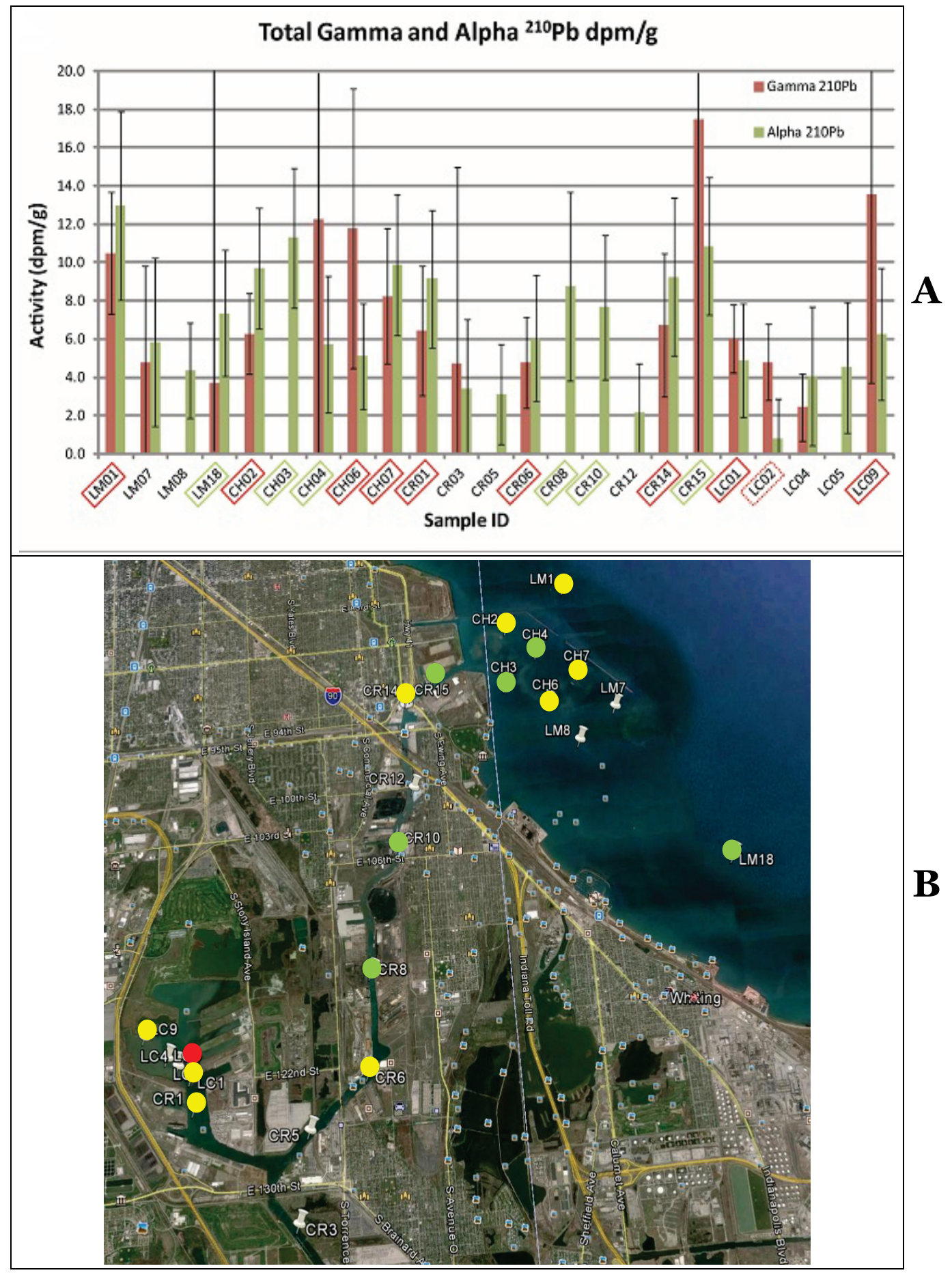




\section{Principal component analysis (PCA)}

\section{Historic Calumet dredging data}

The historical data set includes geochemical data (e.g., metals, organic compounds), referred to here as variables, on sediments from the Calumet River for over 40 years. The type of data and methods used were inconsistent through the years. Therefore, most of the historical variables contained extensive missing data to exceed the $10 \%$ limit. These variables were removed from the analysis. For the entire dataset, spanning from 1967 to 2007, only six characterization variables were usable: ammoniumnitrogen $\left(\mathrm{NH}_{4}-\mathrm{N}\right), \mathrm{Pb}, \mathrm{Cr}$, total phosphorous (TP), Cu, and $\mathrm{Zn}$ concentrations. A model was developed containing five PCs with $91 \%$ of the variance in the data explained by PC 1-2. Calculated F-residuals found that two of the samples, Cal 75-2 (Mar 1975) and CalR 1002-003 (2002) acted as leverage outliers, statistically far from the model center, yet still reside in the same hyperplane described by the PC model.

The bivariate plot (Figure 8) shows that all of these variables were positively loaded on $\mathrm{PC}-1$, with the nutrient-related variables, $\mathrm{NH}_{4}-\mathrm{N}$ and TP positively loaded on $\mathrm{PC}-2$ while three of the heavy metals $(\mathrm{Cu}, \mathrm{Pb}$, and $\mathrm{Zn}$ ) were negatively loaded on PC-2. All the variables were significantly loaded on both PC 1-2, but Cr was especially important for PC-1 based on the small angle between this variable and the principal axis. In particular, the explained variance was dominated by PC-1 (78\%). Extrapolating from the positions of the variable loadings in Figure 9, it was expected that the scores for the sediment samples containing the highest concentrations of these heavy metal and nutrient solutes (representing the dirtiest samples) would be similarly loaded on PC 1-2 while the scores representing the cleanest samples would be anti-correlated to the dirtiest samples. These conclusions are further demonstrated by grouping the samples with respect to their ranges for each variable. For example, Figure 9 shows that the highest sediment concentrations for $\mathrm{NH}_{4}-\mathrm{N}, \mathrm{Cu}$, and $\mathrm{Zn}$ occur among samples positively loaded in PC-1. 
Figure 8. Bivariate plot showing the variable loadings and sample scores ( $P$ and $T$, respectively in Equation 1) for the first two PCs of the historical Calumet sediment characterization data.

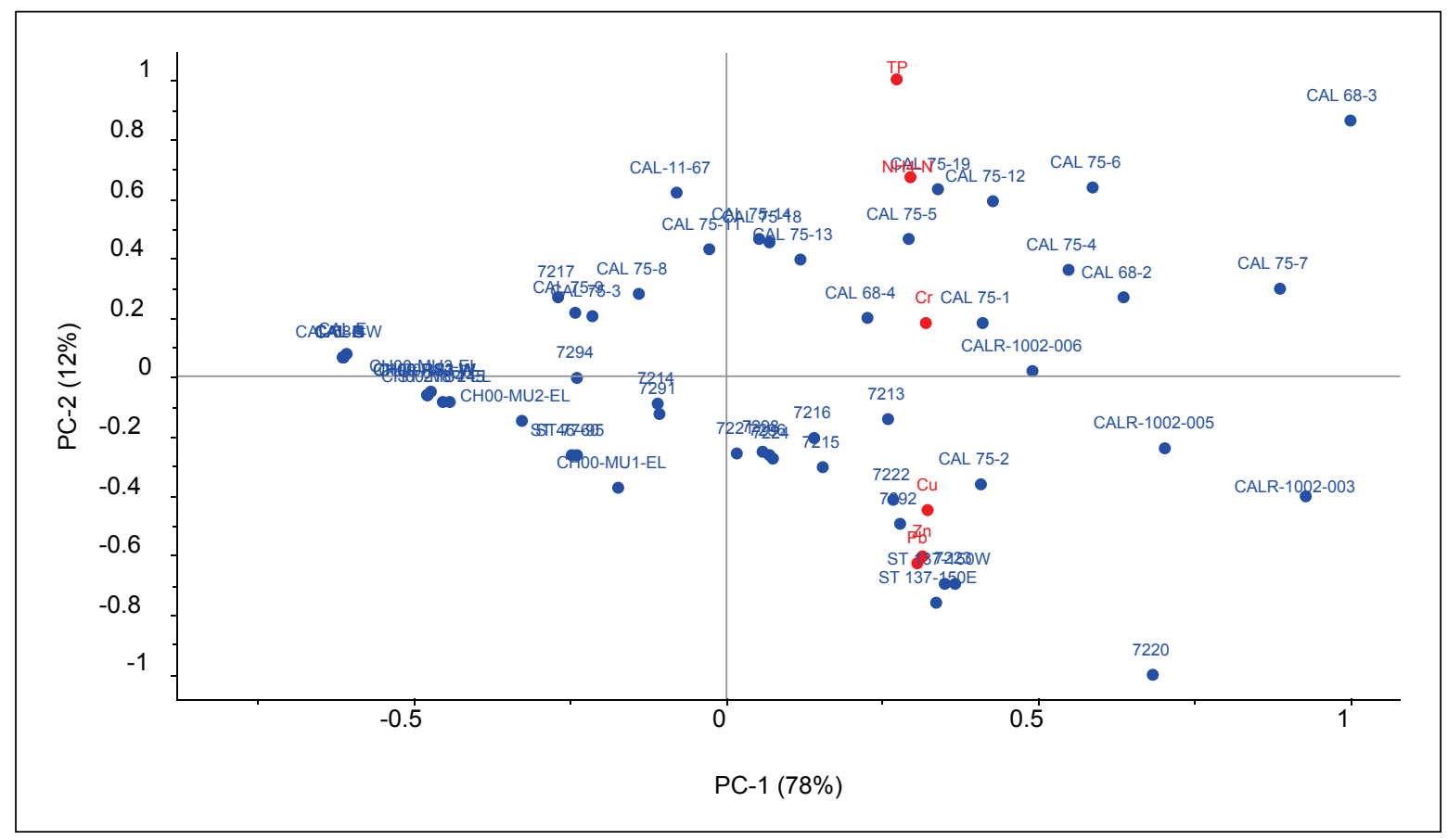

Replotting the scores with respect to their sampling time (Figure 10) showed trends with respect to the temporal geochemistry of the sediments. In general, older sediment samples were positively loaded on PC-1 while newer samples were negatively loaded on PC-1, with again, agricultural $\left(\mathrm{NH}_{4}-\mathrm{N}, \mathrm{TP}\right)$ and heavy metal contaminants $(\mathrm{Pb}, \mathrm{Zn}, \mathrm{Cu})$ generally collapsing into a single cluster highly and negatively loaded on PC-1 (as indicated by the dotted lines). Notable exceptions to these trends occurred with Cal A-E, Cal N, and Cal W samples (collected in 1967-1968) and the three CalR-1002-3,5-6 samples collected in 2002. It is hypothesized that these exceptions arose from particular conditions at the sampling sites. For example, a close visual inspection of the Calumet River maps and historic sampling points indicates that the 2002 samples were collected at positions along the river in proximity to spoil piles located at the river's edge. Thus, it was expected that the sediment geochemistry was impacted by mixture of the spoil material with the sediment such as during erosional (e.g., high rainfall) events. 
Figure 9. Plots showing the relative concentration ranges for $(A) \mathrm{NH}_{4}-\mathrm{N},(\mathrm{B}) \mathrm{Cu}$, and (C) $\mathrm{Zn}$ as reported in the historic sediment Calumet data.

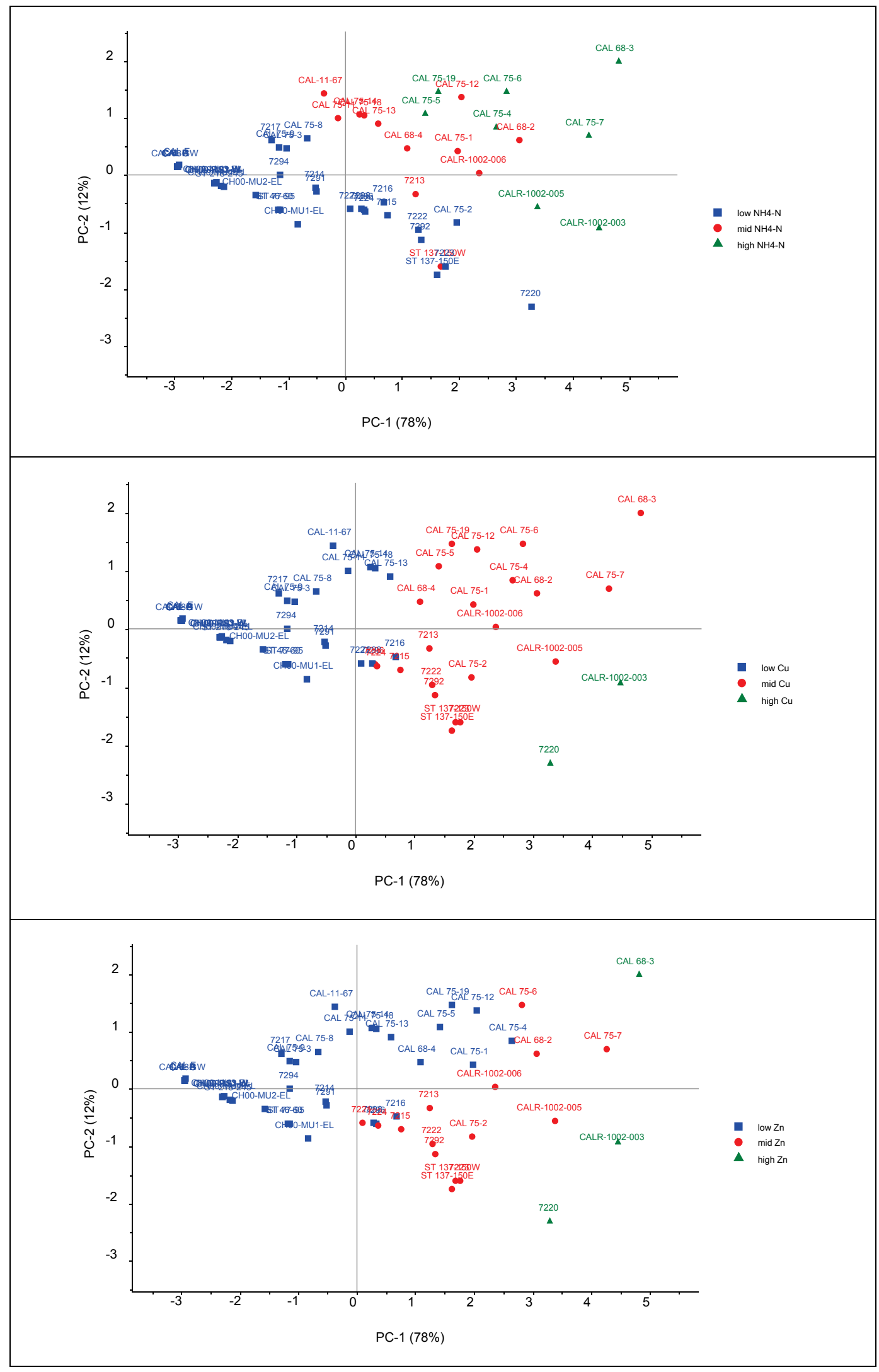

A

B

C 
Figure 10. Scores for the historic Calumet samples for PC 1-2 plotted with respect to their sampling time. The dashed lines demonstrate the collapse of the data set to a single cluster with time.

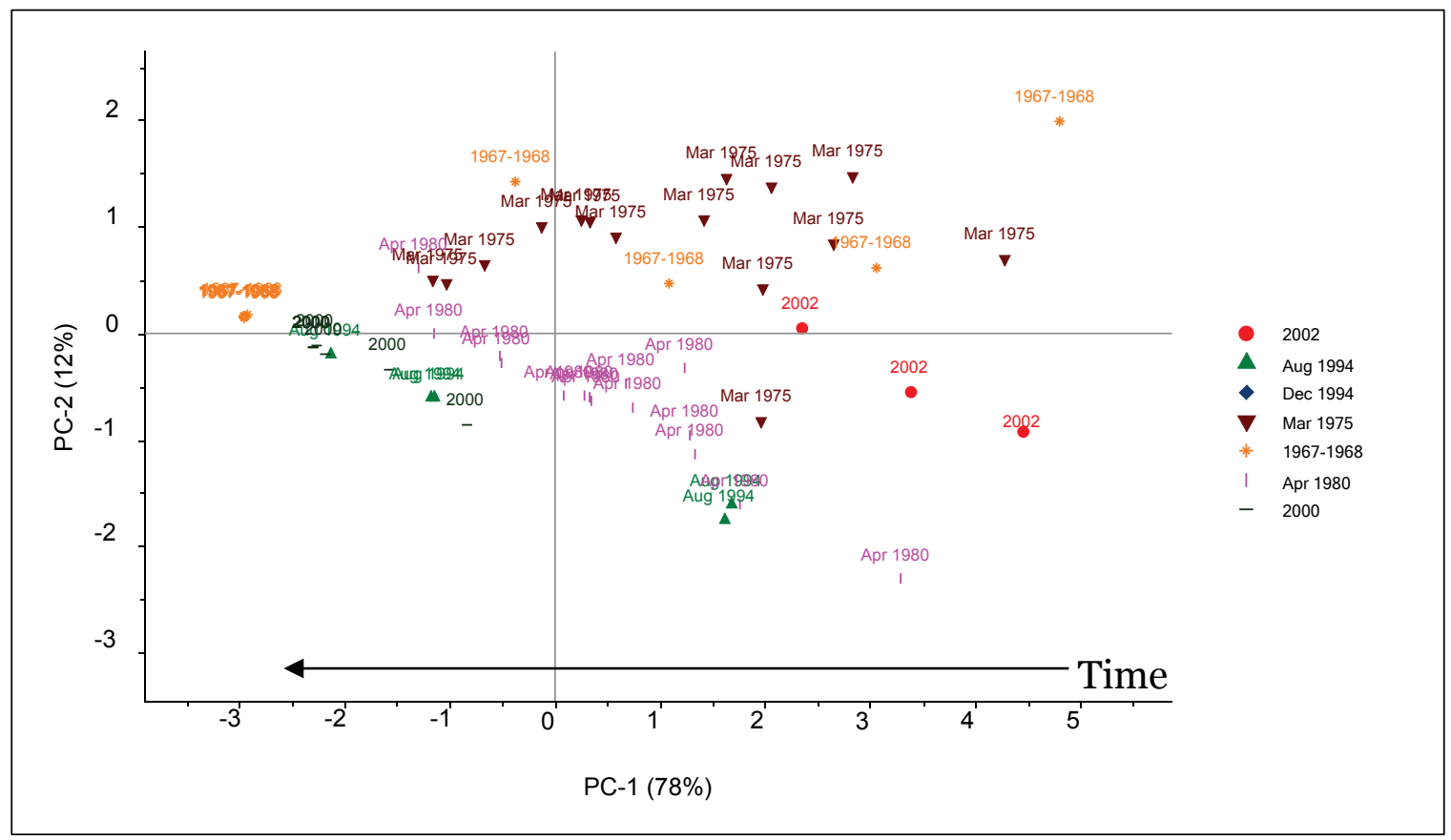

Such clear temporal trends are diagnostic of shifts in the surrounding environment, such as those associated with urban development or unsuspected long-term contaminant leaks. For example, an important temporal shift in sediment geochemical characteristics should be evident in sediments following the passage of substantial environmental legislation, such as U.S. Environmental Protection Act's (USEPA's) Clean Water Act. This hypothesis is borne out by re-examining the data and loosening the constrictions on the potential variable sets that can be used to elucidate these relationships. Narrowing the sample collection times to 1975-2002 allowed for expansion of the analysis to a larger characterization matrix consisting of 13 variables (including Chemical Oxygen Demand [COD], oil and grease, $\mathrm{Fe}, \mathrm{Mn}, \mathrm{Ba}$, and total potassium and nitrogen [TKN]).

Inclusion of these additional variables allowed for the creation of a 5-PC model explaining $95 \%$ of the variance in the data. The model was readily optimized by the removal of two substantial leverage outliers from the December 1994 collections: samples 94-1228 and 94-1219. Figure 11 shows that the variables all load positively in $\mathrm{PC}-1$ (explaining $58 \%$ of the variance) similar to the loadings in Figure 8. With the addition of a third PC, Figure 11 (B) shows that PC-2 (explaining 22\% of variance) distinguishes the macronutrient and organic-related contaminants/characteristics (negatively loaded on PC-2) from the mineral-relevant characteristics (percent fines) 
and heavy metal contaminants (with the exception of Ni). Thus, the Mn, As, $\mathrm{Cu}$, and $\mathrm{Zn}$ variables were highly correlated, forming a distinct cluster among these contaminants. Among the macronutrients and organic soluterelated variables, $\mathrm{COD}, \mathrm{TKN}$, and TP were closely correlated. Interestingly, oil and grease represented the only variable that could be considered anticorrelated with the heavy metal/clay fines samples. This suggests that these variables represent the two extremes of the sample characteristics. In other words, samples high in oil and grease exhibited very different properties than sediments only high in heavy metals.

Figure 11. Loading plots calculated from PCA of the refined historical data set. Panel A shows PC-3 plotted against PC-1 while panel B plots PC-3 against PC-2.

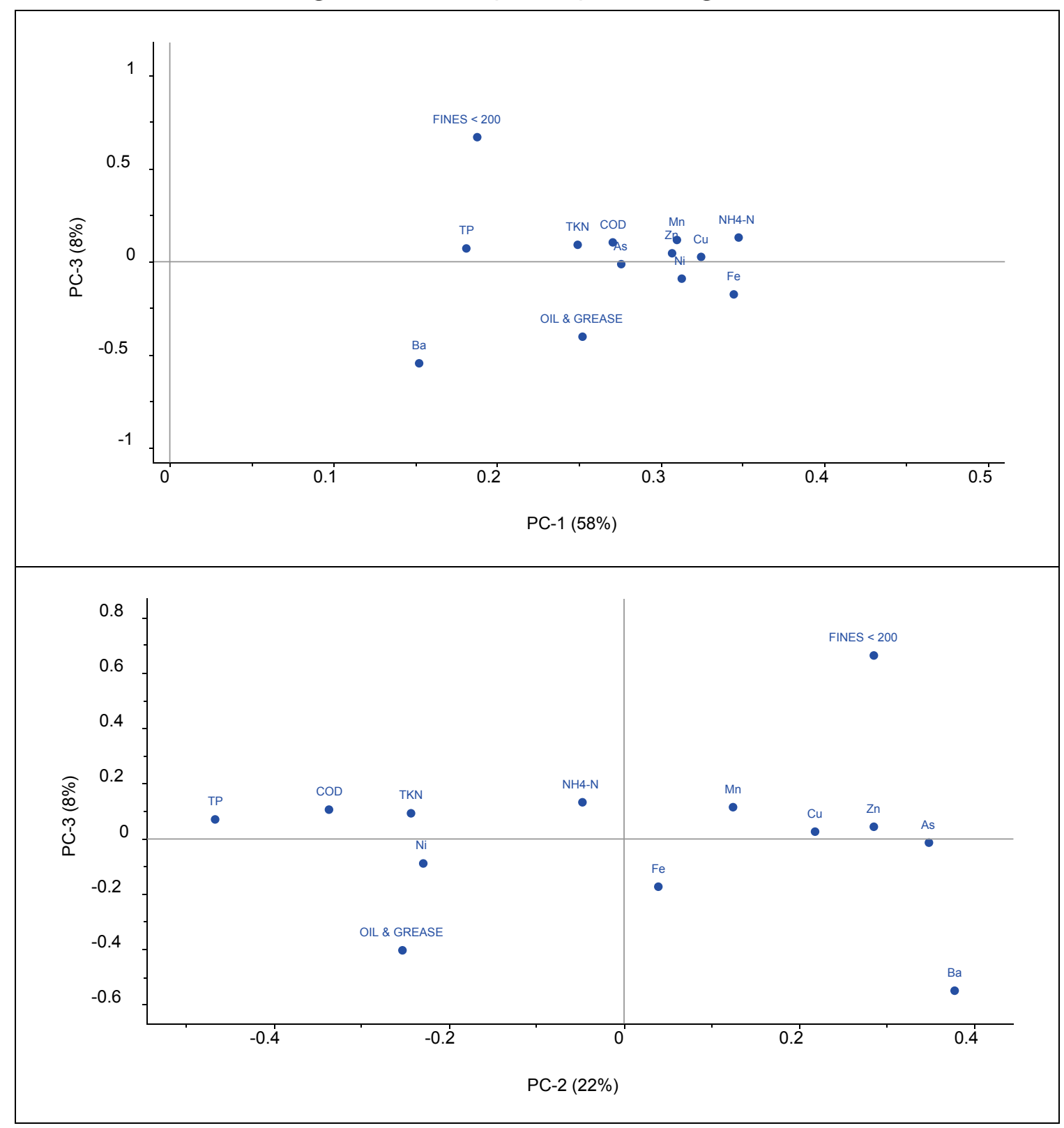

A

B 
Figure 12 shows the refined sample set for the distinct temporal separation of collections in PC-2. Mentally rotating Figure 12 (A) $90^{\circ}$ shows strong clustering of the older March 1975 samples from the remaining collections. These results suggest that the first priority in reducing pollution inputs to the Calumet system involved the mitigation of agricultural and petroleumbased contaminants. With time, this effort was followed up with more detailed efforts to mitigate heavy metal contamination, although some lingering heavy metal contamination seems to exist (as of 2002) at discrete locations along the river system.

Figure 12. Score plots calculated from PCA of the refined historical data set. The above plots represent the loadings in three dimensions, with (B) representing a $90^{\circ}$ rotation of plot (A).

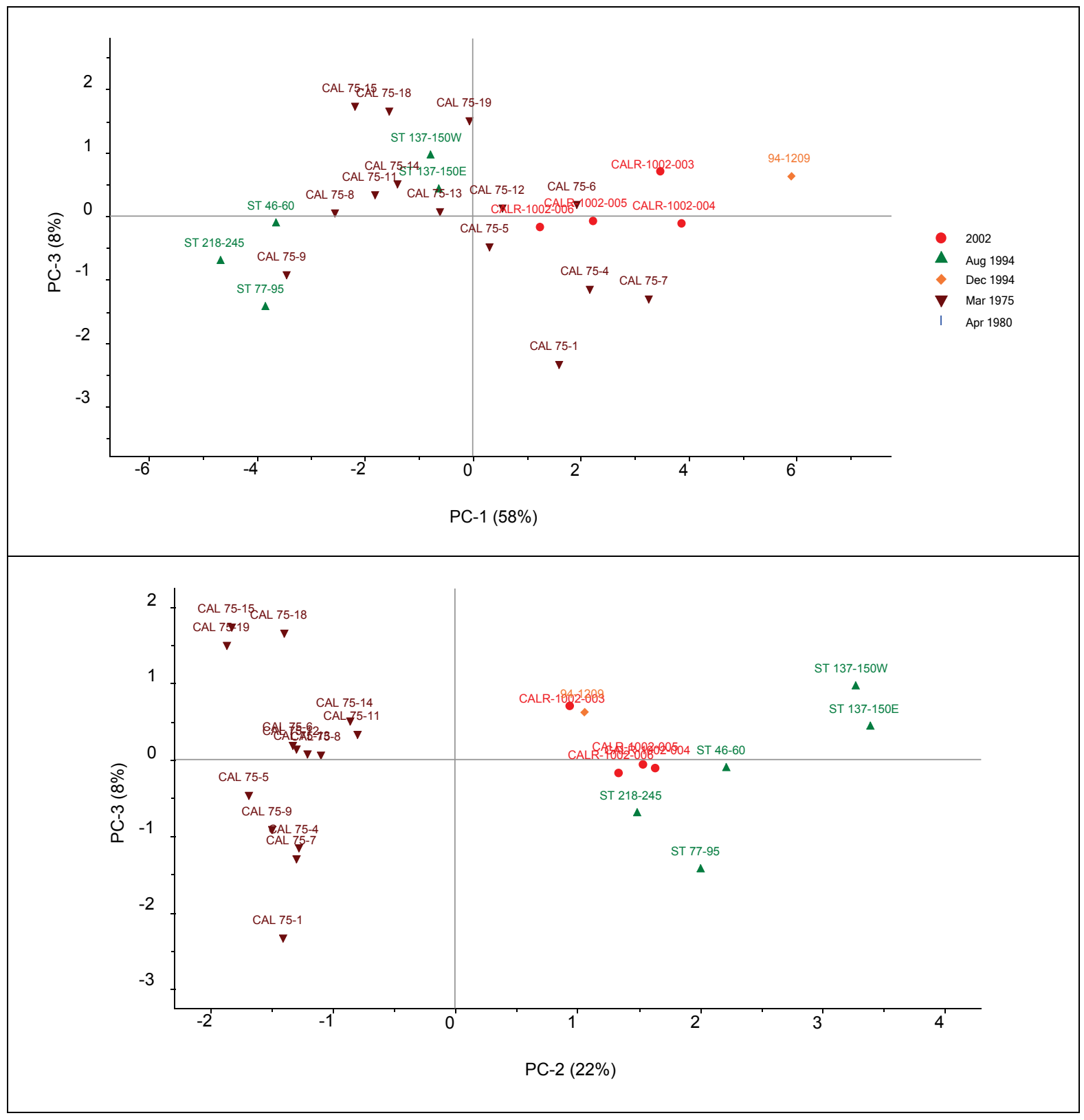

B 


\section{Sediment data}

For the sediment samples collected across the Calumet River system, an overall PCA model was found containing six PCs explaining $83 \%$ of the variance in the data. This overall PCA model demonstrated strong patterns that there were sensible relationships among the different soils. This suggested that that the original groupings (based on sampling location) may serve well to statistically distinguish the sediments. The analysis showed that the Calumet River samples were more correlated with the Lake Calumet samples, while anti-correlated with the Lake Michigan samples. Also, Lake Michigan samples were highly correlated with the Lake Calumet and Calumet Harbor samples, pointing toward their expected geochemical similarities (Figure 13). The loading plot (Figure 13 [A]), showing the total covariance among the characterization data, pointed toward the relationships of the variables to each other, as well as the samples in the score plot (Figure 13 [B]). For example, \%sand was correlated with the Lake Michigan samples, while anti-correlated with \%clay and \%silt, which shared the strongest correlation to Calumet River samples.

While sensible patterns exist among the different objects and variables, there was substantial overlap in the samples, making it difficult to unambiguously assign them to any single class membership. Part of the reason for this ambiguity was attributed to the two substantial leverage outlier sets, Pullman Creek and Indian Creek. As leverage outliers, Pullman Creek and Indian Creek samples are statistically far from the model center, yet still reside in the same hyperplane described by the PC model. This has the result of stretching out the ellipsoid and thus contributing to the ambiguity in discriminating the appropriate classes for most of the samples. With the PCA model clearly discriminating out the Pullman Creek and Indian Creek samples as distinct classes, the removal of these samples from the overall PCA model provided more clarity for the remaining samples.

The overall PCA model, after the removal of leverage outliers, was further optimized by removing the Sn concentration variable (which made no contribution to any of the PCs). This resulted in a 4-PC model explaining $79 \%$ of the variance in the data. The optimized score plot (Figure 14) articulates clearer clustering of samples, yet substantial ambiguity remained as indicated by the overlap of the clusters defining the different classes of samples. Using PLS-DA (Figure 15), it was determined that some of the important variables for overall discriminating samples among the various 
classes included TOC, Total Carbon (TC), Pb, P, V, Ba, \%N, Se, Al, \%silt, \%clay, $\mathrm{Mg}$, and \%sand. The influence of three of these variables (\%sand, TC, and $\mathrm{Ni}$ ) are demonstrated graphically in Figure 16. Here, coarse-textured sediment samples were positively loaded in Factors 1 and 2 while samples with higher TC (including both TOC and Total Inorganic Carbon (TIC)) and heavy metal concentrations were generally negatively loaded on Factor 1.

Figure 13. Overall PCA model for all the entire dataset of sediment samples. (A) The loading plot showing interrelationships among the variables. (B) Score plot showing covariate relationships among the samples based on the covariance among its constituent variables.

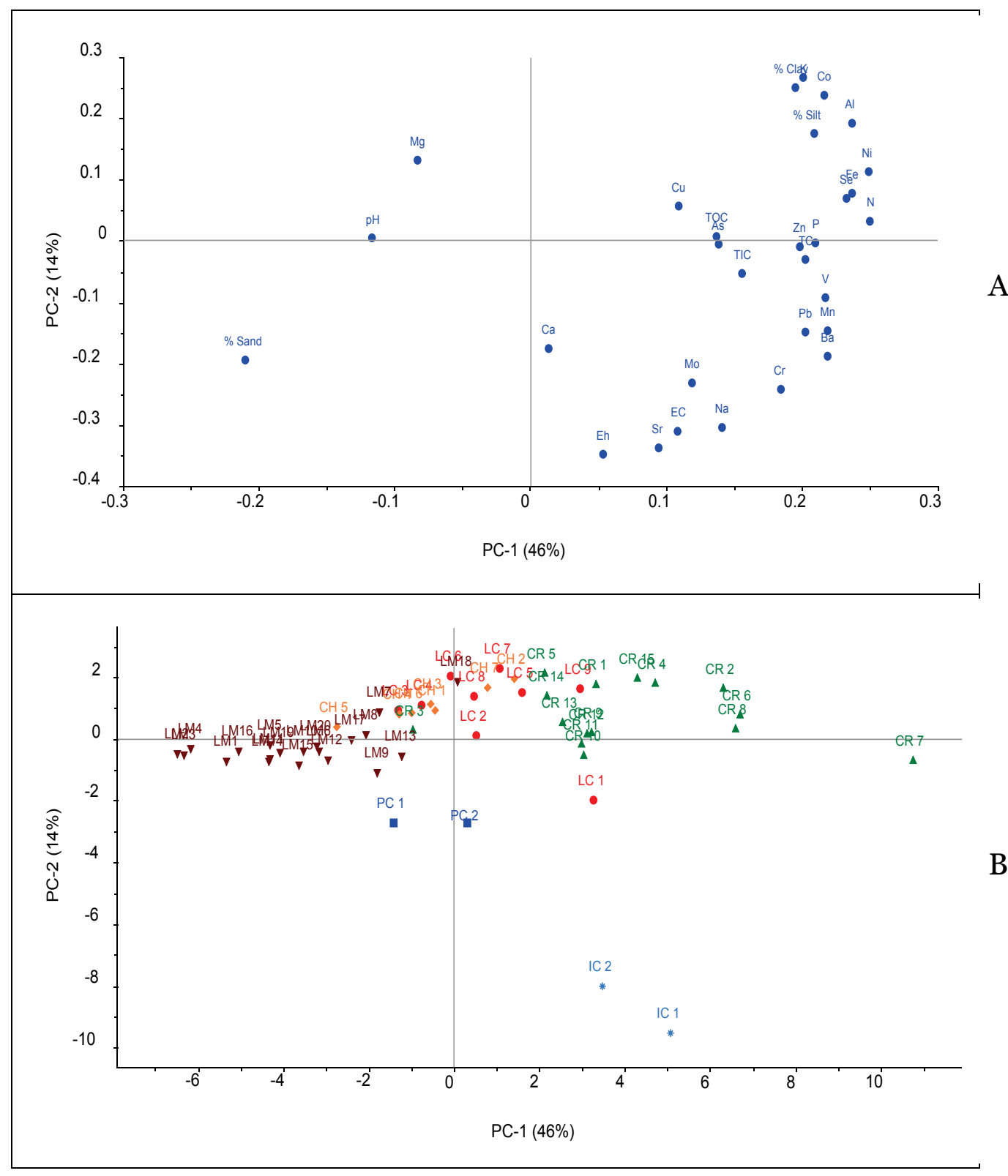


Figure 14. Results of the overall PCA model after removing the leverage outliers, Pullman and Indian Creeks, and the variable Sn. Note that there was virtually no change in the correlations displayed in the loading plot from the model optimization.

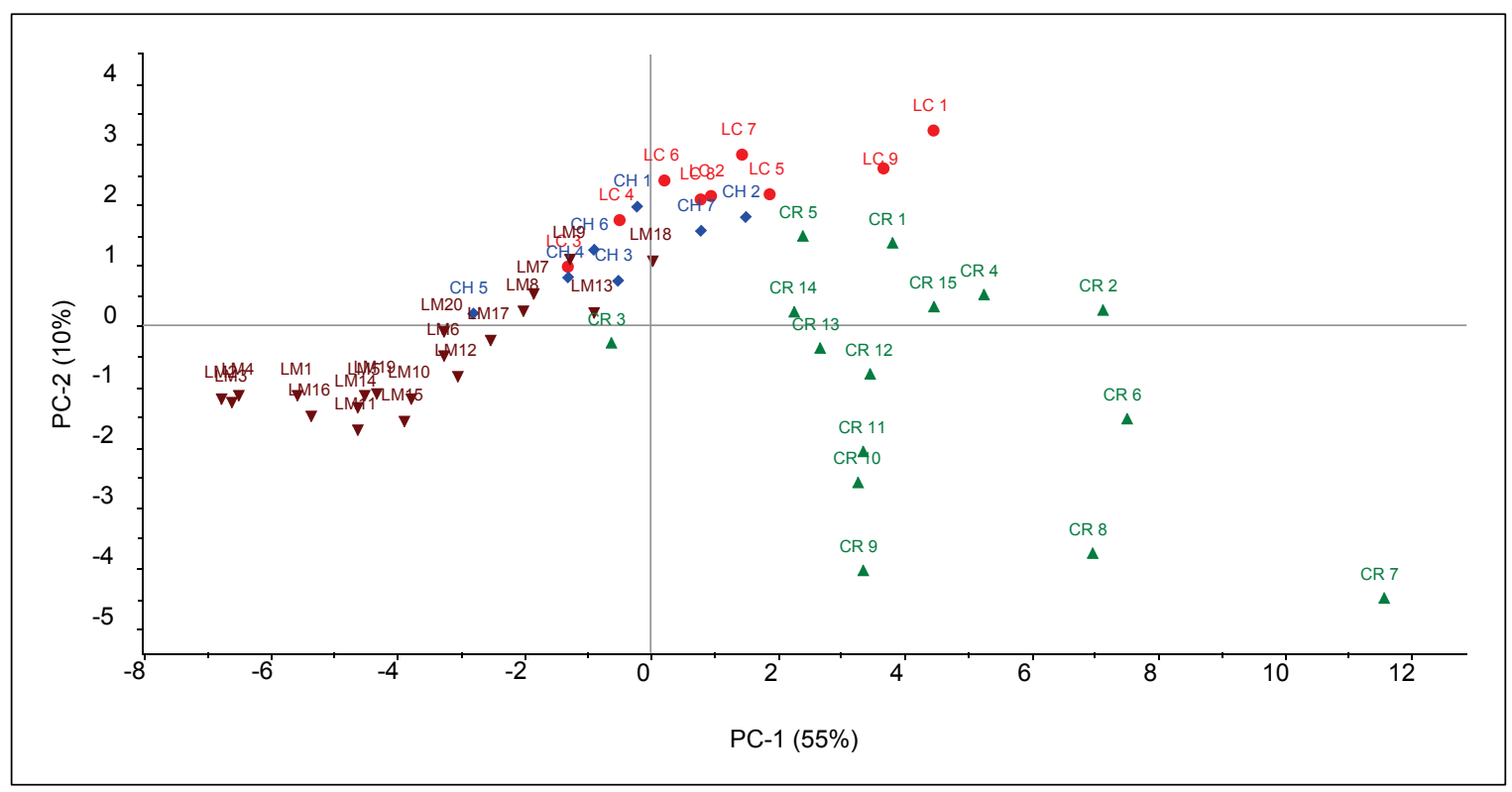

To formally assess the statistical validity of the assigned class memberships for the sediment samples, the unsupervised classification method called SIMCA was utilized. SIMCA allows for the classification of samples based on the relative distance among the different PCA models built for each group of sediments. A sample's distance $\left(D_{i}\right)$ between two classes from the PCA model is calculated as the orthogonal distance from the sample to the different classes previously defined by their principal components as

$$
D_{i}=\frac{\frac{1}{K_{q}} \sum_{k=1}^{K_{q}} s_{q}(m, k)^{2}+\frac{1}{K_{m}} \sum_{k=1}^{K_{m}} s_{m}(q, k)^{2}}{\frac{1}{K_{m}} \sum_{k=1}^{K_{m}} s_{m}(m, k)^{2}+\frac{1}{K_{q}} \sum_{k=1}^{K_{q}} s_{q}(q, k)^{2}}
$$

where $\mathrm{s}_{\mathrm{i}}=$ the standard deviation for variable $k$ when fitting samples from two different PCA models (e.g., fitting model $q$ onto model $m$ ). $D_{i}$ values close to zero indicate that the two classes $(m, q)$ are virtually identical while values $>1$ indicate the two classes are statistically distinguishable (Svante and Michael 1977). 
Figure 15. (A) Score and (B) loading plots from PLS-DA of the Calumet River samples. Here, important variables for Factors 1-2 are found within the outer ellipse of the loading plot.

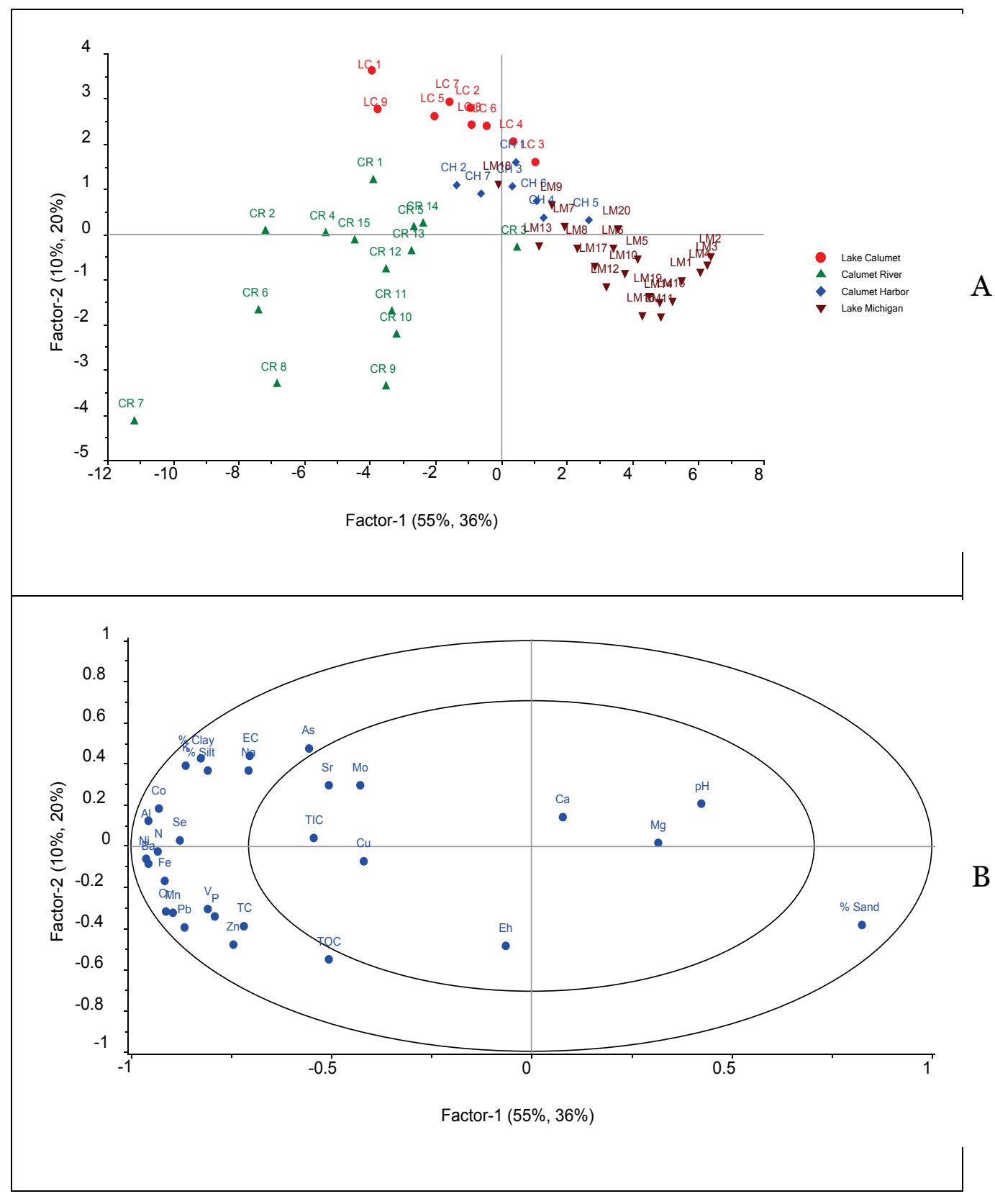


Figure 16. Samples grouped by selected variables influential in discriminating the sediment types by their geochemistry for the first PCs explaining $40 \%$ of the variance in the data: (A)

\%sand, (B) TC, and (C) sediment Ni concentration, as determined in the optimized PCA calculations.
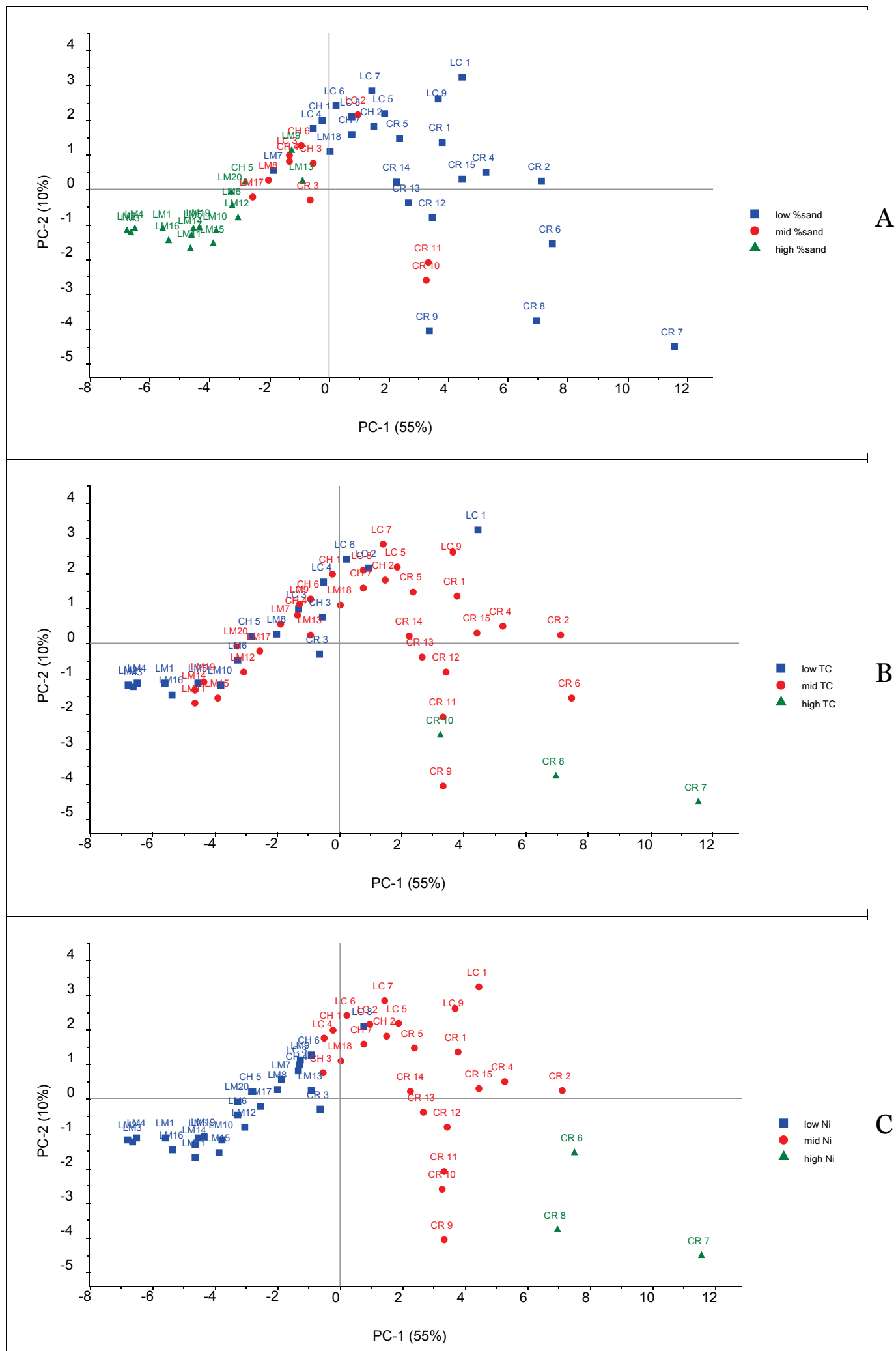

- low Ni

- mid Ni

$\mathrm{C}$

PC-1 (55\%) 
The results of the SIMCA calculations showed that samples from Lake Calumet, Calumet River, Calumet Harbor, and Lake Michigan each formed a unique class. A table displaying these classification results can be found in Appendix F. No classes were assigned to the PC and IC samples as they were previously determined in the overall PCA to exist in their own unique classes.

The SIMCA results also elucidated the most important variables for discriminating between each class. For example, Figure 17 shows that $\mathrm{Cu}$ was the most important variable distinguishing members in the Lake Calumet class from members in the Calumet River class. In general, heavy metal concentrations served as the discriminating variables between the Calumet River class and the Lake Calumet and Calumet Harbor classes. Concentration and texture (\%clay, silt, sand) were the most important variables discriminating the Lake Calumet class from the Calumet Harbor class.

Figure 17. Plot showing the discriminating variables most important for distinguishing members of the Lake Calumet class from members of the Calumet River class, as defined by their calculated PCA models.

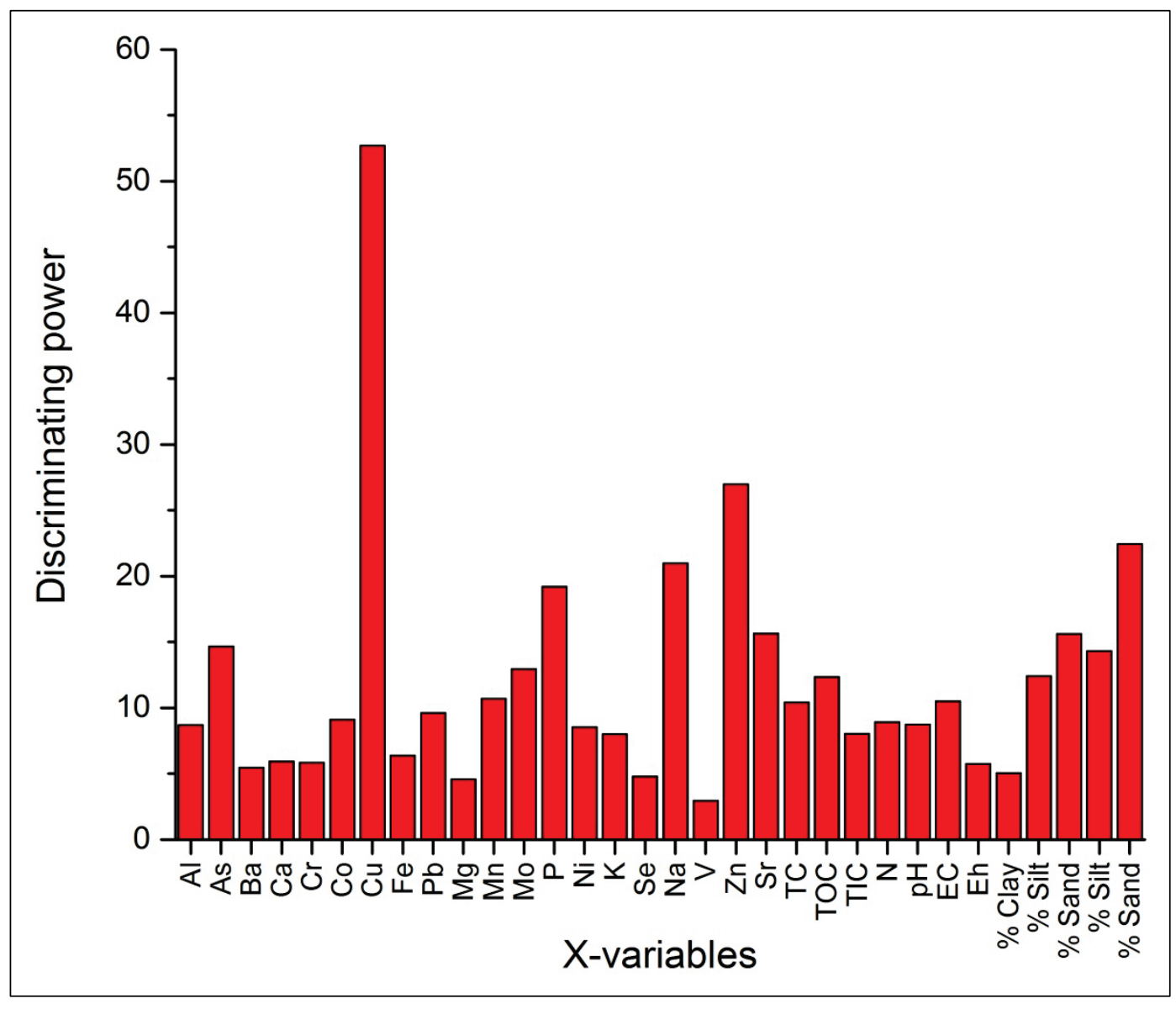




\section{Summary}

The multiple geochemical parameters that were measured on the sediment samples collected from the Calumet River system provided a robust dataset that was useful in quantifying and grouping sediments into classes. The multivariate PCA, PLS-DA, and SIMCA analyses were able to distinguish sediment groupings from each other based on these geochemical parameters and to fingerprint a sediment type that correlated with six geospatial locations (Lake Calumet, Calumet River, Calumet Harbor, Lake Michigan, Pullman Creek, and Indian Creek). These fingerprints were then used to evaluate if sediment from these locations was being deposited within the stretch of the Calumet River between Thomas J. O'Brien lock and Lake Michigan.

Within these groupings, sediments from Pullman Creek and Indian Creek were identified as outliers to the rest of the system. The previously conducted CSM showed no evidence of sediment input into the Calumet River coming from Indian Creek even during/after heavy rainfall events. The fact that the Calumet River sediments near the mouth of Indian Creek did not show similar geochemical signatures as Indian Creek samples further support that conclusion. While the CSM did indicate Pullman Creek as being a primary source of sediment into Lake Calumet following large precipitation events, it is important to point out that during those conditions the creek could be transporting a significant portion of fine sediment in suspension. At the time of the sampling, flow in Pullman Creek was low, and the bottom sediments that were collected may not be representative of what is typically transported into Lake Calumet during precipitation events.

While the remaining sediment groupings (Lake Michigan, Calumet Harbor, Lake Calumet, Calumet River) all displayed unique fingerprints, SIMCA results showed that samples from Lake Calumet, Calumet River, and Calumet Harbor shared some similarity that was not seen in the Lake Michigan samples. This result also aligns with the CSM observation of sediments being suspended and transported from both Lake Calumet and Calumet Harbor into the Calumet River during periods of high wind/wave events. Radioisotope activities also indicated limited transport of sediments from Lake Calumet and Calumet Harbor into their respective adjoining areas of the Calumet River. It is suspected that wave events also suspend fine sediments in the shallow, nearshore waters of Lake Michigan. 
However, previous high wind and wave events that are common in late winter and early spring could have already suspended and transported this material prior to the sampling in May 2014. The predominately sandy texture and the inconsistency in measurable ${ }^{210} \mathrm{~Pb}$ activities of the LM samples support this conclusion.

Though similarities between Calumet Harbor, Lake Calumet, and Calumet River samples were observed, the PCA and PLS-DA score data clearly showed the Calumet River group to plot primarily in a different region from the other groupings. Heavy metal concentrations were found to be one of the primary causes for this difference. The fact that similar levels of metals were not found in the harbor or Lake Calumet suggests that the source of these metals is within the reach of the Calumet River between Lake Calumet and Calumet Harbor. This suggests that the residence time of bottom sediments in Calumet River is sufficient enough to pick up this additional heavy metal signature. Analysis showed that $\mathrm{Cu}$ and $\mathrm{Zn}$ are the primary loadings responsible for the geochemical difference between CR sediments and those from LC and CH. Additionally, mineralogy results showed certain areas of the river to contain chromite that was not found elsewhere in the system. While identifying the exact source of this contamination was beyond the scope of this project, the common industrial usage of $\mathrm{Cr}, \mathrm{Cu}$, and $\mathrm{Zn}$ suggest that anthropogenic activities along this stretch of the river are likely responsible for this signature.

In addition to providing information about likely sources of sediment and contamination into the Calumet River, the geochemical fingerprinting also produced a tool that allows for the monitoring of sediment geochemical characteristics over time. Previous, historical data obtained from dredge material sampling was utilized to showcase how the geochemical fingerprint of the dredged material from the Calumet River changed with time. The PCA, PLS-DA, and SIMCA analyses performed on the samples collected in 2014 produced six classifications of sediment types. Future sediment samples processed with the same methods and models used in this study would allow for the spatial and temporal monitoring of any change in the chemical nature of these sediments. 


\section{References}

Appleby, P. G., and F. Oldfield. 1983. The assessment of ${ }^{210} \mathrm{~Pb}$ data from sites with varying sediment accumulation rates. Hydrobiologia 103(1):29-35.

ASTM D6913-04(2009)e1 Standard test methods for particle-size distribution (gradation) of soils using sieve analysis. West Conshohocken, PA: ASTM International. http://dx.doi.org/10.1520/D6913-04R09E01

Baskaran, M. 1995. A search for the seasonal variability on the depositional fluxes of $7 \mathrm{Be}$ and 210 Pb. Journal of Geophysical Research: Atmospheres 100(D2):2833-2840.

Beletsky, D., D. J. Schwab, P. J. Roebber, M. J. McCormick, G. S. Miller, and J. H. Saylor. 2003. Modeling wind-driven circulation during the March 1998 sediment resuspension event in Lake Michigan. Journal of Geophysical Research: Oceans 108(C2).

Borole, D. V., S. Krisnáswami, and B. L. K. Somayájulu. 1982. Uranium isotopes in rivers, estuaries and adjacent coastal sediments of western India: Their weathering, transportation and oceanic budget. Geochimica et Cosmochimica Acta 46(2):125-137.

Chappell, M. A., C. L. Price, B. E. Porter, B. A. Pettway, R. D. George. 2011. Differential kinetics and temperature dependence of abiotic and biotic processes controlling the environmental fate of TNT in simulated marine systems. Marine Pollut. Bull. 62(8):1736-1743.

Chappell, M. A., J. M. Seiter, A. J. Bednar, C. L. Price, D. Averett, B. Lafferty, R. Tappero, J. S. Stanley, A. J. Kennedy, J. A. Steevens, Z. Pingheng, E. Morikawa, M. Merchan, A. Roy. 2014. Stability of solid-phase selenium species in dredged fly ash after prolonged submersion in a natural river system. Chemosphere 95:174181.

Collins, A. L., and D. E. Walling. 2002. Selecting fingerprint properties for discriminating potential suspended sediment sources in river basins. Journal of hydrology 261(1):218-244.

Collins, A. L., D. E. Walling, L. Webb, and P. King. 2010. Apportioning catchment scale sediment sources using a modified composite fingerprinting technique incorporating property weightings and prior information. Geoderma 155(3):249261.

Eadie, B. J., D. J. Schwab, R. A. Assel, N. Hawley, M. B. Lansing, G. S. Miller, and R. E. Holland, and T. H. Johengen. 1996. Development of recurrent coastal plume in Lake Michigan observed for first time. Eos, Transactions American Geophysical Union 77(35):337-338.

Eadie, B. J., D. J. Schwab, T. H. Johengen, P. J. Lavrentyev, G. S. Miller, R. E. Holland, and N. Hawley. 2002. Particle transport, nutrient cycling, and algal community structure associated with a major winter-spring sediment resuspension event in southern Lake Michigan. Journal of Great Lakes Research 28(3):324-337. 
Esbensen, K. H. 2010. Multivariate Data Analysis-In Practice. CAMO Software AS, Norway.

Feng, H., J. K. Cochran, D. J. Hirschberg, and R. E. Wilson. 1998. Small-scale spatial variations of natural radionuclide and trace metal distributions in sediments from the Hudson River Estuary. Estuaries 21(2):263-280.

Feng, H., J. K. Cochran, and D. J. Hirschberg. 1999. ${ }^{234}$ Th and 7Be as tracers for the transport and dynamics of suspended particles in a partially mixed estuary. Geochimica et Cosmochimica Acta 63 (17):2487-2505.

Flynn, W. W. 1968. The determination of low levels of polonium-210 in environmental materials. Analytica chimica acta 43:221-227.

Gireeshkumar, T. R., P. M. Deepulal, and N. Chandramohanakumar. 2013. Distribution and sources of sedimentary organic matter in a tropical estuary, southwest coast of India (Chochin estuary): A baseline study. Marine Pollution Bulletin 66(12):239-245.

Grisso, R. D., M. M. Alley, D. L. Holshouser, and W. E. Thomason. 2009. Precision Farming Tools. Soil Electrical Conductivity. http://hdl.handle.net/10919/51377

Hancock, G., and G. G. Caitcheon. 2010. Sediment sources and transport to the LoganAlbert River estuary during the January 2008 flood event. CSIRO Water for a Health Country. Series ISSN: 835-095X, CSIRO.

Jweda, J., M. Baskaran, E. van Hees, and L. Schweitzer. 2008. Short-lived radionuclides $\left(7 \mathrm{Be}\right.$ and $\left.{ }^{210} \mathrm{~Pb}\right)$ as tracers of particle dynamics in a river system in southeast Michigan. Limnology and Oceanography 53(5):1934-1944.

Kim, G., N. Hussain, J. R. Scudlark, and T. M. Church. 2000. Factors influencing the atmospheric depositional fluxes of stable $\mathrm{Pb}, 210 \mathrm{~Pb}$, and ${ }_{7} \mathrm{Be}$ into Chesapeake Bay. Journal of Atmospheric Chemistry 36(1):65-79.

Kirchner, G. 2011. ${ }^{210} \mathrm{~Pb}$ as a tool for establishing sediment chronologies: Examples of potentials and limitations of conventional dating models. Journal of Environmental Radioactivity 102(5):490-494.

Lou, J., D. J. Schwab, D. Beletsky, and N. Hawley. 2000. A model of sediment resuspension and transport dynamics in southern Lake Michigan. Journal of Geophysical Research: Oceans 105(C3):6591-6610.

Mathangwane, B. T., M. A. Chappell, J. R. V. Pils, L. S. Sonon, V. P. Evangelou. 2008. Dispersion potential of selected Iowa lake sediments as influenced by dissolved and solid-phase constituents. CLEAN-Soil, Air, Water 36(2):201-208.

Mullenbach, B. L., and C. A. Nittrouer. 2000. Rapid deposition of fluvial sediment in the Eel Canyon, northern California. Continental Shelf Research 20(16):2191-2212.

Mullenbach, B. L., C. A. Nittrouer, P. Puig, and D. L. Orange. 2004. Sediment deposition in a modern submarine canyon: Eel Canyon, northern California. Marine Geology 211:101-119. 
Nittrouer, C. A., R. W. Sternberg, R. Carpenter, and J. T. Bennett. 1979. The use of Pb-210 geochronology as a sedimentological tool: application to the Washington continental shelf. Marine Geology 31(3):297-316.

Olsen, C. R., I. L. Larsen, P. D. Lowry, N. H. Cutshall, J. F. Todd, G. T. F. Wong, and W. H. Casey. 1985. Atmospheric fluxes and marsh-soil inventories of $7 \mathrm{Be}$ and ${ }^{210} \mathrm{~Pb}$. Journal of Geophysical Research: Atmospheres 90(D6):10487-10495.

Papanicolaou, A. N., J. F. Fox, and J. Marshall. 2003. Soil fingerprinting in the Palouse Basin, USA, using stable carbon and nitrogen isotopes. International Journal of Sediment Research 18(2)278-284.

Ritchie, J. C., and J. R. McHenry. 1990. Application of radioactive fallout cesium-137 for measuring soil erosion and sediment accumulation rates and patterns: A review. Journal of Environmental Quality 19(2):215-233.

Savoye, N., C. Benitez-Nelson, A. B. Burd, J. K. Cochran, M. Charette, K. O. Buesseler, G. A. Jackson, M. Roy-Barman, S. Schmidt, and M. Elskens. 2006. ${ }^{234}$ Th sorption and export models in the water column: A review. Marine Chemistry 100(34):234-249.

Sommerfield, C. K. 2006. On sediment accumulation rates and stratigraphic completeness: Lessons from Holocene ocean margins. Continental Shelf Research 26(17-18):2225-2240.

Steevens, J., A. J. Bednar, J. Brame, M. Chappell, A. J. Kennedy, J. Seiter, J. Stanley. 2011. Evaluation of metals release from oxidation of fly ash during dredging of the Emory River, TN. ERDC/EL TR-11-9. Vicksburg, MS: U.S. Army Engineer Research and Development Center.

Wold, S., and M. Sjostrom. 1977. SIMCA: A method for analyzing chemical data in terms of similarity and analogy. In Chemometrics: Theory and Application, 243-282. Washington, DC: American Chemical Society.

U.S. Environmental Protection Agency (USEPA). 1986. Atomic absorption methods: Test methods for evaluating solid waste. SW846, Method 3050B. Washington, DC: USEPA, Office of Solid Waste and Emergency Response.

Waples, J. T., C. Benitez-Nelson, N. Savoye, M. Rutgers van der Loeff, M. Baskaran, and O. Gustafsson. 2006. An introduction to the application and future use of ${ }^{234} \mathrm{Th}$ in aquatic systems. Marine Chemistry 100(3-4):166-189.

Wilson, C. G., G. Matisoff, P. J. Whiting, and D. M. Klarer. 2005. Transport of fine sediment through a wetland using radionuclide tracers: Old Woman Creek, $\mathrm{OH}$. Journal of Great Lakes Research 31(1):56-67. 


\section{Appendix A: Grain Size Data}

Table A1. Weight percentage sand, silt, and clay are presented for the bottom samples collected in May 2014. PC=Pullman Creek, IC=Indian Creek, $L C=$ Lake Calumet, $C R=$ Calumet River, $\mathrm{CH}=$ Calumet Harbor, $\mathrm{LM}=$ Lake Michigan.

\begin{tabular}{|c|c|c|c|c|c|c|c|}
\hline Sample & \%Sand & \%Silt & \%Clay & Sample & \%Sand & \%Silt & \%Clay \\
\hline PC1 & 86 & 12 & 2 & $\mathrm{CH} 1$ & 21 & 63 & 16 \\
\hline PC2 & 70 & 26 & 4 & $\mathrm{CH} 2$ & 12 & 76 & 12 \\
\hline PC Average & 78 & 19 & 3 & $\mathrm{CH} 3$ & 65 & 28 & 7 \\
\hline IC1 & 57 & 41 & 2 & $\mathrm{CH} 4$ & 39 & 53 & 7 \\
\hline IC2 & 56 & 41 & 2 & $\mathrm{CH} 5$ & 82 & 15 & 3 \\
\hline IC Average & 57 & 41 & 2 & $\mathrm{CH} 6$ & 48 & 45 & 7 \\
\hline LC1 & 26 & 58 & 16 & $\mathrm{CH} 7$ & 16 & 73 & 11 \\
\hline LC2 & 42 & 48 & 10 & CH Average & 41 & 50 & 9 \\
\hline LC3 & 39 & 48 & 13 & LM1 & 93 & 6 & 1 \\
\hline LC4 & 36 & 52 & 13 & LM2 & 100 & 0 & 0 \\
\hline LC5 & 8 & 73 & 18 & LM3 & 98 & 2 & 0 \\
\hline LC6 & 32 & 52 & 16 & LM4 & 99 & 1 & 0 \\
\hline LC7 & 10 & 72 & 18 & LM5* & 99 & - & - \\
\hline LC8 & 17 & 67 & 16 & LM6* & 97 & - & - \\
\hline LC9 & 5 & 82 & 14 & LM7 & 36 & 57 & 7 \\
\hline LC Average & 24 & 61 & 15 & LM8 & 50 & 45 & 5 \\
\hline CR1 & 9 & 76 & 15 & LM9 & 73 & 24 & 3 \\
\hline CR2 & 13 & 69 & 19 & LM10* & 99 & - & - \\
\hline CR3 & 62 & 31 & 7 & LM11 & 92 & 8 & 0 \\
\hline CR4 & 16 & 66 & 18 & LM12 & 92 & 7 & 0 \\
\hline CR5 & 29 & 55 & 16 & LM13 & 70 & 26 & 4 \\
\hline CR6 & 19 & 67 & 14 & LM14 & 92 & 8 & 0 \\
\hline CR7 & 19 & 64 & 18 & LM15 & 87 & 13 & 0 \\
\hline CR8 & 30 & 60 & 10 & LM16 & 98 & 2 & 0 \\
\hline CR9 & 35 & 57 & 9 & LM17 & 47 & 49 & 4 \\
\hline CR10 & 48 & 43 & 9 & LM18 & 24 & 61 & 15 \\
\hline CR11 & 38 & 54 & 8 & LM19 & 87 & 13 & 0 \\
\hline CR12 & 29 & 57 & 14 & LM21* & 100 & 0 & 0 \\
\hline CR13 & 36 & 51 & 13 & LM Average & 79 & 19 & 2 \\
\hline CR14 & 24 & 59 & 17 & \multirow{3}{*}{\multicolumn{4}{|c|}{$\begin{array}{l}\text { *Grain size analysis performed by dry sieve } \\
\text { method. No clay and silt analysis performed. }\end{array}$}} \\
\hline CR15 & 16 & 67 & 17 & & & & \\
\hline CR Average & 28 & 58 & 14 & & & & \\
\hline
\end{tabular}




\section{Appendix B: Light Element Data}

Table B1. Weight percent TOC, TC, TN along with atomic OC/N ratios for the bottom samples collected in May 2014 are presented. $\mathrm{PC}=$ Pullman Creek, IC=Indian Creek, $\mathrm{LC}=$ Lake Calumet, $\mathrm{CR}=$ Calumet River, $\mathrm{CH}=\mathrm{Calumet}$ Harbor, LM=Lake Michigan, BD=Below Detection, N/A=Not Applicable.

\begin{tabular}{|c|c|c|c|c|c|c|c|c|c|}
\hline Sample & \%TOC & \%TC & \%TN & $\mathrm{OC} / \mathrm{N}(\mathrm{a})$ & Sample & \%TOC & $\% \mathrm{TC}$ & \%TN & $\mathrm{OC} / \mathrm{N}(\mathrm{a})$ \\
\hline PC1 & 2.31 & 5.13 & $\mathrm{BD}$ & $\mathrm{N} / \mathrm{A}$ & $\mathrm{CH} 1$ & 2.01 & 4.87 & $\mathrm{BD}$ & $\mathrm{N} / \mathrm{A}$ \\
\hline PC2 & 1.43 & 4.39 & $\mathrm{BD}$ & $\mathrm{N} / \mathrm{A}$ & $\mathrm{CH} 2$ & 1.48 & 6.04 & 0.14 & 12.33 \\
\hline PC Average & 1.87 & 4.76 & $B D$ & N/A & $\mathrm{CH} 3$ & 0.8 & 3.46 & $\mathrm{BD}$ & N/A \\
\hline IC1 & 2.1 & 5.87 & 0.21 & 11.67 & $\mathrm{CH} 4$ & 1.47 & 4.96 & 0.08 & 21.44 \\
\hline IC2 & 1.7 & 7.54 & 0.15 & 13.22 & $\mathrm{CH} 5$ & 1.02 & 3.99 & $\mathrm{BD}$ & N/A \\
\hline IC Average & 1.9 & 6.71 & 0.18 & 12.31 & $\mathrm{CH} 6$ & 1.17 & 5.41 & 0.1 & 13.65 \\
\hline LC1 & 1.46 & 4.31 & 0.15 & 11.36 & $\mathrm{CH} 7$ & 1.32 & 6.11 & 0.15 & 10.27 \\
\hline LC2 & 1.27 & 4.15 & 0.12 & 12.35 & CH Average & 1.32 & 4.97 & 0.12 & 12.83 \\
\hline LC3 & 1.2 & 3.77 & $\mathrm{BD}$ & N/A & LM1 & 0.9 & 2.49 & $\mathrm{BD}$ & $\mathrm{N} / \mathrm{A}$ \\
\hline LC4 & 1.05 & 3.6 & 0.06 & 20.42 & LM2 & $\mathrm{BD}$ & 1.05 & $\mathrm{BD}$ & $\mathrm{N} / \mathrm{A}$ \\
\hline LC5 & 1.57 & 4.89 & 0.12 & 15.26 & LM3 & $\mathrm{BD}$ & 1.05 & $\mathrm{BD}$ & $\mathrm{N} / \mathrm{A}$ \\
\hline LC6 & 1.09 & 3.72 & $\mathrm{BD}$ & $\mathrm{N} / \mathrm{A}$ & LM4 & $B D$ & 1.34 & BD & $\mathrm{N} / \mathrm{A}$ \\
\hline LC7 & 1.46 & 4.81 & 0.11 & 15.48 & LM5 & 1.05 & 2.3 & $B D$ & N/A \\
\hline LC8 & 1.58 & 4.86 & 0.11 & 16.76 & LM6 & 1 & 3.6 & $\mathrm{BD}$ & N/A \\
\hline LC9 & 2.64 & 5.63 & 0.18 & 17.11 & LM7 & 2.09 & 5.48 & $\mathrm{BD}$ & N/A \\
\hline LC Average & 1.48 & 4.42 & 0.12 & 14.39 & LM8 & 2.7 & 4.54 & $\mathrm{BD}$ & $\mathrm{N} / \mathrm{A}$ \\
\hline CR1 & 2.25 & 5.35 & 0.19 & 13.82 & LM9 & 1.25 & 4.97 & 0.11 & 13.26 \\
\hline CR2 & 2.76 & 5.43 & 0.26 & 12.38 & LM10 & 2.11 & 4.27 & $\mathrm{BD}$ & $\mathrm{N} / \mathrm{A}$ \\
\hline CR3 & 2.76 & 3.77 & 0.11 & 29.27 & LM11 & 2.9 & 5.02 & $\mathrm{BD}$ & $\mathrm{N} / \mathrm{A}$ \\
\hline CR4 & 2.64 & 5.34 & 0.28 & 11.00 & LM12 & 1.46 & 5.43 & $\mathrm{BD}$ & $\mathrm{N} / \mathrm{A}$ \\
\hline CR5 & 1.55 & 4.7 & 0.15 & 12.06 & LM13 & 3.18 & 5.87 & 0.15 & 24.73 \\
\hline CR6 & 3.27 & 6.53 & 0.23 & 16.59 & LM14 & 2.11 & 4.85 & $\mathrm{BD}$ & N/A \\
\hline CR7 & 4.57 & 10.47 & 0.29 & 18.39 & LM15 & 3.38 & 5.65 & $B D$ & N/A \\
\hline CR8 & 6.82 & 11.59 & 0.23 & 34.59 & LM16 & 1.49 & 2.88 & $\mathrm{BD}$ & $\mathrm{N} / \mathrm{A}$ \\
\hline CR9 & 7.96 & 7.98 & 0.17 & 54.63 & LM17 & 3.6 & 5.47 & $\mathrm{BD}$ & N/A \\
\hline CR10 & 3.11 & 8.42 & 0.17 & 21.34 & LM18 & 2.89 & 6.08 & $\mathrm{BD}$ & $\mathrm{N} / \mathrm{A}$ \\
\hline CR11 & 4.12 & 6.21 & 0.14 & 34.33 & LM19 & 2.28 & 5.12 & $B D$ & $\mathrm{~N} / \mathrm{A}$ \\
\hline CR12 & 2.55 & 5.78 & 0.14 & 21.25 & LM21 & 2.57 & 5.29 & $\mathrm{BD}$ & $\mathrm{N} / \mathrm{A}$ \\
\hline CR13 & 0.89 & 6.13 & 0.24 & 4.33 & LM Average & 2.17 & 4.14 & 0.13 & 19.51 \\
\hline CR14 & 3.04 & 5.97 & 0.2 & 17.73 & \multirow{3}{*}{\multicolumn{5}{|c|}{$\begin{array}{l}\mathrm{BD}=\text { Below Detection limit, } 0.1 \% \\
\mathrm{~N} / \mathrm{A}=\text { Not Applicable }\end{array}$}} \\
\hline CR15 & 2.51 & 7.68 & 0.26 & 11.26 & & & & & \\
\hline CR Average & 3.39 & 6.76 & 0.2 & 19.78 & & & & & \\
\hline
\end{tabular}




\section{Appendix C: Trace Element Data}

Table C1. Total metal concentrations ( $\mathrm{mg} / \mathrm{kg}$ ) of aluminum, arsenic, barium, cadmium, calcium, chromium, cobalt, and copper for the bottom sediment samples collected in May 2014. $\mathrm{PC}=$ Pullman Creek, IC=Indian Creek, $\mathrm{LC}=$ =Lake Calumet, $\mathrm{CR}=$ Calumet River.

\begin{tabular}{|c|c|c|c|c|c|c|c|c|}
\hline Sample & Al & As & Ba & Cd & Ca & Cr & Co & Cu \\
\hline PC1 & 3580 & 9.4 & 63.9 & 1.12 & 40300 & 19.7 & 3.77 & 28.7 \\
\hline PC2 & 5210 & 18.3 & 102 & 2 & 65100 & 42.4 & 3.93 & 36.3 \\
\hline PC Average & 4395 & 13.85 & 82.95 & 1.56 & 52700 & 31.05 & 3.85 & 32.5 \\
\hline IC1 & 3860 & 8.71 & 91.7 & 1.08 & 69200 & 172 & 3.64 & 25.5 \\
\hline IC2 & 1910 & 33.2 & 145 & 1.81 & 160000 & 23.3 & 3.19 & 50 \\
\hline IC Average & 2885 & 20.96 & 118.35 & 1.45 & 114600 & 97.65 & 3.42 & 37.75 \\
\hline LC1 & 7250 & 16.3 & 53.5 & 0.42 & 96900 & 36.4 & 8.13 & 18.9 \\
\hline LC2 & 5210 & 35.7 & 32.9 & 0.45 & 68100 & 13 & 7.75 & 18.8 \\
\hline LC3 & 3580 & 20.6 & 16.8 & 0.64 & 41100 & 8.21 & 7.19 & 15 \\
\hline LC4 & 6130 & 20.1 & 30.1 & 0.34 & 57800 & 12 & 8.55 & 14.3 \\
\hline LC5 & 6640 & 26.3 & 31.4 & 0.69 & 56700 & 15.7 & 9 & 23.9 \\
\hline LC6 & 7510 & 14 & 34.6 & 0.46 & 48900 & 13.2 & 8.42 & 16.9 \\
\hline LC7 & 6950 & 20.9 & 33.3 & 0.7 & 53700 & 17.1 & 9.13 & 23.2 \\
\hline LC8 & 5470 & 22.8 & 30.9 & 0.9 & 47900 & 16.6 & 7.46 & 22.6 \\
\hline LC9 & 8500 & 25.9 & 53.8 & 1.41 & 52900 & 24.5 & 10.4 & 34.4 \\
\hline LC Average & 6360 & 22.51 & 35.26 & 0.67 & 58222 & 17.41 & 8.45 & 20.89 \\
\hline CR1 & 9900 & 17.2 & 54.2 & 1.08 & 57400 & 27.4 & 9.99 & 31.5 \\
\hline CR2 & 11900 & 19.3 & 81.7 & 1.48 & 51200 & 52.1 & 11.7 & 42.2 \\
\hline CR3 & 5010 & 7.82 & 34.3 & 0.57 & 53000 & 18.9 & 6.81 & 21.6 \\
\hline CR4 & 11000 & 12.7 & 74.7 & 1.24 & 51000 & 35.6 & 9.98 & 38.8 \\
\hline CR5 & 7840 & 9.39 & 50.9 & 0.69 & 61000 & 22.1 & 8.25 & 328 \\
\hline CR6 & 10300 & 19.1 & 88.7 & 2.26 & 56700 & 56.4 & 12.3 & 60.1 \\
\hline CR7 & 12300 & 19.2 & 88.5 & 2.41 & 63100 & 79.6 & 12.8 & 69.2 \\
\hline CR8 & 8450 & 15 & 66.1 & 2.01 & 40100 & 54.2 & 9.67 & 64.7 \\
\hline CR9 & 5330 & 13.1 & 44.2 & 1.49 & 36500 & 40.7 & 7.93 & 52.8 \\
\hline CR10 & 7930 & 10.1 & 51.7 & 1.03 & 49500 & 43.6 & 8.89 & 36.3 \\
\hline CR11 & 7560 & 13.6 & 61.8 & 1.06 & 54800 & 32.8 & 9.23 & 37.6 \\
\hline CR12 & 8000 & 12.6 & 76.1 & 0.91 & 54100 & 26.2 & 8.81 & 31.4 \\
\hline CR13 & 7470 & 12.2 & 59.2 & 0.74 & 50100 & 22.2 & 9.28 & 36.7 \\
\hline CR14 & 6730 & 13.3 & 48.8 & 0.52 & 55600 & 18.8 & 8.69 & 28.8 \\
\hline CR15 & 10200 & 13.1 & 64.9 & 0.71 & 59500 & 28.3 & 9.6 & 29.6 \\
\hline CR Average & 8661 & 13.85 & 63.05 & 1.21 & 52907 & 37.26 & 9.6 & 60.62 \\
\hline & & & & & & & & \\
\hline
\end{tabular}


Table C2. Total metal concentrations ( $\mathrm{mg} / \mathrm{kg}$ ) of aluminum, arsenic, barium, cadmium, calcium, chromium, cobalt, and copper for the bottom sediment samples collected in May 2014. $\mathrm{CH}=$ Calumet Harbor, $\mathrm{LM}=$ Lake Michigan, $\mathrm{BD}=$ Below Detection.

\begin{tabular}{|c|c|c|c|c|c|c|c|c|}
\hline Sample & Al & As & Ba & Cd & Ca & Cr & Co & Cu \\
\hline CH1 & 5250 & 12.7 & 23.2 & 0.18 & 109000 & 11.7 & 6.57 & 19 \\
\hline CH2 & 8270 & 9.01 & 40.3 & 0.52 & 83100 & 19.1 & 7.93 & 30.5 \\
\hline CH3 & 6150 & 14 & 28.7 & 0.24 & 44100 & 12.1 & 9.78 & 21 \\
\hline CH4 & 4200 & 7.65 & 21.1 & 0.38 & 74000 & 10.8 & 5.57 & 12.8 \\
\hline CH5 & 3120 & 9.86 & 16.4 & 0.19 & 52600 & 8.18 & 6.14 & 12.1 \\
\hline CH6 & 4940 & 7.77 & 27.9 & 0.38 & 79500 & 13.8 & 5.66 & 13.9 \\
\hline CH7 & 7450 & 8.39 & 36.6 & 0.42 & 84700 & 17.3 & 7.41 & 19.6 \\
\hline CH Average & 5626 & 9.91 & 27.74 & 0.33 & 75286 & 13.28 & 7.01 & 18.41 \\
\hline LM1 & 1290 & 3.81 & 6.67 & 0.13 & 59000 & 4.25 & 2.78 & 2.97 \\
\hline LM2 & 901 & 4.52 & 5.27 & BD & 19400 & 2.63 & 2.5 & 2.12 \\
\hline LM3 & 920 & 3.57 & 5.12 & BD & 25100 & 2.97 & 2.26 & 2.02 \\
\hline LM4 & 761 & 2.75 & 5.31 & BD & 23300 & 2.42 & 1.81 & 2.02 \\
\hline LM5 & 2460 & 12.6 & 14.3 & 0.19 & 30800 & 5.6 & 5.13 & 10 \\
\hline LM6 & 2400 & 16.6 & 17.1 & 1.07 & 77600 & 6.21 & 5.53 & 11.6 \\
\hline LM7 & 3700 & 5.38 & 20.1 & 0.31 & 72300 & 11.2 & 4.9 & 12.6 \\
\hline LM8 & 3150 & 4.65 & 20.2 & 0.42 & 99800 & 13.9 & 4.64 & 9.8 \\
\hline LM9 & 3500 & 6.14 & 27.8 & 0.32 & 97300 & 11.7 & 5.75 & 9.15 \\
\hline LM10 & 2400 & 16.1 & 14.8 & 0.11 & 59400 & 7.35 & 5.43 & 6.09 \\
\hline LM11 & 1210 & 3.18 & 6.8 & 0.23 & 75600 & 4.65 & 2.8 & 2.84 \\
\hline LM12 & 3060 & 5.06 & 20.1 & 0.3 & 76300 & 10.9 & 3.83 & 8.4 \\
\hline LM13 & 4290 & 7.51 & 30.3 & 0.3 & 90500 & 13.3 & 5.51 & 11.6 \\
\hline LM14 & 1420 & 3.69 & 8.54 & 0.13 & 79100 & 5.41 & 3.07 & 3.83 \\
\hline LM15 & 1520 & 3.37 & 8.3 & 0.15 & 94300 & 6.15 & 3.11 & 4.03 \\
\hline LM16 & 944 & 3.15 & 5.35 & BD & 50000 & 4.54 & 2.52 & 2.89 \\
\hline LM17 & 2910 & 5.27 & 16.5 & 0.26 & 102000 & 9.11 & 3.98 & 10.7 \\
\hline LM18 & 5690 & 9.55 & 24.1 & 0.24 & 62400 & 10.8 & 9.52 & 23.5 \\
\hline LM19 & 1440 & 3.62 & 8.14 & 0.14 & 77200 & 5.46 & 3.32 & 5.26 \\
\hline LM21 & 2170 & 20.1 & 23.4 & 0.15 & 78900 & 5.9 & 6.79 & 9.93 \\
\hline LM Average & 2307 & 7.03 & 14.41 & 0.28 & 67515 & 7.22 & 4.26 & 7.57 \\
\hline
\end{tabular}


Table C3. Total metal concentrations ( $\mathrm{mg} / \mathrm{kg}$ ) of iron, lead, magnesium, manganese, molybdenum, phosphorous, nickel, and potassium for the bottom sediment samples collected in May 2014. PC=Pullman Creek, IC=Indian Creek, LC=Lake Calumet, CR=Calumet River.

\begin{tabular}{|c|c|c|c|c|c|c|c|c|}
\hline Sample & $\mathrm{Fe}$ & $\mathrm{Pb}$ & $\mathrm{Mg}$ & $\mathrm{Mn}$ & Mo & $P$ & $\mathrm{Ni}$ & $\mathrm{K}$ \\
\hline PC1 & 9250 & 118 & 16700 & 348 & 1.95 & 408 & 11.2 & 562 \\
\hline PC2 & 9600 & 155 & 28200 & 743 & 3.58 & 545 & 15.5 & 777 \\
\hline PC Average & 14425 & 136.5 & 22450 & 545.5 & 2.77 & 476.5 & 13.35 & 669.5 \\
\hline IC1 & 27600 & 95.8 & 12700 & 3410 & 15.7 & 644 & 19.9 & 450 \\
\hline IC2 & 10600 & 441 & 10600 & 500 & 30 & 251 & 15.8 & 379 \\
\hline IC Average & 19100 & 268.4 & 11650 & 1955 & 22.85 & 447.5 & 17.85 & 414.5 \\
\hline LC1 & 39800 & 24.9 & 20300 & 1230 & 39.9 & 421 & 25.7 & 1970 \\
\hline LC2 & 25400 & 33.3 & 23600 & 569 & 7.57 & 420 & 22.5 & 1680 \\
\hline LC3 & 15600 & 17.8 & 21600 & 453 & 3.85 & 322 & 15.4 & 993 \\
\hline LC4 & 17600 & 31.6 & 30000 & 462 & 3.67 & 294 & 20.5 & 1700 \\
\hline LC5 & 23600 & 52.7 & 28700 & 592 & 5.32 & 344 & 23.5 & 1870 \\
\hline LC6 & 20100 & 30.2 & 24900 & 514 & 3.53 & 264 & 21.9 & 2020 \\
\hline LC7 & 21900 & 51.5 & 28600 & 586 & 4.56 & 310 & 24 & 1960 \\
\hline LC8 & 18500 & 56.4 & 23800 & 502 & 3.02 & 330 & 19.2 & 1460 \\
\hline LC9 & 24900 & 123 & 27200 & 654 & 4.69 & 337 & 27.6 & 2200 \\
\hline LC Average & 23044 & 46.82 & 25411 & 618 & 8.46 & 338 & 22.26 & 1761 \\
\hline CR1 & 26200 & 82.9 & 26900 & 922 & 3.04 & 631 & 27.2 & 2550 \\
\hline CR2 & 37100 & 174 & 22400 & 1620 & 3.23 & 869 & 32.9 & 2690 \\
\hline CR3 & 17700 & 57.7 & 24600 & 609 & 1.95 & 509 & 18.5 & 1170 \\
\hline CR4 & 30500 & 122 & 23900 & 1040 & 2.55 & 1020 & 29.5 & 2610 \\
\hline CR5 & 23600 & 132 & 25200 & 634 & 3.31 & 413 & 25.6 & 2010 \\
\hline CR6 & 42200 & 263 & 23900 & 2030 & 4.68 & 1030 & 35.3 & 1990 \\
\hline CR7 & 62300 & 308 & 22600 & 2780 & 9.95 & 1400 & 49.8 & 2140 \\
\hline CR8 & 50900 & 239 & 18400 & 1470 & 7.77 & 696 & 37.6 & 1700 \\
\hline CR9 & 46300 & 168 & 15800 & 1120 & 6.28 & 447 & 29.9 & 1010 \\
\hline CR10 & 33400 & 120 & 21600 & 1340 & 5.32 & 415 & 33.9 & 1280 \\
\hline CR11 & 39800 & 149 & 24200 & 1430 & 6.28 & 440 & 33.3 & 1380 \\
\hline CR12 & 34300 & 148 & 22300 & 1110 & 6.38 & 539 & 27.3 & 1750 \\
\hline CR13 & 32300 & 131 & 24800 & 1040 & 5.32 & 375 & 25.9 & 1830 \\
\hline CR14 & 38800 & 69.2 & 27200 & 876 & 7.04 & 392 & 29.8 & 1680 \\
\hline CR15 & 52900 & 86.9 & 27100 & 1410 & 3.43 & 518 & 24.4 & 2310 \\
\hline CR Average & 37887 & 150.05 & 23393 & 1295.4 & 5.1 & 646.27 & 30.73 & 1873 \\
\hline
\end{tabular}


Table C4. Total metal concentrations ( $\mathrm{mg} / \mathrm{kg}$ ) of iron, lead, magnesium, manganese, molybdenum, phosphorous, nickel, and potassium for the bottom sediment samples collected in May 2014. $\mathrm{CH}=$ Calumet Harbor, LM=Lake Michigan

\begin{tabular}{|c|c|c|c|c|c|c|c|c|}
\hline Sample & $\mathrm{Fe}$ & $\mathrm{Pb}$ & $\mathrm{Mg}$ & $\mathrm{Mn}$ & $\mathrm{Mo}$ & $\mathrm{P}$ & $\mathrm{Ni}$ & $\mathrm{K}$ \\
\hline CH1 & 25700 & 83.6 & 49700 & 655 & 5.57 & 242 & 21.3 & 1380 \\
\hline CH2 & 22300 & 60 & 39800 & 639 & 2.26 & 413 & 21.4 & 2100 \\
\hline CH3 & 25600 & 26.8 & 22900 & 384 & 9.88 & 259 & 24.5 & 1890 \\
\hline CH4 & 14100 & 23.4 & 36000 & 446 & 2.54 & 298 & 15.4 & 1150 \\
\hline CH5 & 18700 & 16.5 & 27400 & 324 & 5.53 & 226 & 15 & 951 \\
\hline CH6 & 16800 & 30.1 & 36200 & 459 & 1.54 & 319 & 15.4 & 1270 \\
\hline CH7 & 18800 & 31.9 & 41300 & 570 & 1.99 & 396 & 20.2 & 1960 \\
\hline CH Average & 20286 & 38.9 & 36186 & 496.71 & 4.19 & 307.57 & 19.03 & 1529 \\
\hline LM1 & 6220 & 7.36 & 32700 & 261 & 0.59 & 239 & 6.73 & 340 \\
\hline LM2 & 5050 & 3.56 & 11100 & 122 & 0.42 & 101 & 4.19 & 214 \\
\hline LM3 & 4480 & 6.95 & 14100 & 141 & 0.35 & 184 & 4.25 & 226 \\
\hline LM4 & 4040 & 3.67 & 12000 & 120 & 0.43 & 126 & 3.97 & 187 \\
\hline LM5 & 12400 & 28.5 & 15200 & 257 & 2.63 & 143 & 11.6 & 765 \\
\hline LM6 & 14700 & 13.2 & 37000 & 436 & 3.1 & 226 & 14.1 & 699 \\
\hline LM7 & 12800 & 37.3 & 36000 & 403 & 1.35 & 298 & 13.6 & 983 \\
\hline LM8 & 14800 & 25.1 & 48300 & 476 & 1.07 & 359 & 14.5 & 771 \\
\hline LM9 & 14400 & 20.7 & 31100 & 397 & 1.42 & 393 & 14.6 & 914 \\
\hline LM10 & 15500 & 10.4 & 31100 & 378 & 1.39 & 228 & 11.5 & 467 \\
\hline LM11 & 8110 & 6.66 & 42800 & 275 & 0.33 & 421 & 7.89 & 269 \\
\hline LM12 & 10700 & 20.7 & 37200 & 378 & 0.78 & 312 & 11.2 & 824 \\
\hline LM13 & 13900 & 23.6 & 36100 & 427 & 1.08 & 417 & 15.4 & 1100 \\
\hline LM14 & 7880 & 9.5 & 44600 & 314 & 0.36 & 302 & 8.6 & 310 \\
\hline LM15 & 8630 & 8.61 & 53000 & 336 & 0.44 & 442 & 10.3 & 346 \\
\hline LM16 & 7010 & 7.11 & 28600 & 236 & 0.33 & 294 & 6.43 & 198 \\
\hline LM17 & 9760 & 17.7 & 53600 & 460 & 1.12 & 306 & 13.2 & 777 \\
\hline LM18 & 18700 & 55.5 & 33800 & 408 & 7.12 & 240 & 26 & 1840 \\
\hline LM19 & 7120 & 32.7 & 43000 & 308 & 0.42 & 331 & 8.79 & 333 \\
\hline LM21 & 17700 & 12.5 & 40300 & 449 & 3.8 & 236 & 15.6 & 697 \\
\hline LM Average & 10695 & 17.57 & 34080 & 329.1 & 1.43 & 279.9 & 11.12 & 613 \\
\hline & & & & & & & & \\
\hline
\end{tabular}


Table C5. Total metal concentrations ( $\mathrm{mg} / \mathrm{kg}$ ) of selenium, sodium, silver, thallium, tin, Vanadium, zinc, and strontium for the bottom sediment samples collected in May 2014. PC=Pullman Creek, IC=Indian Creek, $\mathrm{LC}=$ Lake Calumet, $\mathrm{CR}=$ Calumet River, $\mathrm{BD}=$ Below Detection.

\begin{tabular}{|c|c|c|c|c|c|c|c|c|}
\hline Sample & Se & $\mathrm{Na}$ & $\mathrm{Ag}$ & $\mathrm{TI}$ & $\mathrm{Sn}$ & $\mathrm{V}$ & $\mathrm{Zn}$ & $\mathrm{Sr}$ \\
\hline PC1 & 0.53 & 536 & $\mathrm{BD}$ & 0.29 & 7.05 & 10.5 & 158 & 35.4 \\
\hline PC2 & 0.67 & 702 & 0.11 & 0.32 & 7.7 & 15 & 250 & 53.5 \\
\hline PC Average & 0.6 & 619 & 0.11 & 0.31 & 7.38 & 12.75 & 204 & 44.45 \\
\hline IC1 & 0.74 & 1190 & $\mathrm{BD}$ & $\mathrm{BD}$ & 3.63 & 38.7 & 157 & 94.6 \\
\hline IC2 & 1.14 & 519 & 0.21 & 0.2 & 10.8 & 12.6 & 417 & 225 \\
\hline IC Average & 0.94 & $\mathbf{8 5 4 . 5}$ & 0.21 & 0.2 & 7.22 & $\mathbf{2 5 . 6 5}$ & 287 & 159.8 \\
\hline LC1 & 0.79 & 639 & $\mathrm{BD}$ & 0.47 & 0.14 & 35 & 72.6 & 84.6 \\
\hline LC2 & 0.71 & 352 & $\mathrm{BD}$ & 0.53 & 0.14 & 14.9 & 100 & 42.5 \\
\hline LC3 & 0.72 & 182 & $\mathrm{BD}$ & 0.55 & 0.72 & 9.87 & 113 & 18.8 \\
\hline LC4 & 0.33 & 250 & $\mathrm{BD}$ & 0.54 & 0.19 & 13.7 & 92.3 & 26.7 \\
\hline LC5 & 0.97 & 279 & $\mathrm{BD}$ & 0.71 & 0.26 & 14.9 & 160 & 26.8 \\
\hline LC6 & 0.8 & 258 & $\mathrm{BD}$ & 0.59 & 0.35 & 14 & 89.1 & 24.2 \\
\hline LC7 & 0.8 & 265 & $\mathrm{BD}$ & 0.75 & 3.14 & 14 & 161 & 25.5 \\
\hline LC8 & 0.88 & 350 & $\mathrm{BD}$ & 0.65 & 0.87 & 12.6 & 171 & 24.7 \\
\hline LC9 & 1.03 & 472 & $\mathrm{BD}$ & 1.01 & 1.25 & 16.3 & 242 & 29.2 \\
\hline LC Average & 0.78 & 338.56 & $\mathrm{BD}$ & 0.64 & 0.78 & 16.14 & 133.44 & 33.67 \\
\hline CR1 & 1 & 295 & 0.11 & 0.59 & 0.45 & 21 & 276 & 31 \\
\hline CR2 & 1.67 & 371 & 0.28 & 0.49 & 0.92 & 27.8 & 543 & 31.9 \\
\hline CR3 & 0.63 & 232 & 0.12 & 0.31 & 0.5 & 12.7 & 197 & 23.5 \\
\hline CR4 & 1.26 & 357 & 0.3 & 0.47 & 0.78 & 21.6 & 379 & 29.6 \\
\hline CR5 & 0.74 & 295 & 0.16 & 0.55 & 4.08 & 15 & 281 & 35.3 \\
\hline CR6 & 1.23 & 374 & 0.59 & 0.51 & 2.13 & 25.1 & 866 & 37.8 \\
\hline CR7 & 1.39 & 375 & 0.78 & 0.57 & 3.05 & 48.5 & 1020 & 41.3 \\
\hline CR8 & 1.12 & 274 & 0.83 & 0.59 & 1.65 & 28.9 & 1040 & 27 \\
\hline CR9 & 0.91 & 165 & 0.4 & 0.54 & 2.07 & 22.1 & 692 & 23.9 \\
\hline CR10 & 0.63 & 240 & 0.27 & 0.58 & 3.7 & 30.5 & 364 & 28.3 \\
\hline CR11 & 0.82 & 262 & 0.23 & 0.74 & 1.7 & 31 & 348 & 30.1 \\
\hline CR12 & 1.11 & 279 & 0.11 & 0.75 & 0.51 & 22.1 & 248 & 35.6 \\
\hline CR13 & 0.91 & 228 & $\mathrm{BD}$ & 0.63 & 0.4 & 19.2 & 229 & 27.3 \\
\hline CR14 & 0.82 & 202 & 0.12 & 0.71 & 0.33 & 16.4 & 155 & 26.4 \\
\hline CR15 & 0.94 & 240 & 0.12 & 0.49 & 0.53 & 23.8 & 230 & 30.9 \\
\hline CR Average & 1.01 & 279.27 & 0.32 & 0.57 & 1.52 & 24.38 & 457.87 & 30.66 \\
\hline
\end{tabular}


Table C6. Total metal concentrations ( $\mathrm{mg} / \mathrm{kg}$ ) of selenium, sodium, silver, thallium, tin, Vanadium, zinc, and strontium for the bottom sediment samples collected in May 2014.

$\mathrm{CH}=$ Calumet Harbor, $\mathrm{LM}=$ Lake Michigan, $\mathrm{BD}=$ Below Detection.

\begin{tabular}{|c|c|c|c|c|c|c|c|c|}
\hline Sample & Se & Na & Ag & TI & Sn & V & Zn & Sr \\
\hline CH1 & 0.42 & 196 & BD & 0.61 & 2.75 & 12.3 & 48.4 & 37.1 \\
\hline CH2 & 1.08 & 204 & BD & 0.4 & 0.98 & 17.6 & 101 & 32.4 \\
\hline CH3 & 0.94 & 155 & BD & 0.93 & 0.17 & 16.3 & 91.1 & 21.4 \\
\hline CH4 & 0.65 & 169 & BD & 0.31 & 0.19 & 11.7 & 67.2 & 27 \\
\hline CH5 & 0.57 & 139 & BD & 0.35 & 0.12 & 11.6 & 69.4 & 19.1 \\
\hline CH6 & 0.96 & 221 & BD & 0.23 & 0.52 & 14.4 & 92.1 & 32.7 \\
\hline CH7 & 0.88 & 198 & BD & 0.33 & 0.24 & 16.6 & 81.7 & 31.6 \\
\hline CH Average & 0.79 & 183.14 & $\mathrm{BD}$ & 0.45 & 0.71 & 14.36 & 78.7 & 28.76 \\
\hline LM1 & 0.18 & 123 & $\mathrm{BD}$ & $\mathrm{BD}$ & 0.22 & 8.49 & 32.6 & 17 \\
\hline LM2 & 0.21 & 79.8 & $\mathrm{BD}$ & $\mathrm{BD}$ & $\mathrm{BD}$ & 5.01 & 13.7 & 8.68 \\
\hline LM3 & 0.22 & 76.9 & $\mathrm{BD}$ & $\mathrm{BD}$ & 0.41 & 4.62 & 22.6 & 10.8 \\
\hline LM4 & 0.19 & 75.3 & $\mathrm{BD}$ & $\mathrm{BD}$ & $\mathrm{BD}$ & 4.4 & 10.7 & 11.3 \\
\hline LM5 & 0.31 & 95.5 & 1.19 & 0.25 & 0.92 & 8.72 & 50.6 & 13 \\
\hline LM6 & 0.47 & 194 & $\mathrm{BD}$ & 0.23 & 0.46 & 11.4 & 592 & 30.7 \\
\hline LM7 & 0.65 & 161 & $\mathrm{BD}$ & 0.21 & 1.13 & 12 & 66.5 & 26.3 \\
\hline LM8 & 0.66 & 244 & $\mathrm{BD}$ & 0.14 & 1.73 & 16 & 112 & 34.2 \\
\hline LM9 & 0.5 & 350 & $\mathrm{BD}$ & 0.16 & 0.6 & 12.2 & 111 & 51.4 \\
\hline LM10 & 0.55 & 164 & $\mathrm{BD}$ & 0.1 & 0.12 & 10.9 & 43.8 & 17.7 \\
\hline LM11 & 0.38 & 145 & $\mathrm{BD}$ & $\mathrm{BD}$ & 0.2 & 18.4 & 51.6 & 19.4 \\
\hline LM12 & 0.62 & 161 & $\mathrm{BD}$ & 0.11 & 1.44 & 11.4 & 73.3 & 27.7 \\
\hline LM13 & 0.69 & 311 & $\mathrm{BD}$ & 0.16 & 0.66 & 13.4 & 93.1 & 42.4 \\
\hline LM14 & 0.38 & 162 & 0.91 & $\mathrm{BD}$ & 13.2 & 14.6 & 43.3 & 20.6 \\
\hline LM15 & 0.74 & 189 & $\mathrm{BD}$ & $\mathrm{BD}$ & 0.39 & 21.5 & 46.7 & 23.3 \\
\hline LM16 & 0.33 & 100 & $\mathrm{BD}$ & $\mathrm{BD}$ & 0.51 & 11.8 & 29.6 & 14.5 \\
\hline LM17 & 0.57 & 204 & $\mathrm{BD}$ & 0.11 & 0.69 & 12.6 & 63.1 & 27.6 \\
\hline LM18 & 0.66 & 166 & $\mathrm{BD}$ & 0.79 & 2.24 & 14.5 & 57.5 & 21.6 \\
\hline LM19 & 0.39 & 155 & $\mathrm{BD}$ & $\mathrm{BD}$ & 9.97 & 14.3 & 45 & 20.3 \\
\hline LM21 & 0.54 & 179 & $\mathrm{BD}$ & 0.31 & 0.22 & 9.67 & 50 & 31.3 \\
\hline LM Average & 0.46 & 166.78 & 1.05 & 0.23 & 1.95 & 11.8 & 80.44 & 23.49 \\
\hline
\end{tabular}




\section{Appendix D: Electrical Conductivity (EC) and pH Data}

Table D1. $\mathrm{pH}$ and EC $(\mu \mathrm{S} / \mathrm{cm})$ data for the bottom sediments collected in May 2014. $P C=$ Pullman Creek, IC=Indian Creek, LC=Lake Calumet, $C R=$ Calumet River, $\mathrm{CH}=$ Calumet Harbor, $\mathrm{LM}=$ Lake Michigan.

\begin{tabular}{|c|c|c|c|c|c|}
\hline Sample & $\mathrm{pH}$ & EC & Sample & $\mathrm{pH}$ & EC \\
\hline PC1 & 7.59 & 2072.00 & $\mathrm{CH} 1$ & 7.96 & 604.00 \\
\hline PC2 & 7.70 & 1300.00 & $\mathrm{CH} 2$ & 7.75 & 419.70 \\
\hline PC Average & 7.65 & 1686.00 & $\mathrm{CH} 3$ & 7.86 & 454.10 \\
\hline IC1 & 7.53 & 4198.00 & $\mathrm{CH} 4$ & 6.82 & 472.80 \\
\hline IC2 & 7.45 & 1370.00 & $\mathrm{CH} 5$ & 7.58 & 444.50 \\
\hline IC Average & 7.49 & 2784.00 & $\mathrm{CH} 6$ & 7.81 & 401.80 \\
\hline LC1 & 7.89 & 575.70 & $\mathrm{CH} 7$ & 7.64 & 349.10 \\
\hline LC2 & 7.82 & 662.60 & $\mathrm{CH}$ Average & 7.63 & 449.43 \\
\hline LC3 & 7.84 & 582.90 & LM1 & 7.92 & 187.70 \\
\hline LC4 & 7.78 & 619.10 & LM2 & 8.56 & 141.60 \\
\hline LC5 & 7.63 & 781.70 & LM3 & 8.58 & 138.90 \\
\hline LC6 & 7.93 & 670.00 & LM4 & 7.39 & 112.90 \\
\hline LC7 & 7.90 & 608.30 & LM5 & 7.64 & 254.00 \\
\hline LC8 & 7.85 & 768.40 & LM6 & 7.92 & 179.70 \\
\hline LC9 & 7.77 & 909.40 & LM7 & 7.65 & 318.70 \\
\hline LC Average & 7.82 & 686.46 & LM8 & 7.75 & 322.90 \\
\hline CR1 & 7.43 & 812.50 & LM9 & 7.65 & 815.60 \\
\hline CR2 & 7.55 & 855.20 & LM10 & 7.68 & 130.80 \\
\hline CR3 & 7.47 & 803.10 & LM11 & 7.94 & 118.20 \\
\hline CR4 & 7.42 & 740.30 & LM12 & 7.54 & 316.20 \\
\hline CR5 & 7.57 & 401.70 & LM13 & 7.55 & 645.10 \\
\hline CR6 & 7.26 & 572.50 & LM14 & 7.83 & 126.10 \\
\hline CR7 & 7.50 & 621.90 & LM15 & 8.30 & 168.30 \\
\hline CR8 & 7.57 & 611.80 & LM16 & 7.23 & 156.40 \\
\hline CR9 & 7.12 & 542.00 & LM17 & 7.76 & 309.00 \\
\hline CR10 & 7.63 & 421.80 & LM18 & 7.86 & 452.40 \\
\hline CR11 & 7.65 & 525.10 & LM19 & 7.64 & 167.20 \\
\hline CR12 & 7.31 & 478.30 & LM21 & 8.84 & 115.50 \\
\hline CR13 & 7.64 & 409.80 & LM Average & 7.86 & 258.86 \\
\hline CR14 & 7.47 & 524.70 & & & \\
\hline CR15 & 7.36 & 366.00 & & & \\
\hline CR Average & 7.46 & 579.11 & & & \\
\hline
\end{tabular}




\section{Appendix E: Radioisotope Data}

Table E1. Radioisotope activity (dpm/g) and error ( \pm ) for all samples. Significant, measurable activities and associated error are indicated by black font. Red font indicates that no significant radioisotope activities were measured.

\begin{tabular}{|c|c|c|c|c|c|c|c|c|c|c|}
\hline \multirow[b]{2}{*}{ ID } & \multicolumn{2}{|c|}{${ }^{7} \mathrm{Be}-\mathrm{dpm} / \mathrm{g}$} & \multicolumn{2}{|c|}{${ }^{137} \mathrm{Cs}-\mathrm{dpm} / \mathrm{g}$} & \multicolumn{2}{|c|}{${ }^{234} \mathrm{Th}-\mathrm{dpm} / \mathrm{g}$} & \multicolumn{2}{|c|}{$\begin{array}{l}\text { Gamma }{ }^{210} \mathrm{~Pb} \\
-\mathrm{dpm} / \mathrm{g}\end{array}$} & \multicolumn{2}{|c|}{$\begin{array}{l}\text { Alpha }{ }^{210} \mathrm{~Pb}- \\
\mathrm{dpm} / \mathrm{g}\end{array}$} \\
\hline & ${ }^{7} \mathrm{Be}$ & $(+/-)$ & ${ }^{137} \mathrm{Cs}$ & $(+/-)$ & ${ }^{234} \mathrm{Th}$ & $(+/-)$ & ${ }^{210} \mathrm{~Pb}$ & $(+/-)$ & ${ }^{210} \mathrm{~Pb}$ & $(+/-)$ \\
\hline LM1 & 0.53 & 0.69 & -0.01 & 0.06 & -1.07 & 3.17 & 10.50 & 3.17 & 12.99 & 4.93 \\
\hline LM7 & 0.61 & 0.81 & 0.26 & 0.17 & 2.51 & 2.71 & 4.77 & 5.04 & 5.82 & 4.40 \\
\hline LM8 & 1.23 & 1.53 & 0.14 & 0.10 & 6.33 & 7.22 & 0.00 & 41.0 & 4.35 & 2.51 \\
\hline LM18 & 2.18 & 1.23 & 0.01 & 0.10 & 2.86 & 6.04 & 3.73 & 14.3 & 7.35 & 3.29 \\
\hline $\mathrm{CH} 2$ & -0.23 & 1.49 & 0.00 & 0.23 & 2.26 & 2.09 & 6.26 & 2.11 & 9.72 & 3.15 \\
\hline $\mathrm{CH} 3$ & 0.08 & 1.19 & 0.07 & 0.11 & 3.09 & 5.19 & -5.55 & 6.97 & 11.28 & 3.66 \\
\hline $\mathrm{CH} 4$ & 0.27 & 0.97 & 0.16 & 0.16 & 2.60 & 6.37 & 12.28 & 24.6 & 5.71 & 3.55 \\
\hline $\mathrm{CH} 6$ & 1.51 & 1.43 & 0.24 & 0.18 & 2.55 & 3.62 & 11.77 & 7.30 & 5.11 & 2.78 \\
\hline $\mathrm{CH} 7$ & -0.59 & 1.39 & 0.32 & 0.21 & 3.09 & 3.49 & 8.24 & 3.55 & 9.88 & 3.69 \\
\hline CR1 & & 1.6 & 0.04 & 0.16 & 4.55 & 3.13 & & 3.37 & & 3.60 \\
\hline CR3 & & 0.91 & 0.10 & 0.11 & -1.03 & 3.00 & & 10.3 & 3.42 & 3.62 \\
\hline CR5 & & & 0.17 & 0.16 & 6.22 & 8.55 & -9.21 & 28.8 & 3.11 & 2.62 \\
\hline CR6 & 1.03 & 1.21 & 0.00 & 0.13 & 0.94 & 2.75 & 4.75 & 2.38 & 6.04 & 3.29 \\
\hline CR8 & 2.13 & 1.73 & 0.49 & 0.12 & 4.42 & 5.86 & 0.00 & 27.9 & 8.77 & 4.93 \\
\hline CR10 & & 1.60 & 0.07 & 0.15 & -2.49 & 4.35 & -6.97 & 18.3 & 7.66 & 3.77 \\
\hline CR12 & 0.06 & 1.05 & 0.15 & 0.13 & 5.53 & 5.59 & -16.81 & 30.4 & 2.16 & 2.55 \\
\hline CR14 & -0.66 & 1.44 & 0.09 & 0.15 & 1.87 & 4.40 & 6.75 & 3.75 & 9.24 & 4.13 \\
\hline CR15 & 1.25 & 1.12 & 0.26 & 0.14 & 6.11 & 6.82 & 17.45 & 17.8 & 10.86 & 3.62 \\
\hline LC1 & 0.40 & 1.01 & 0.02 & 0.15 & 4.55 & 1.90 & 6.02 & 1.78 & 4.88 & 2.97 \\
\hline LC2 & 1.42 & 1.13 & 0.05 & 0.12 & 2.69 & 2.91 & 4.80 & 1.99 & 0.80 & 2.05 \\
\hline LC4 & 1.34 & 1.92 & 0.13 & 0.11 & 3.89 & 2.14 & 2.44 & 1.74 & 4.06 & 3.62 \\
\hline LC5 & 0.37 & 1.16 & 0.21 & 0.15 & 4.24 & 6.50 & -1.16 & 1.74 & 4.51 & 3.44 \\
\hline LC9 & 0.21 & 1.29 & 0.20 & 0.16 & 3.00 & 4.24 & 13.54 & 9.81 & 6.26 & 3.42 \\
\hline
\end{tabular}




\section{Appendix F: Multivariate Statistic Data SIMCA Classification Results}

Table F1. SIMCA classification results. No grouping was assigned to PC samples because they were previously identified as outliers and removed from the model.

\begin{tabular}{|c|c|c|c|c|}
\hline Sample & Lake Calumet & Calumet River & Calumet Harbor & Lake Michigan \\
\hline \multicolumn{5}{|l|}{ PC 2} \\
\hline \multicolumn{5}{|l|}{ PC 1} \\
\hline LC 9 & * & & & \\
\hline LC 7 & * & & & \\
\hline LC 8 & * & & & \\
\hline LC 6 & * & * & & \\
\hline LC 5 & * & & & \\
\hline LC 4 & * & & & \\
\hline LC 3 & * & & & \\
\hline LC 2 & * & & & \\
\hline LC 1 & * & & & \\
\hline CR 1 & & * & & \\
\hline CR 2 & & * & & \\
\hline CR 3 & & * & & \\
\hline CR 4 & & * & & \\
\hline CR 5 & & * & & \\
\hline CR 6 & & * & & \\
\hline CR 7 & & * & & \\
\hline CR 8 & & * & & \\
\hline CR 9 & & * & & \\
\hline CR 10 & & * & & \\
\hline CR 11 & & * & & \\
\hline CR 12 & & * & & \\
\hline CR 13 & & * & & \\
\hline CR 14 & & * & & \\
\hline CR 15 & & * & & \\
\hline $\mathrm{CH} 1$ & & & * & \\
\hline $\mathrm{CH} 2$ & & & * & \\
\hline $\mathrm{CH} 3$ & & & * & \\
\hline $\mathrm{CH} 4$ & & & * & * \\
\hline $\mathrm{CH} 5$ & & & * & * \\
\hline $\mathrm{CH} 6$ & & & * & * \\
\hline $\mathrm{CH} 7$ & & & * & \\
\hline
\end{tabular}


Table F2. SIMCA classification results. No grouping was assigned IC samples because they were previously identified as outliers and removed from the model.

\begin{tabular}{|c|c|c|c|c|}
\hline Sample & Lake Calumet & Calumet River & Calumet Harbor & Lake Michigan \\
\hline LM 1 & & & & * \\
\hline LM 2 & & & & * \\
\hline LM 3 & & & & * \\
\hline LM 4 & & & & * \\
\hline LM 5 & & & & * \\
\hline LM 6 & & & & * \\
\hline LM 7 & & & * & * \\
\hline LM 8 & & & & * \\
\hline LM 9 & & & & * \\
\hline LM 10 & & & & * \\
\hline LM 11 & & & & * \\
\hline LM 12 & & & & * \\
\hline LM 13 & & & & * \\
\hline LM 14 & & & & * \\
\hline LM 15 & & & & * \\
\hline LM 16 & & & & * \\
\hline LM 17 & & & & * \\
\hline LM 18 & & & & * \\
\hline LM 19 & & & & * \\
\hline LM 20 & & & & * \\
\hline \multicolumn{5}{|l|}{ IC 1} \\
\hline IC 2 & & & & \\
\hline
\end{tabular}




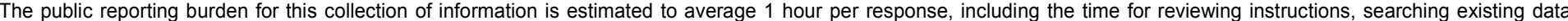

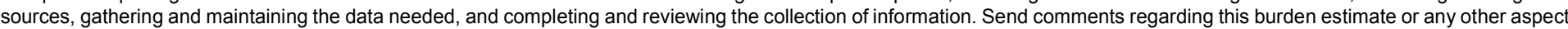

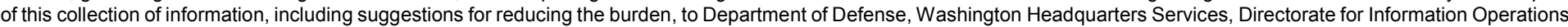

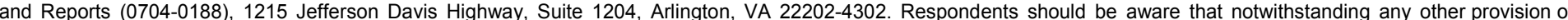
law, no person shall be subject to any penalty for failing to comply with a collection of information if it does not display a currently valid OMB control number.

PLEASE DO NOT RETURN YOUR FORM TO THE ABOVE ADDRESS.

\begin{tabular}{l|l|l}
\hline $\begin{array}{l}\text { 1. REPORT DATE } \\
\text { April } 2017\end{array}$ & $\begin{array}{l}\text { 2. REPORT TYPE } \\
\text { Final }\end{array}$ & 3. DATES COVERED (FrOm - To) \\
\hline
\end{tabular}

\section{TITLE AND SUBTITLE}

Identification of Sediment Sources to Calumet River through Geochemical

Fingerprinting

\section{5a. CONTRACT NUMBER}

5b. GRANT NUMBER

5c. PROGRAM ELEMENT NUMBER

5d. PROJECT NUMBER

A1060-449021-56B673

5e. TASK NUMBER

5f. WORK UNIT NUMBER

8. PERFORMING ORGANIZATION REPORT NUMBER

ERDC TR-17-1

\section{PERFORMING ORGANIZATION NAME(S) AND ADDRESS(ES)}

Coastal and Hydraulics Laboratory

Environmental Laboratory

U.S. Army Engineer Research and Development Center

3909 Halls Ferry Road

Vicksburg, MS 39180-6199

9. SPONSORING/MONITORING AGENCY NAME(S) AND ADDRESS(ES)

Dredging Operations and Environmental Research Program

Coastal and Hydraulics Laboratory

Environmental Laboratory

U.S. Army Engineer Research and Development Center

3909 Halls Ferry Road, Vicksburg, MS 39180-6199

\section{DISTRIBUTION/AVAILABILITY STATEMENT}

Approved for public release; distribution is unlimited.

\section{SUPPLEMENTARY NOTES}

\section{ABSTRACT}

Geochemical sedimentary markers provide a well-established methodology for fingerprinting various sources of sediments accumulating within a region of concern. To help identify possible sources of contaminated sediment infilling a reach of the Calumet River between the Thomas J. O’Brien lock and Lake Michigan, multiple bottom sediment samples were collected in 2014 from six potential sediment sources. Additionally, geochemical data from historic dredging records spanning a 40-year period were examined to develop a historic geochemical fingerprint for sediments within this reach of the river. Geochemical measurements and advanced multivariate statistics were used to successfully distinguish between all six potential sediment sources. Calumet River samples showed elevated levels of heavy metals and a geochemical signature that was distinct from the potential source sediments, suggesting that heavy metal contamination was occurring locally within the river. Additionally, multivariate analysis was able to show historic reductions in heavy metal and organic contaminants in the dredge records that likely correlates with implementation of the Clean Water Act. Geochemical fingerprints were successfully used to track changes in sediments both spatially and temporally within the project area. These fingerprints could be used further to identify any future changes in sediments within this reach of the Calumet River.

\section{SUBJECT TERMS}

Calumet River (Ill.), Contaminated sediment, Dredging, Dredging spoil, Contaminated sediments, Geochemical fingerprint, Environmental geochemistry, Lake Calumet, Principal component analysis, Sedimentation and deposition, Sedimentation and analysis, Sediment source

\section{SECURITY CLASSIFICATION OF:}

\section{a. REPORT}

Unlimited

\begin{tabular}{|l|c|} 
b. ABSTRACT & c. THIS PAGE \\
Unlimited & Unlimited
\end{tabular}

17. LIMITATION OF ABSTRACT SAR
18. NUMBER OF 19a. NAME OF RESPONSIBLE PERSON PAGES

65

\section{David Perkey}

19b. TELEPHONE NUMBER (Include area code) 601-634-2736 